\title{
Meeting Future Energy Needs in the Hindu Kush Himalaya
}

\section{Coordinating Lead Authors}

Shobhakar Dhakal, Associate Professor and Head, Department of Energy, Environment and Climate Change, School of Environment, Resources and Development, Asian Institute of Technology, Bangkok, Thailand. e-mail: shobhakar@ait.ac.th; shobhakar.dhakal@gmail.com

Leena Srivastava, Vice Chancellor, TERI School of Advanced Studies, New Delhi, India. e-mail: leena@terisas.ac.in

Bikash Sharma, former Senior Environmental Economist, Livelihoods, ICIMOD, Kathmandu, Nepal. e-mail: bikasharma99@gmail.com (corresponding author)

\section{Lead Authors}

Debajit Palit, Senior Fellow \& Director, Rural Energy \& Livelihoods Division, TERI, New Delhi, India. e-mail: debajitp@teri.res.in

Brijesh Mainali, Researcher/Lecturer, Department of Built Environment and Energy Technology, Linnaeus University, Växjö, Sweden. e-mail: brijesh.mainali@1nu.se

Rabindra Nepal, Senior Lecturer in Economics, Tasmanian School of Economics and Finance, University of Tasmania, Hobart, Australia. e-mail: Rabindra.Nepal@utas.edu.au

Pallav Purohit, Research Scholar, Air Quality \& Greenhouse Gases (AIR) Program, International Institute for Applied Systems Analysis (IIASA), Laxenburg, Austria. e-mail: purohit@iiasa.ac.at Anandajit Goswami, Management Development Programme Coordinator, TERI School of Advanced Studies, New Delhi, India. e-mail: anandajit.goswami@terisas.ac.in

Ghulam Mohd Malikyar, Ecosystem Health Expert, Deputy Director General for Technical Affairs of the National Environmental Protection Agency of the Islamic Republic of Afghanistan, Kabul, Afghanistan. e-mail: malikyargh@gmail.com

Kul Bahadur Wakhley, former Chief Executive Officer, Bhutan Electricity Authority, Ministry of Economic Affairs, Royal Government of Bhutan, Thimphu, Bhutan. e-mail: kbwakhley@hotmail.com;

kbwakhley@gmail.com

\section{Contributing Authors}

Ranjan Parajuli, Research Scholar, Ralph E. Martin Department of Chemical Engineering, University of Arkansas, Fayetteville, Arkansas, USA. e-mail: rparajul@uark.edu

Muhammad Indra al Irsyad, PhD candidate, School of Earth and Environmental Science, University of Queensland, St Lucia, Queensland, Australia. e-mail: m.alirsyad@uq.edu.au Yuwan Malakar, Research Scholar, Energy and Poverty Research Group, School of Chemical Engineering, The University of Queensland, St Lucia - Queensland, Australia. e-mail: y.malakar@uq.edu.au Bhupendra Shakya, PhD candidate, School of Photovoltaic and Renewable Energy Engineering (SPREE), The University of New South Wales (UNSW), Sydney, Australia. e-mail: b.shakya@unsw.edu.au

\section{Review Editor}

Bikash Raj Pandey, Director Clean Energy, Winrock International, Arlington, Virginia, USA. e-mail: BPandey@winrock.org

\section{Corresponding Author}

Bikash Sharma, former Senior Environmental Economist, Livelihoods, ICIMOD, Kathmandu, Nepal. e-mail: bikasharma99@gmail.com 


\section{Contents}

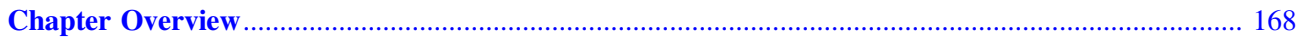

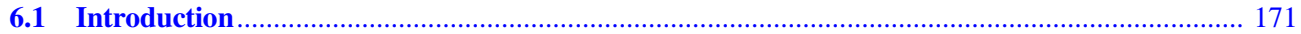

6.1.1 Setting the Scene: The Transition Challenge..................................................................... 171

6.1.2 Transformation in Energy Systems: Multidimensional Linkages …...................................... 172

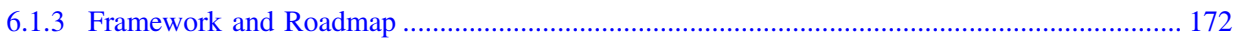

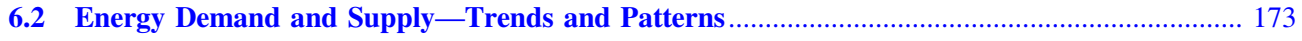

6.2.1 Biophysical and Socioeconomic Context Shaping Energy Demand........................................ 173

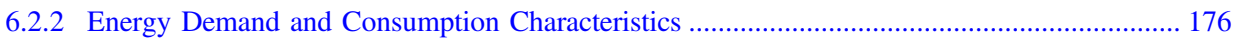

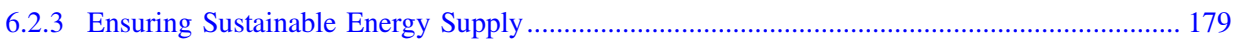

6.3 National Energy Policies, Programmes, Institutions, and Markets ......................................... 181

6.3.1 Energy in Relation to National Development Strategies...................................................... 181

6.3.2 National Energy Policy Framework, Programmes, and Markets .............................................. 183

6.3.3 Cross-Regional Experiences and Recommendations .............................................................. 186

6.4 Challenges and Opportunities for Sustainable Energy ….......................................................... 186

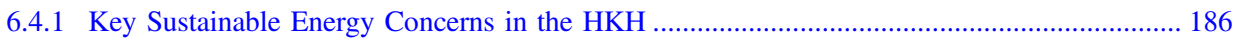

6.4.2 Links Between Energy and the SDGs: Synergies and Trade-offs .......................................... 188

6.4.3 Assessing the Vulnerability of Vital Energy Services and Systems ....................................... 190

6.4.4 Overcoming Barriers and Seizing Potential Opportunities........................................................ 190

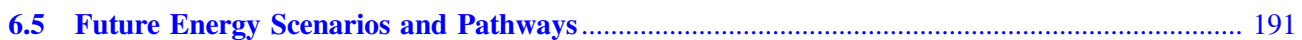

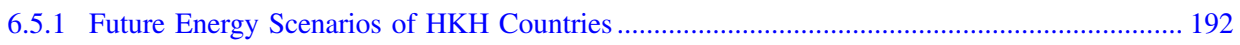

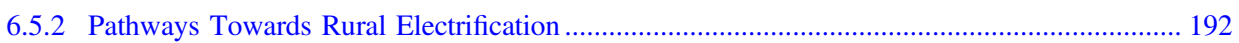

6.5.3 Pathways Towards Sustainable Clean Cooking Energy .......................................................... 195

6.5.4 A Sustainable Energy Future: Barriers and Opportunities ....................................................... 196

6.6 Energy Cooperation in HKH: National, Regional, and Global Linkages ................................. 197

6.6.1 Energy Challenges and Regional Cooperation .............................................................. 197

6.6.2 Models for Energy Cooperation......................................................................................... 198

6.6.3 Role of Multi-level Governance in Securing Sustainable Energy in HKH.............................. 199

6.6.4 Climate Change, Energy Resilience, and Regional Energy Cooperation ................................. 200

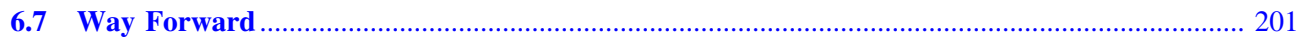

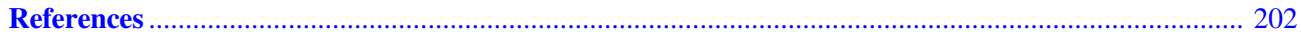

\section{Chapter Overview}

\section{Key Findings}

1. The Hindu Kush Himalaya (HKH), despite having huge hydropower potential of $\sim 500 \mathrm{GW}$, remains energy poor and vulnerable. More than $80 \%$ of the rural population in HKH countries, a large part of whom live in mountain areas, rely on traditional biomass fuels for cooking and about 400 million people in $\mathrm{HKH}$ countries still lack basic access to electricity.
2. Measures to enhance energy supply in the HKH have had less than satisfactory results because of low prioritization and a failure to address challenges of remoteness and fragility. However, this is slowly changing, with an emphasis on innovative business models for remote off-grid areas including mountains.

3. Inadequate data and analyses are a major barrier to designing context-specific interventions. This weakness deters the addressing of the special challenges faced by mountain communities: 
scale economics, access to infrastructure and resources, poverty levels and capability gaps, and also thwarts the large-scale replication of successful innovative demonstration/pilot projects that have been implemented in the region.

\section{Policy Messages}

1. Quantitative targets (accompanied by quality specifications of alternative energy options) based on an explicit recognition of the full costs and benefits should be the basis of designing policies, prioritizing actions and strengthening investments. To do this, the institutions and mechanisms for systematic data collection and analyses need to be strengthened. Capacity building, and empowering institutions involved in designing and monitoring the progress of outcome-based energy policies and programmes, must be undertaken.

2. Governments of the HKH countries need to prioritize use of locally available energy resources. Policies that seek to maximize energy independence through promotion of community-based and off-grid renewable energy solutions, perhaps through private sector participation, are essential. Large hydropower projects with well-defined benefit-sharing mechanisms would be beneficial. Vibrant markets need to be created to meet the strong, latent demand for decentralized sustainable energy in the mountains.

3. A high-level, empowered, regional mechanism should be established to strengthen regional energy trade and cooperation. This mechanism should be equipped to recognize, and take, an integrated approach to meet development needs, as exemplified by the sustainable development goals (SDGs) and their interlinkages.

As mentioned in earlier chapters, the HKH regions form the entirety of some countries, a major part of other countries, and a small percentage of yet others. Because of this, when we speak about meeting the energy needs of the HKH region we need to be clear that we are not necessarily talking about the countries that host the HKH, but the clearly delineated mountainous regions that form the $\mathrm{HKH}$ within these countries. It then immediately becomes clear that energy provisioning has to be done in a mountain context characterized by low densities of population, low incomes, dispersed populations, grossly underdeveloped markets, low capabilities, and poor economies of scale. In other words, the energy policies and strategies for the HKH region have to be specific to these mountain contexts.

This chapter critically examines the energy outlook of the $\mathrm{HKH}$ in its diverse aspects, including demand-and-supply patterns; national policies, programmes, and institutions; emerging challenges and opportunities; and possible transformational pathways for sustainable energy. We set out to answer three broad questions:

1. How does the abundance of renewable energy resources in the HKH inform, and be informed by, national, regional, and global energy and climate policies?

2. How can energy-deprived mountain communities be empowered to meet their growing energy demands in an environmentally benign and sustainable way?

3. How can the enabling environment for regional integration and cooperation be strengthened to seize climate mitigation, adaptation, and development opportunities and make rapid, meaningful progress?

Despite its vast potential of hydropower and other renewables, the $\mathrm{HKH}$ region remains energy poor and vulnerable. Climate change is posing a new challenge to energy security on account of receding treelines, the contribution of biomass burning to short-lived carbon pollutants, altered rainfall patterns, and unpredictable water stocks and flows among other factors. The challenge for the $\mathrm{HKH}$ is to simultaneously address the issues of energy security, climate change, and poverty while attaining multiple SDGs. Success will require urgent action and massive investment for energy transformation. If technology access remains inadequate and energy infrastructure continues to be of poor quality, the HKH will neither be able to respond to SDG 7 (affordable and clean energy) nor to any of the related SDGs (wellestablished).

The HKH, by virtue of its massive stock of snow and ice, represents the third pole of Planet Earth. The snow melt from the Himalayan mountains, and the rainfall catchment they provide, feed and supplement the water flows of a number of the rivers that originate from this region. Both the felling of trees for biomass production and the burning of biomass for energy provision have an adverse impact on the water balance of the region. How the region handles its water, energy and forest resources would have a significant impact on the health of the Himalayan mountain ecosystems, the health 
and wellbeing of its populations, on the vulnerability of its people and those living downstream to glacier melting and associated impacts, and on the opportunities to mitigate climate change impacts at a wider scale (well-established). The world needs to engage with the HKH to define an ambitious new energy vision: one that involves building an inclusive green society and economy, with mountain communities enjoying modern, affordable, reliable, and sustainable energy to improve their lives and the environment. Specifically, the region requires a radical energy transformation that ensures universal electricity access, through grid-connected and off-grid power for lighting and productive uses, and the complete replacement of traditional, inefficient sources for cooking and heating energy with clean sustainable energy options that are efficient, reliable, affordable, and demand-driven (well-established).

Translating this new energy vision into action will require a reform agenda much more ambitious than today's efforts. By tapping into the full potential of hydropower and other renewables, the $\mathrm{HKH}$ can overcome its energy poverty and attain energy security, while mitigating and adapting to climate change. Success, however, will critically depend on removing policy, institutional, and capacity barriers that now perpetuate energy poverty and vulnerability in mountain communities.

As there are no "one-size-fits-all" solutions for ensuring universal access to modern energy in mountain areas, the $\mathrm{HKH}$ regions must create an enabling environment to ensure access to energy services in a technology- and resource-neutral manner, albeit bearing in mind the leverage energy access provides for meeting other development goals. (well-established).

\section{A priority action agenda for sustainable energy transformation}

This chapter presents a four-point priority action agenda for a sustainable energy transition to ensure energy security for all, in a climate-resilient manner, through hydropower and other renewables. It also highlights the urgent need to customize SDG 7 targets and indicators to the specific needs and priorities of the $\mathrm{HKH}$ region.

Underpinning the implementation of our proposed HKH energy vision and action agenda is a crucial guiding principle: that sustainable energy is a shared responsibility. To accelerate progress and make it meaningful, all key stakeholders must partner with one another and work synergistically for a sustainable energy transition.

The action agenda calls for:
- Making mountain-specific energy policies and programmes an integral part of national energy development strategy. A coherent mountain-specific policy framework needs to be well integrated in the national development strategy and translated into action. A prerequisite will be to establish a regional mountain-specific energy data generation and management system that supports national institutions in periodic energy data gathering and in assessing various aspects of energy access.

- Establishing monitorable quantitative and qualitative targets for each energy end use and tracking the progress of different attributes of clean energy access. This needs a mountain-specific multi-tier assessment framework, with appropriate energy access indicators, to facilitate a demand-driven approach to energy service provisioning and to prioritize interventions with the largest co-benefits for SDGs.

- Scaling up current investments and ensuring access to finance through capacity building at different levels. Innovative and affordable international, regional, national, and local funds will need to be mobilized to support energy planning and infrastructure investments. Incentives for commercial lending, de-risking investments, and leveraging private finance will be needed, to accelerate rapid diffusion and scale-up of appropriate, customized business models for off-grid renewable energy solutions, by empowering local communities.

- Accelerating the pace of regional trade and cooperation in sustainable energy through a high-level, empowered, regional mechanism. This can be achieved through integrated regional energy planning, trade, and establishment of institutional mechanisms. These will also ensure that environmental externalities are managed and that revenue-sharing mechanisms for the local areas are in place. Climate change-induced human security threats have the potential to drive energy cooperation and facilitate multilateral agreements on the basis of a common framework.

\section{Meeting Future Energy Needs and the SDGs}

Energy is an essential input for the achievement of most SDGs. Transition to sustainable energy, therefore, should be the region's major priority and must be central to national development strategies. An a priori recognition of interlinkages between energy and other context-specific SDGs would allow countries to 
maximize the developmental benefits of energy provisioning. This is, however, a complex exercise requiring capacity building, governance and institutional changes, and effective design of incentive systems.

That said, SDG 7 and its three targets will need to be customized to the specific needs of each $\mathrm{HKH}$ country. Such customization could follow the sectorally integrated Energy Plus approach, maximizing synergies while managing trade-offs.

- Target 7.1- “By 2030, ensure universal access to affordable, reliable and modern energy services" HKH needs a multi-tier, mountain-specific assessment framework that captures improved quantity, quality, and reliability of electricity supply. This should assure the availability, efficiency, affordability, safety, health (reduced emissions of short-lived climate pollutants (SLCPs)), and convenience (reduced drudgery for women and children) of modern, clean cooking facilities, and allow progress on energy poverty to be more visible and measurable for national, regional, and global public policy makers.

- Target 7.2- “By 2030, increase substantially the share of renewable energy in the global energy mix"

The objective could be to move towards a fossil fuel-free and efficient energy future. Such renewable energy, in both centralized and decentralized forms, must serve local populations and meet their demands and fuel growth. Given the low current consumption levels, and the opportunity to provide customized energy, the objective of governments should be to meet all the energy demands of the region.

- Target 7.3-“By 2030, double the global rate of improvement in energy efficiency"

Policies should focus on the traditionally biomass-dependent residential sector, which has the highest energy use but the lowest energy efficiency. Each country should develop mountain-specific energy efficiency indicators (and should not use energy intensity as a proxy, a practice that can generate misleading results). These indicators should use final energy demand at the most disaggregated end-use level, to accurately reflect energy efficiency improvements and to monitor progress towards the target.

\subsection{Introduction}

\subsubsection{Setting the Scene: The Transition Challenge}

Recognizing that energy is fundamental to human development, SDG 7 states that access to affordable, reliable and sustainable energy is crucial not only for future energy security, but for also meeting other SDGs. Although energy is essential for all development needs, current energy systems continue to face major pressures to address energy security, climate change, and energy poverty (Van Vuuren et al. 2012). Given the important role energy security plays for dimensions of human security, a robust energy strategy is key to any country's future development. Prevailing notions of energy, however, are largely supply-biased and growth-centred and fail to respond to the energy development nexus, especially in the HKH.

Mountain areas of the $\mathrm{HKH}$ are hotspots for energy poverty-related development challenges. The region also faces a host of issues around energy security and climate change impacts, while having the potential to mitigate the emissions of greenhouse gases (GHGs), in particular SLCPs. The mountain areas of the eight HKH countries (Afghanistan, Bangladesh, Bhutan, China, India, Myanmar, Nepal, and Pakistan) host $9 \%$ of the collective population. It is these areas (rather than $\mathrm{HKH}$ countries) that are referred to as the $\mathrm{HKH}$ region in this chapter. More than $80 \%$ of the rural population in the HKH countries lack a modern energy source for cooking (IEA and World Bank 2015), although these country-level data gloss over the realities of energy poverty in the HKH region. Heavy reliance on traditional solid fuel used in traditional ways entrenches poverty, and erodes indoor air quality and environmental sustainability. Caught between poverty and environmental degradation, mountain communities in most of the HKH find it increasingly difficult to meet their daily energy service needs in a sustainable manner. For mountain people in general, and women in particular, the foremost priority is to meet household energy needs for cooking and space heating. The endless cycle of gathering and burning biomass in homes causes enormous damage to the environment, triggers widespread harm to human health, and results in serious social deprivation (Sharma et al. 2005).

Excessive biomass usage and the resulting deforestation and biomass loss are widespread in the HKH, and have a major impact on ecosystem services, climate change, and human health. Sustainable energy has now emerged as the centrepiece of mitigation and adaptive responses to the impacts of both SLCPs and GHGs. Black carbon is 
considered an SLCP and is now recognized as a major concern in the climate-sensitive HKH, linked with enhanced glacier melting alongside other impacts on public health, environment, and livelihood security (Menon et al. 2002; Ramanathan and Carmichael 2008; Ramanathan et al. 2007). For these and other reasons, expanding access to sustainable energy for reducing these emissions promises significant co-benefits for the HKH.

\subsubsection{Transformation in Energy Systems: Multidimensional Linkages}

The HKH is interconnected biophysically and socioeconomically across sectors, and this affects the energy supply, demand, underlying drivers, and the solutions themselves. The costs and benefits of energy are not always confined to the $\mathrm{HKH}$, and this requires extended thinking about benefit sharing. One such example is hydroelectricity production in the mountains and hills of the $\mathrm{HKH}$ region, which feeds largely into the plain areas. We also find significant sectoral interdependencies in energy, climate, water, and food, and these are numerous, growing, multidimensional and dynamic (Beniston 2013; Hoff 2011; Hussey and Pittock 2012; Marsh and Sharma 2007; Rasul and Sharma 2016; Rockström et al. 2009; State of the Planet Declaration 2012). Sustaining Himalayan freshwater ecosystem services is critical for food, water, and energy security in the $\mathrm{HKH}$ and downstream river basins (Rasul 2014a, b). These interdependencies make it crucial for policy makers to understand the cross-sectoral policy linkages, and their effects at multiple scales, while taking into account the transboundary nature of $\mathrm{HKH}$ ecosystems and rivers. A regional perspective will be needed so appropriate strategies for energy system transformation can be found, allowing a common solution to be reached by determining and resolving trade-offs, and by exploiting potentials for synergy.

\subsubsection{Framework and Roadmap}

Sustainable energy development is an evolving concept (Sovacool et al. 2011). Adequacy, reliability, quality, and guarantee of energy resources and carriers on the supply side, and accessibility and affordability on the demand-side serve as important boundaries for sustainable energy transitions (Fig. 6.1). Between supply and demand are enablers who can make and influence current developments and the transitions needed through policy, regulation, design, and implementation of financing solutions, market development, and equitable solutions. If a reliable energy system is not in place, households cannot obtain access to modern fuel, even if they can afford and use such fuel (Fig. 6.1, area C). Regardless of the availability and acceptability of energy technologies (Fig. 6.1, area B), the vast majority of rural people will be unable to afford them because of lack of funds or credit facilities. Even when modern forms of energy are affordable and available (Fig. 6.1, area A) households may not use them if they are not culturally acceptable or if they are less convenient, less reliable, and more expensive than
Fig. 6.1 Framework for addressing sustainable energy transition (Sharma 2009)

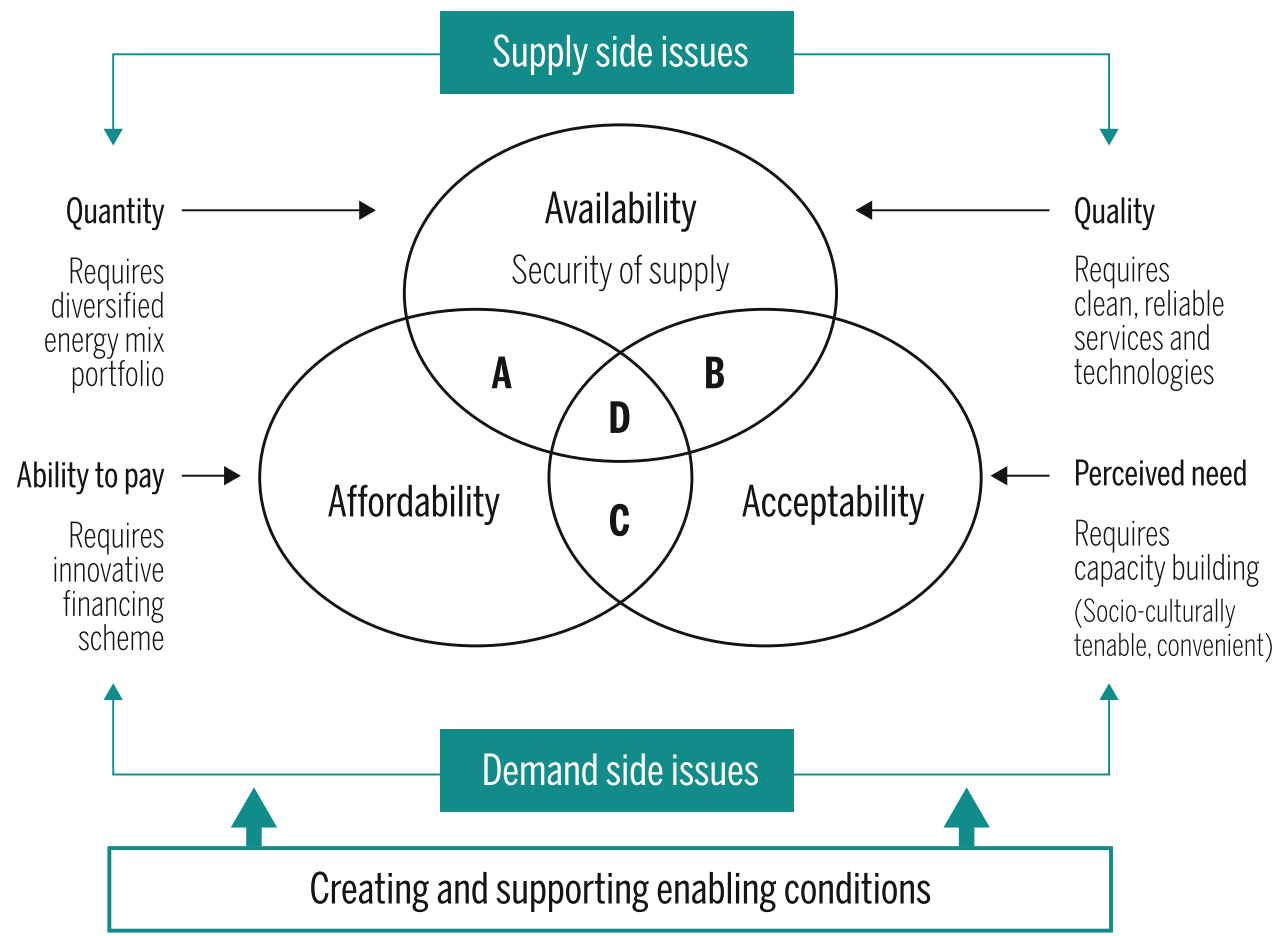


traditional biomass. Scaling up modern energy services depends on the existence of effective governance and policy frameworks that create an enabling environment for increased adoption and investment in energy access.

We can see there are multiple possible visions of energy transition pathways that could reach the goal of sustainable energy development for the HKH. Each pathway will come with its own barriers and opportunities, and the need for specific transformation in multiple domains. The framework for assessing sustainable energy adopted in this chapter is, therefore, based on the three pillars of sustainable development: social, economic, and environmental. It uses a set of underlying indicators to study the current situation, policies and action; find the gaps and challenges in options and action; provide pathways to sustainable energy futures; and offer insights to the key elements of enabling conditions for decision makers.

Section 6.2 examines the energy supply and demand trends, and the transition pattern, using the available information on the HKH countries. This section also draws on insights into the energy profile of the HKH and discusses the underlying drivers. Section 6.3 examines the key national energy policies, programmes, and institutions in the wider context of national development. Section 6.4 identifies and assesses the challenges and opportunities for sustainable energy facing the HKH countries. Section 6.5 explores the future pathways for sustainable energy solutions through alternative combinations of options and strategies. Section 6.6 offers insights on national, regional, and global linkages of HKH energy resource bases. It also explores avenues for seizing policy opportunities, investing in energy infrastructure, innovative financing mechanisms, capacity development and governance reforms and regional integration and cooperation, among others.

\subsection{Energy Demand and Supply-Trends and Patterns}

Data on energy demand and supply for mountain areas of HKH countries (except in Bhutan and Nepal, which are fully within the HKH) are largely inadequate and of poor quality. Given the significant differences in energy access, economic development, and institutional structures across countries, it is difficult to accurately capture $\mathrm{HKH}$-specific demand-and-supply trends and patterns. This highlights an urgent need to establish a sound energy information base. Equally, understanding the risks and vulnerability of energy systems to socioenvironmental change is essential to ensure proper design of strategies and interventions for improved energy security.

\subsubsection{Biophysical and Socioeconomic Context Shaping Energy Demand}

Mountain-specific characteristics such as inaccessibility, fragility, and marginality combined with the "isolated enclave" nature of mountain economies and communities lead to different manifestations of energy demand patterns and trends (Papola 2002). The following paragraphs explain the context of energy demands as depicted in Fig. 6.2.
Fig. 6.2 Biophysical and socioeconomic contexts of energy demand in the $\mathrm{HKH}$

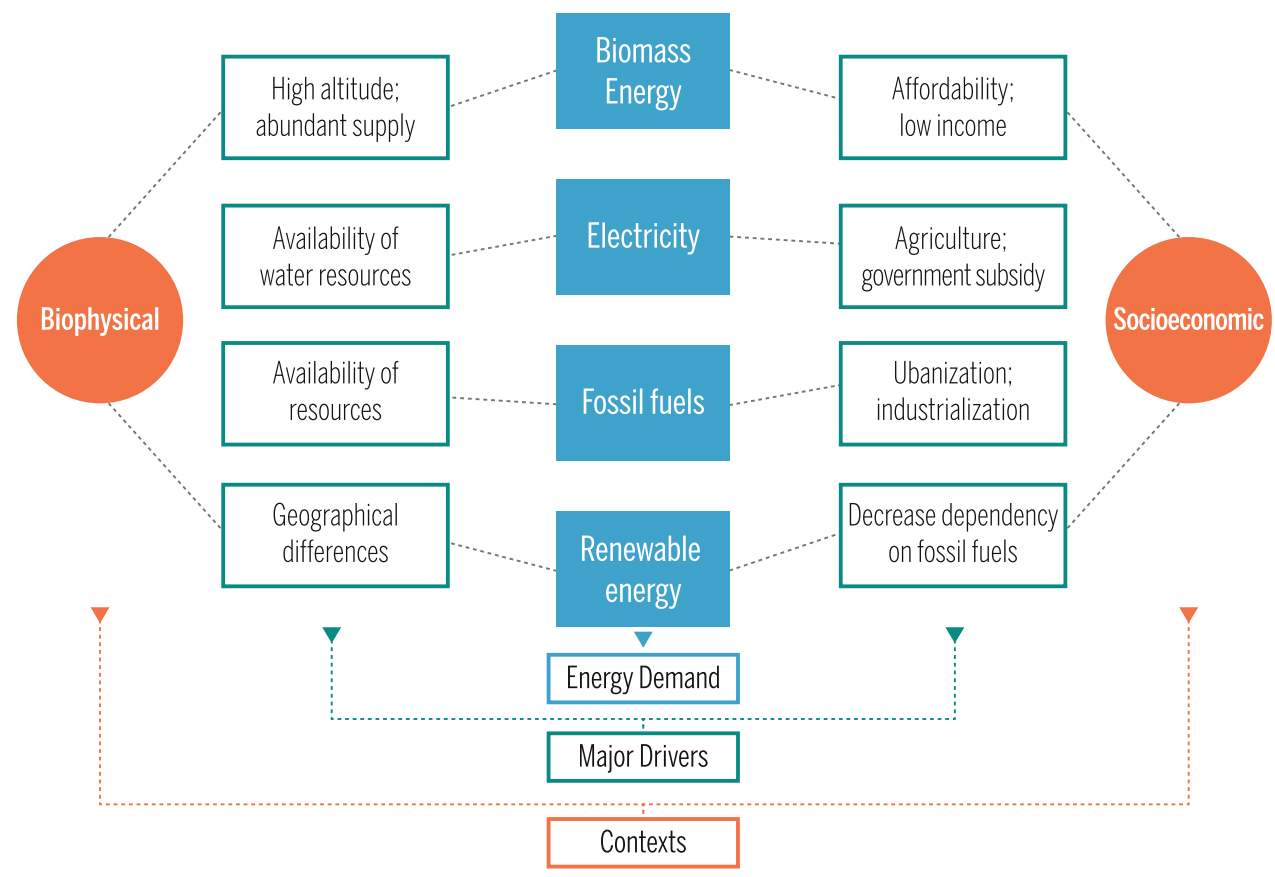


Table 6.1 Energy access in HKH countries during 1990-2014

\begin{tabular}{|c|c|c|c|c|c|c|c|c|}
\hline \multirow[t]{2}{*}{ Country } & \multicolumn{4}{|c|}{ Access to electricity ( $\%$ of population) } & \multicolumn{4}{|c|}{$\begin{array}{l}\text { Access to clean fuels and technologies for cooking } \\
\text { (\% of population) }\end{array}$} \\
\hline & 2000 & 2010 & 2012 & 2014 & 2000 & 2010 & 2012 & 2014 \\
\hline Afghanistan & 38 & 43 & 69 & 90 & 23 & 19 & 18 & 17 \\
\hline Bangladesh & 32 & 55 & 59 & 62 & 11 & 10 & 10 & 10 \\
\hline Bhutan & 69 & 82 & 92 & 100 & 38 & 60 & 64 & 68 \\
\hline China & 98 & 100 & 100 & 100 & 46 & 54 & 56 & 57 \\
\hline India & 60 & 76 & 80 & 79 & 24 & 32 & 33 & 34 \\
\hline Myanmar & 47 & 49 & 51 & 52 & 4 & 8 & 8 & 9 \\
\hline Nepal & 27 & 67 & 76 & 85 & 7 & 21 & 23 & 26 \\
\hline Pakistan & 75 & 91 & 94 & 98 & 24 & 39 & 42 & 45 \\
\hline
\end{tabular}

Source IEA and World Bank (2017)

Energy access: About 400 million people in HKH countries, a large percentage of whom live in mountain areas, still lack basic access to electricity and rely on traditional biomass fuels for cooking (Table 6.1). At the same time, the impacts of climate change on hydropower and biomass resources may bring greater uncertainty to the region (Kaltenborn et al. 2010). However, access to modern energy forms is crucial to support water, food, and livelihood security and to reduce the vulnerability of mountain communities to the impacts of climate change.

Middle- and high-altitude climatic conditions: Due to the generally cool to cold weather throughout the $\mathrm{HKH}$, the need for space and water heating ranks high, as fuel is needed for cooking and lighting. Use of biomass as a cooking fuel serves the additional purpose of heating in the middle- and high-altitude regions of the HKH (Bhatt and Sachan 2004; Palit and Garud 2010; Santner and Jussel 2003). Because of this, smokeless stoves have failed to catch on in Bhutan because they are poor sources of space heating (Palit and Garud 2010), and the demand for traditional fuels for space heating remains high (Rahut et al. 2016). However, experimentation with new technologies is also taking place in the region; one such example is fuel-efficient stoves with attached water warming facilities, in Pakistan.

Abundant primary energy supply: The HKH comprises $20 \%$ forests, 15\% shrub lands, and 39\% grasslands (Schild 2008). The region is also known as the "water tower" of Asia, with an estimated hydroelectricity generation potential of more than $500 \mathrm{GW}$ (Vaidya 2013). The primary energy base of the $\mathrm{HKH}$ is, therefore, biomass, hydro, solar, and wind, although solar and wind potentials remain largely unquantified. Yadama et al. (2012) suggest that the possibility of using biomass increases with easy access to forests.
Supply of modern energy: The demand for modern energy is linked with creating improved economic opportunity, rising income, proliferation of new technologies, reducing indoor pollution, modernizing agriculture, entrepreneurship development, and others. Although it is widely recognized that access to modern and clean energy services contributes to tackling poverty (Practical Action 2014), people living in the $\mathrm{HKH}$ have limited access to these forms of energy (Shrestha 2013). Despite large-scale availability of fossil fuel reserves and resources beyond the mountainous region of the $\mathrm{HKH}$ (Table 6.2), these countries also import fossil fuels to meet their domestic demand, contributing to a growing share of fossil fuels in the total primary energy supply mix of the HKH (Fig. 6.3 and Table 6.3).

Affordability: Low income is a key determinant for continual use of biomass for cooking (Hosier and Dowd 1987). Not only are modern fuels more expensive, but the associated costs of appliances are also high (Bhattacharyya 2006). In urban households, the decreasing share of biomass use is often attributed to rising incomes (Duan et al. 2014). Given

Table 6.2 Proven fossil fuel reserves in HKH countries, 2015

\begin{tabular}{l|l|l|l}
\hline $\begin{array}{l}\text { HKH } \\
\text { countries }\end{array}$ & $\begin{array}{l}\text { Coal } \\
\text { (Million } \\
\text { tonnes) }\end{array}$ & $\begin{array}{l}\text { Oil } \\
\text { thousand million } \\
\text { tonnes) }\end{array}$ & $\begin{array}{l}\text { Natural gas } \\
\text { (Trillion cubic } \\
\text { metres) }\end{array}$ \\
\hline Bangladesh & N.A. & $0.0038^{\mathrm{a}}$ & 0.2 \\
\hline China & 114,500 & 2.5 & 3.8 \\
\hline India & 60,600 & 0.8 & 1.5 \\
\hline Myanmar & N.A. & $0.068^{\mathrm{a}}$ & 0.5 \\
\hline Pakistan & 2070 & $0.051^{\mathrm{a}}$ & 0.5
\end{tabular}

Sources BP Statistical Review of World Energy (2016); ${ }^{\mathrm{a} C I A}$, The World Factbook (2016)

N.A.: Data not available 
Fig. 6.3 Percentage of fossil fuels in the total primary energy supply in six HKH countries (Based on IEA data from OECD/IEA 2015 World Energy Outlook (C) OECD/IEA 2015 World Energy Outlook, www.iea. org/statistics, Licence: www.iea. org/t\&c; as modified by ICIMOD)

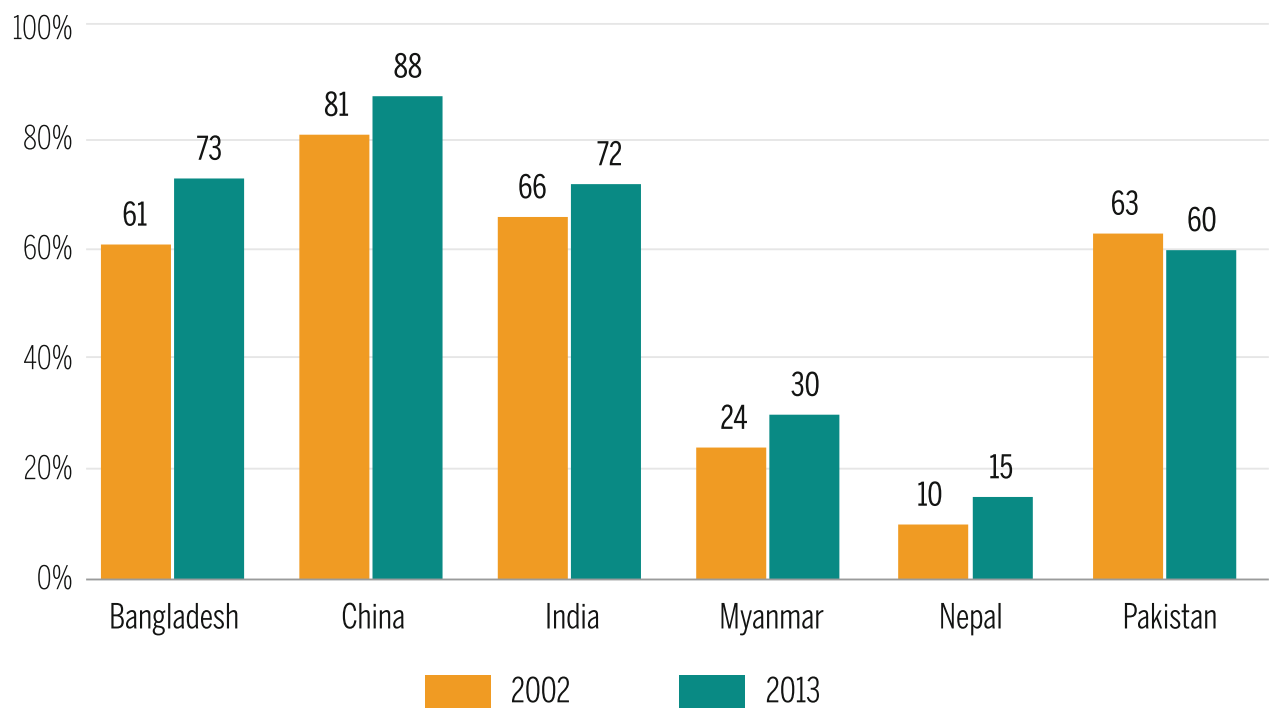

Table 6.3 Electricity generated by fossil fuels in HKH countries (installed capacity)

\begin{tabular}{l|l|l|l|l|l}
\hline $\begin{array}{l}\text { HKH } \\
\text { countries }\end{array}$ & Year & $\begin{array}{l}\% \text { of } \\
\text { the } \\
\text { total }\end{array}$ & $\begin{array}{l}\text { HKH } \\
\text { countries }\end{array}$ & Year & $\begin{array}{l}\% \text { of } \\
\text { the } \\
\text { total }\end{array}$ \\
\hline Afghanistan & 2012 & 35.4 & India & 2016 & 69.3 \\
\hline Bangladesh & 2013 & 97.7 & Myanmar & 2012 & 24.8 \\
\hline Bhutan & 2015 & 0.5 & Nepal & 2016 & 6.2 \\
\hline China & 2016 & 64 & Pakistan & 2015 & 67.7 \\
\hline
\end{tabular}

Source CIA, The World Factbook (2016) (accessed June 2017 at https:// www.cia.gov/library/publications/the-world-factbook/index.html)

the scale of poverty in HKH countries, the unaffordability of modern fuels and associated appliances may have led to a higher demand for biomass energy. However, in recent years, income in the region has risen (owing in large part to tourism development, cash crops, access to information, remittance income, and entrepreneurship development), and so has the affordability of modern fuels and appliances. In some parts of the region, especially in Nepal, foreign remittance has been a key factor behind the rise in household income.

Urbanization and industrialization: Most studies confirm that urbanization and industrialization increase energy demand but the relationship varies at different stages of development ( $\mathrm{Li}$ and Lin 2015). In China, Yang et al. (2016) confirm that urbanization rates are a valid predictor of electricity consumption. The share of urban population in HKH countries is rising (Table 6.4), and will eventually lead to greater demand for modern forms of energy (Duan et al. 2014) (see Fig. 6.4). It is also evident that outmigration from the HKH is relatively high; people shift to urban areas in search of better income-generating options (Wu et al. 2014).
Table 6.4 Urban population (\% of total population) in HKH countries

\begin{tabular}{l|l|l|l|l|l}
\hline $\begin{array}{l}\text { HKH } \\
\text { countries }\end{array}$ & 2007 & 2015 & $\begin{array}{l}\text { HKH } \\
\text { countries }\end{array}$ & 2007 & 2015 \\
\hline Afghanistan & 23.6 & 26.7 & India & 29.9 & 32.7 \\
\hline Bangladesh & 28.2 & 34.3 & Myanmar & 29.9 & 34.1 \\
\hline Bhutan & 32.5 & 38.6 & Nepal & 15.8 & 18.6 \\
\hline China & 45.2 & 55.6 & Pakistan & 35.4 & 38.8 \\
\hline
\end{tabular}

Source World Bank (2017). https://data.worldbank.org/indicator/SP. URB.TOTL.IN.ZS? end $=2015 \&$ start $=1960$

In urban areas, more people own technologies/appliances (e.g., cars) that demand more fossil fuels. Industries are also growing to meet the demands of growing populations and to achieve economic growth. Urbanization may reduce the use of biomass as urban households are more likely to opt for electrical appliances. But, if electricity is produced from fossil fuel, then it is unlikely to help in moving towards clean energy transition.

Diversification and intensification of agriculture: The region is diversifying and intensifying agriculture to improve food production. This demands more irrigation, and then more electricity to power the irrigation. For example, in Balochistan, Pakistan, the demand for electricity for irrigation has increased to support growing more types of fruit in this arid region (Khair 2013). As many HKH countries provide subsidies for electricity used in groundwater extraction, this leads to overexploitation of groundwater as well as increased electricity demand (Khair 2013; Rasul and Sharma 2016). However, one must note that not all agricultural intensification is electricity-based, and the energy intensity of agriculture in hills and mountains will not be as high as in the plains, because agriculture in the hills and mountains continues to be mostly rainfed (see Chap. 8). 
Fig. 6.4 Percentage of urban and rural population with access to electricity in 2014 (Source IEA and World Bank 2017)

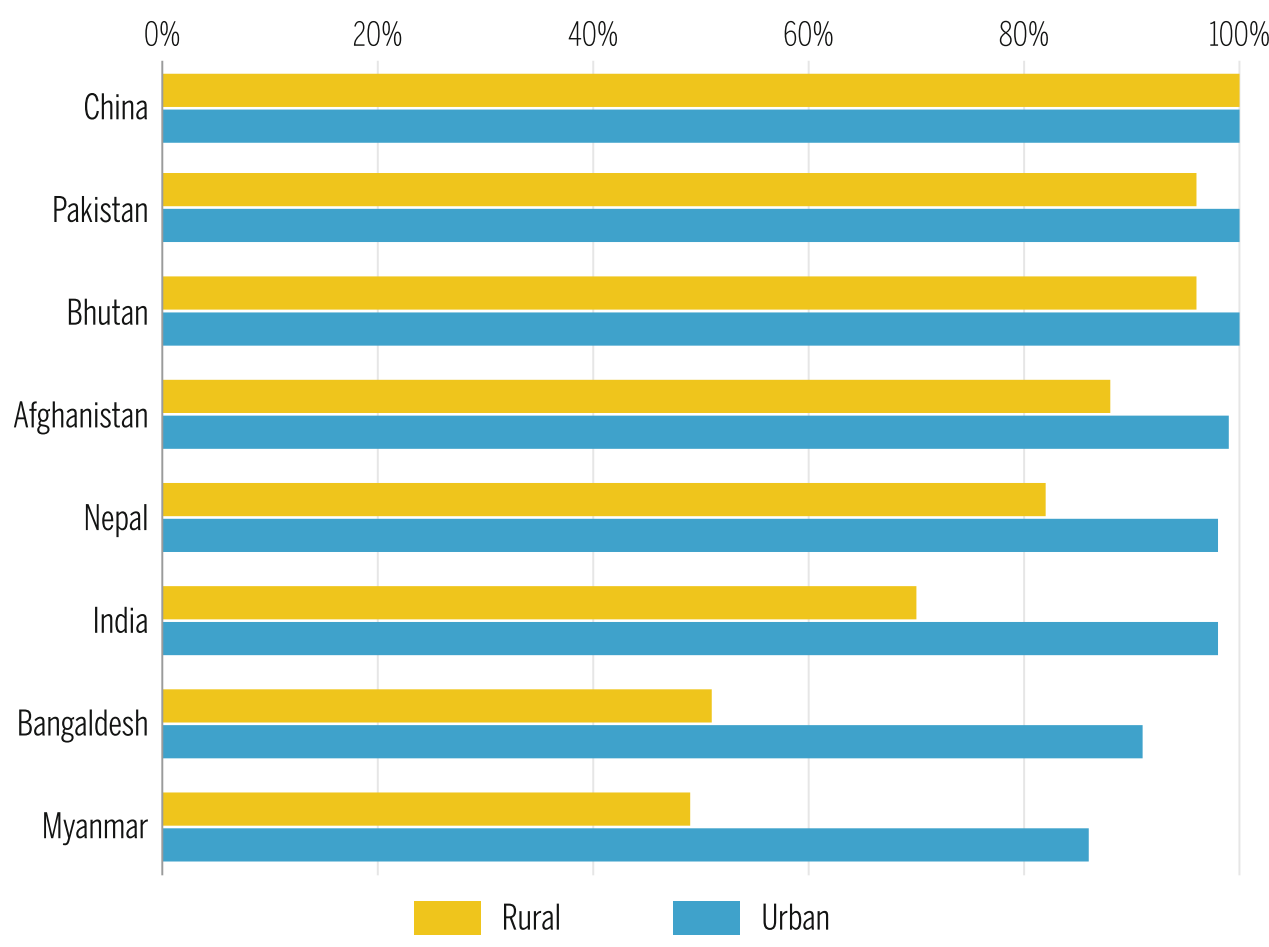

\subsubsection{Energy Demand and Consumption Characteristics}

There has been no realistic assessment of the underlying energy demand-and-supply patterns and trends in the $\mathrm{HKH}$ region since 1999, when Rijal carried out a comprehensive energy assessment in the HKH regions of China, India, Pakistan and Nepal (Rijal 1999). We must, therefore, rely primarily on national-level data to draw these inferences.

National-Level Final Energy Consumption Pattern in HKH Countries: Table 6.5 provides a summary of the national-level total final energy consumption (TFEC) trends by fuel type and sector for 2013. The total energy consumption of HKH countries as a whole (excluding Afghanistan and Bhutan) grew at an average annual rate of $4.6 \%$ over the period 1995-2013. Between 2008 and 2013, Afghanistan recorded the highest annual average growth rate of $16.5 \%$ followed by Bhutan (9.7\%). China and India dominated the other HKH countries in total energy consumption, consuming around $75 \%$ and $20 \%$ overall, respectively. Bhutan and China had the highest overall per capita energy usage, and both these countries had made rapid progress in securing access to basic energy for their rural and mountain populations.

In the absence of data, and in terms of fuel composition, the practice in Bhutan and Nepal (which are largely located in the HKH region) can be used to infer patterns for the region as a whole. As such, while traditional biomass at an aggregate level contributes only $16 \%$ of TFEC, signalling a transition from traditional fuels towards modern fuels in the $\mathrm{HKH}$, its use is still particularly high in Nepal (80\%), Myanmar (70\%), and Bhutan (57\%). Similarly, the sectoral composition of energy consumption reveals that about $45 \%$ of TFEC in $\mathrm{HKH}$ countries as a whole is used in the industrial sector. However, the share of residential sector TFEC is highest in Nepal (83\%), followed by Myanmar (70\%), and Bhutan (58\%).

HKH-specific energy consumption pattern: As discussed above, an important characteristic of household energy use in the $\mathrm{HKH}$ is heavy dependence on traditional biomass fuels (wood, agricultural residues, and animal dung). For example, approximately $90 \%$ of the cooking energy needs in rural areas in India are met through traditional sources of energy (Misra et al. 2005). In Nepal (Table 6.6) more than $85 \%$ of total domestic energy needs are met through traditional fuels. Several studies over time (ADB 2012; Rijal 1999; Shrestha 2013; UNDP 2013; Ramji et al. 2012) revealed this trend, whereby extraction of fuelwood exceeded the sustainable supply. Although the availability of Renewable Energy Technologies (RETs) is improving, their high up-front cost—and subsidized commercial fuel-make them unattractive.

The cold climate in much of the HKH leads to cooking, space heating, and water boiling being other major energy end uses of the residential sector in the HKH. Figure 6.5 shows the distribution of energy consumption in the residential sector of Nepal. The figure indicates that cooking (61\%) and heating (14\%) account for the largest share of 
$\therefore$

플

so

竎

๖

产

蒫

so

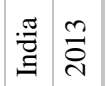

$s^{\circ}$

$\stackrel{n}{2}$

节

.

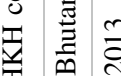

.

兽

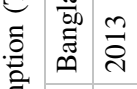

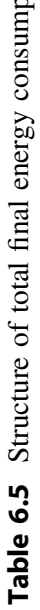

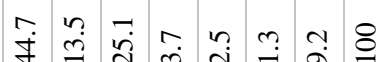

तิ

సิ

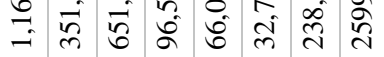

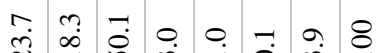

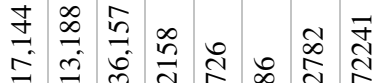

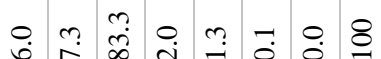

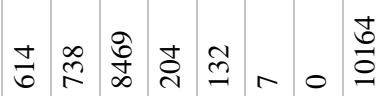

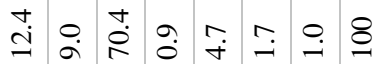

+ o

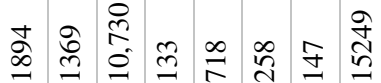

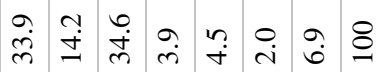

వิ

I

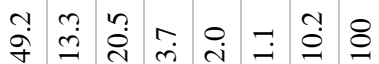

ఫ

ஸे

- 0 n

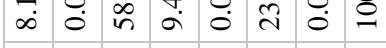

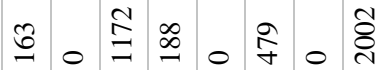

苞

2 if 10

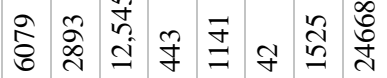

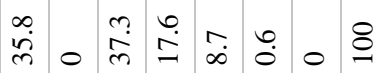

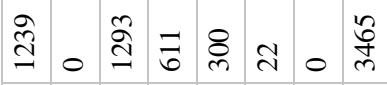

:

$\because$

产.

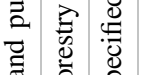

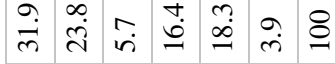

ลू.

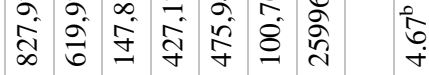

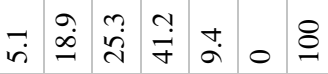

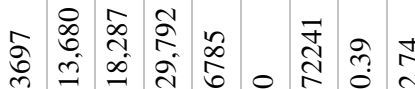

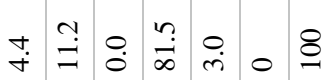

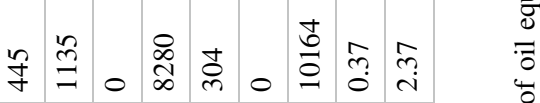

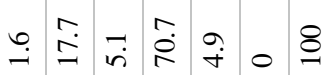

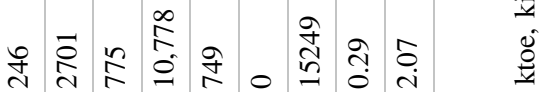

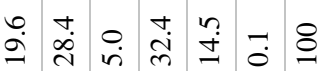

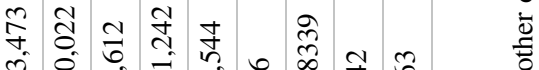

ชิ

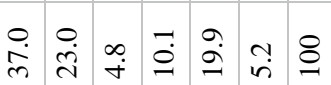

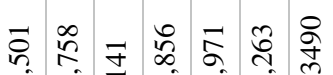

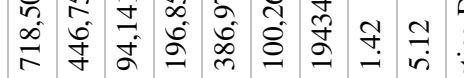

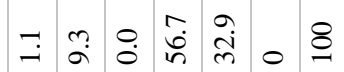

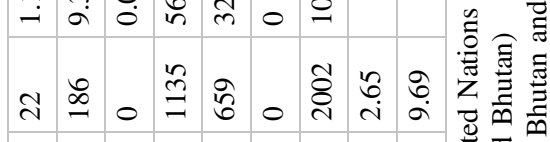

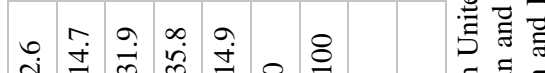

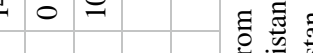

4

బิ

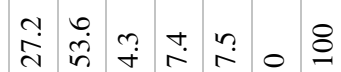

量 $\stackrel{0}{\circ}$

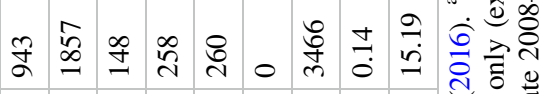

4.

青家

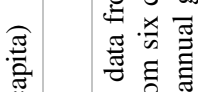

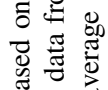


Table 6.6 Structure of total final energy consumption (TFEC) in Nepal 2011-12

\begin{tabular}{|c|c|c|c|c|c|c|c|}
\hline & & $\begin{array}{l}\text { Fuelwood } \\
(\%)\end{array}$ & $\begin{array}{l}\text { Dung and } \\
\text { agri-residue }(\%)\end{array}$ & Coal $(\%)$ & $\begin{array}{l}\text { Petroleum } \\
\text { product }(\%)\end{array}$ & $\begin{array}{l}\text { Electricity } \\
\text { (grid) }(\%)\end{array}$ & $\begin{array}{l}\text { Electricity } \\
\text { (renewables) (\%) }\end{array}$ \\
\hline & National shares $(\%)$ & 71.10 & 8.70 & 3.90 & 12.30 & 2.80 & 1.20 \\
\hline Residential & 80.30 & 94.20 & 100.00 & 0.00 & 15.30 & 45.70 & 100.00 \\
\hline Industrial & 7.80 & 2.60 & 0.00 & 92.30 & 10.50 & 38.30 & 0.00 \\
\hline Commercial and transport & 10.50 & 2.70 & 0.00 & 7.20 & 65.10 & 12.40 & 0.00 \\
\hline Agricultural & 1.20 & 0.00 & 0.00 & 0.00 & 9.00 & 2.20 & 0.00 \\
\hline Others & 0.10 & 0.00 & 0.00 & 0.00 & 0.00 & 1.40 & 0.00 \\
\hline
\end{tabular}

Source WECS (2014)

Table 6.7 Trend in energy efficiency in HKH countries

\begin{tabular}{|c|c|c|c|c|c|c|c|c|c|}
\hline & \multirow{3}{*}{\multicolumn{3}{|c|}{$\begin{array}{l}\text { Primary energy intensity } \\
\text { (megajoules per } 2011 \\
\text { USDPPP) }\end{array}$}} & \multicolumn{5}{|c|}{ Change in energy intensity ${ }^{b}(\%)$} & \multirow{4}{*}{ 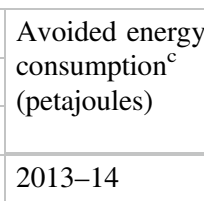 } \\
\hline & & & & \multirow{3}{*}{$\begin{array}{l}\begin{array}{l}\text { Primary } \\
\text { energy }\end{array} \\
2012-14\end{array}$} & \multicolumn{4}{|l|}{ Final energy } & \\
\hline & & & & & \multirow{2}{*}{\begin{tabular}{|l|} 
Agricultural \\
$2012-14$ \\
\end{tabular}} & \multirow{2}{*}{\begin{tabular}{|l|} 
Industry \\
$2012-14$
\end{tabular}} & \multirow{2}{*}{\begin{tabular}{|l|} 
Services \\
$2012-14$
\end{tabular}} & \multirow{2}{*}{$\begin{array}{l}\text { Residential } \\
2012-14\end{array}$} & \\
\hline & 2010 & 2012 & 2012-14 & & & & & & \\
\hline Afghanistan & 2.94 & 2.98 & 2.64 & -6.00 & 4.93 & 5.69 & 5.19 & 0.3 & -4.59 \\
\hline Bangladesh & 3.44 & 3.3 & 3.13 & -2.61 & -5.82 & -4.28 & -1.04 & 1.79 & -13.45 \\
\hline Bhutan & 12.55 & 11.56 & 11.06 & -2.19 & 2.71 & 8.01 & 2.92 & -1.41 & -2.94 \\
\hline China & 8.68 & 8.19 & 7.43 & -4.74 & 0.5 & -4.95 & -3.58 & 2.68 & -2906.04 \\
\hline India & 5.35 & 5.2 & 4.94 & -2.49 & 3.19 & 0.42 & -5.17 & 1.33 & -558.27 \\
\hline Myanmar & 3.15 & 3.1 & 3.24 & 2.29 & 27.03 & $\mathrm{Na}$ & $\mathrm{Na}$ & 0.16 & 15.12 \\
\hline Nepal & 7.97 & 7.27 & 7.67 & 2.69 & 6.06 & 1.33 & -0.25 & 6.02 & -7.31 \\
\hline Pakistan & 4.87 & 4.67 & 4.43 & -2.58 & 4.5 & -3.42 & -2.03 & -0.77 & -84.83 \\
\hline
\end{tabular}

Sources IEA and World Bank (2017)

$\mathrm{Na}$ refers to not available

${ }^{a}$ Primary energy intensity — an imperfect proxy indicator to measure energy efficiency — is the ratio of total primary energy supply (TPES) to gross domestic product (GDP), measured at purchasing power parity (PPP) in constant 2011 US dollars (USD). This indicates how much energy is used to produce one unit of economic output. A lower ratio indicates that less energy is used to produce one unit of economic output

${ }^{\mathrm{b}}$ Refers to the average annual growth rate of primary energy intensity between two years. Negative values represent improvements in energy intensity (less energy is used to produce one unit of economic output), and vice versa

${ }^{c}$ Refers to energy saved because of energy efficiency improvement during the period. A negative value means reduced energy use (avoided energy use) because of energy intensity reduction

energy consumption in Nepal. This might be the case for the mountain regions of other HKH countries as well, though no data are available to confirm this.

In Bhutan, as in other countries, the choice of fuel type for cooking is affected by a multiplicity of factors including income level, household wealth, age, gender, head of household educational level, access to electricity, and location (Rahut et al. 2016). Based on these factors, people choose and shift the type of fuel used along the energy ladder (Cai and Jiang 2008). Electricity is so versatile in meeting most energy services that it is also an important means of supply. Furthermore, the population in rural areas is almost double that in urban areas of Bhutan. In Nepal, a significant proportion $(45 \%)$ of electricity supplied in the residential sector is from the grid. In the past almost all electricity was supplied from domestic hydropower plants. Power shortages in recent years have led to back-up diesel generators and electricity imported from India becoming prevalent too.

Some common cottage industries in the HKH include agro processing, saw mills, potteries, blacksmiths, dairies, workshops, and bakeries. Process heat demand in these industries is generally fulfilled by fuelwood and other biomass, petroleum products, coal, and electricity. Motive power is met by petroleum products and electricity (Rijal 1999). The key commercial sectors in the HKH are local businesses, hotels, and restaurants. Tourism is an emerging sector for employment and income generation in the HKH, and will increase the commercial share of energy consumption as well as of liquid fuel consumption and electricity demand. 


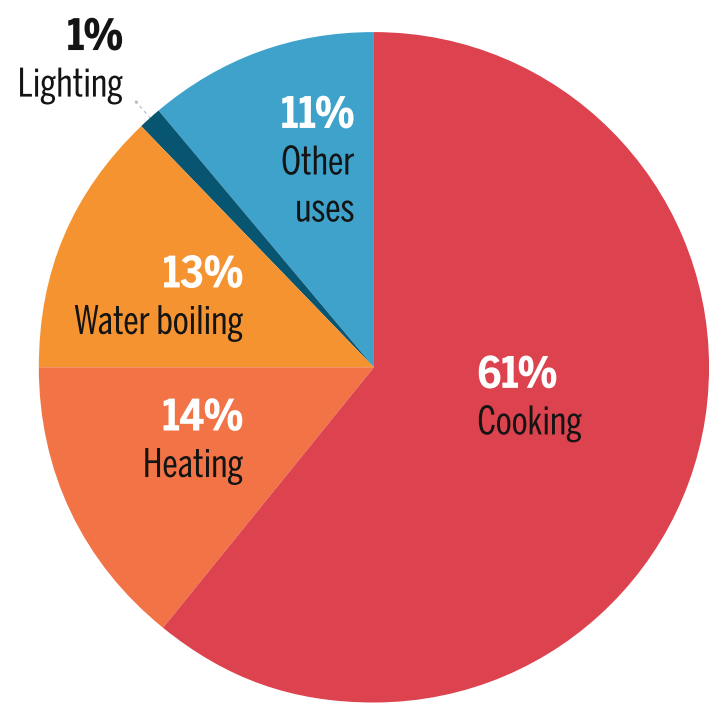

Fig. 6.5 Utilization of Energy in residential sector, Nepal (Source WECS 2014)

The agricultural sector also requires significant energy. In Nepal, its energy consumption is $9.9 \%$ of the total petroleum product consumption and $2.2 \%$ of total electricity consumption (Table 6.6). The end uses to which this energy is applied in Nepal are tillage (52\%), irrigation (32\%), and threshing (13\%) (WECS 2014). The higher demand for electricity and petroleum products reflects the gradual shift from traditional subsistence agriculture to high-value commercial products such as horticulture, medicinal plants, herbs, and vegetables (Rasul 2014a). Some parts of the HKH have also started deploying solar photovoltaic (PV)-based irrigated systems in recent years (Mukherji et al. 2017).

Energy Efficiency: The pace of improvement in energy intensity as an imperfect proxy of energy efficiency varies across HKH countries (Table 6.7). From 2012 to 2014, primary energy intensity declined in all $\mathrm{HKH}$ countries except Myanmar and Nepal, with the highest improvement recorded in Afghanistan and China. Over the same period, China avoided TFEC of 2906 petajoules, mainly as a result of efficiency improvement in two energy-intensive sectors (industry and service). India avoided TFEC of 558 petajoule through significant efficiency improvement in the service sector, resulting in the second highest energy savings worldwide after China (IEA and World Bank 2017). Interestingly, in 2012-14 the intensity of final energy use in the residential sector increased in all HKH countries, implying that there is scope for improving energy efficiency by moving away from the highly inefficient combustion of biomass fuel primarily used in this sector. This is especially needed in the rural areas of the HKH region.

\subsubsection{Ensuring Sustainable Energy Supply}

Most HKH countries rely heavily on commercial energy sources (Fig. 6.1) and over the last few years the share of the supply of commercial energy has increased in all $\mathrm{HKH}$ countries (Table 6.8).

The HKH has large potential for hydroelectricity that could help to reduce the dependency on fossil fuel-based electricity in HKH countries (Vaidya 2013). Compared to its potential, installed capacity in the region remains very low. Yupapin et al. (2011) report that Myanmar has the potential for installed capacity of more than $39 \mathrm{GW}$ of hydroelectricity, but has only installed $0.32 \mathrm{GW}$. Likewise, Nepal has only been able to install less than $2 \%$ of its total potential (Ale and Shrestha 2008). In these countries the share of hydropower in total electricity generation is high (Table 6.10). If hydropower were tapped more fully, it would be possible to meet the domestic demand, as well as a significant share of regional demand for electricity through regional cooperation (Rahman et al. 2011; Srivastava and Misra 2007).

The latest national-level data show that the share of renewable energy use in TFEC varies across HKH countries, ranging from $17 \%$ in Afghanistan and China to $86 \%$ in Bhutan. Traditional solid fuel dominates renewable energy

Table 6.8 Trends in the share of energy sources in total energy consumption in $\mathrm{HKH}$ countries

\begin{tabular}{|c|c|c|c|c|c|}
\hline $\begin{array}{l}\text { HKH } \\
\text { countries }\end{array}$ & Year & $\begin{array}{l}\text { Commercial } \\
\text { energy }(\%)\end{array}$ & Trend & $\begin{array}{l}\text { Renewable } \\
\text { energy }(\%)\end{array}$ & Trend \\
\hline \multirow[t]{2}{*}{ Afghanistan } & 2008 & 75 & \multirow[t]{2}{*}{$\uparrow$} & 25 & \multirow[t]{2}{*}{$\downarrow$} \\
\hline & 2011 & 85 & & 15 & \\
\hline \multirow[t]{2}{*}{ Bangladesh } & 2002 & 61 & \multirow[t]{2}{*}{$\uparrow$} & 39 & \multirow[t]{2}{*}{$\downarrow$} \\
\hline & 2013 & 73 & & 27 & \\
\hline \multirow[t]{2}{*}{ Bhutan } & 2008 & 10 & \multirow[t]{2}{*}{$\uparrow$} & 90 & \multirow[t]{2}{*}{$\downarrow$} \\
\hline & 2011 & 14 & & 86 & \\
\hline \multirow[t]{2}{*}{ China } & 2008 & 82 & \multirow[t]{2}{*}{$\uparrow$} & 18 & \multirow[t]{2}{*}{$\downarrow$} \\
\hline & 2013 & 89 & & 11 & \\
\hline \multirow[t]{2}{*}{ India } & 2002 & 67 & \multirow[t]{2}{*}{$\uparrow$} & 33 & \multirow[t]{2}{*}{$\downarrow$} \\
\hline & 2013 & 74 & & 27 & \\
\hline \multirow[t]{2}{*}{ Myanmar } & 2002 & 24 & \multirow[t]{2}{*}{$\uparrow$} & 76 & \multirow[t]{2}{*}{$\downarrow$} \\
\hline & 2013 & 30 & & 70 & \\
\hline \multirow[t]{2}{*}{ Nepal } & 2002 & 10 & \multirow[t]{2}{*}{$\uparrow$} & 90 & \multirow[t]{2}{*}{$\downarrow$} \\
\hline & 2013 & 15 & & 85 & \\
\hline \multirow[t]{2}{*}{ Pakistan } & 2008 & 59 & \multirow[t]{2}{*}{$\uparrow$} & 41 & \multirow[t]{2}{*}{$\downarrow$} \\
\hline & 2013 & 62 & & 38 & \\
\hline
\end{tabular}

$\uparrow$ arrow shows an increasing and $\downarrow$ arrow shows a decreasing trend Source United Nations Statistics Division 2013 (for Afghanistan and Bhutan); IEA (2015) (for the other countries) 
Table 6.9 Share of renewable energy in total final energy consumption (TFEC) in HKH countries

\begin{tabular}{|c|c|c|c|c|c|c|c|c|c|c|c|}
\hline & \multicolumn{10}{|c|}{ Share in total final energy consumption (\%) } & \multirow{4}{*}{\begin{tabular}{|l}
$\begin{array}{l}\text { Total final } \\
\text { energy use } \\
\text { (petajoules) }\end{array}$ \\
2014
\end{tabular}} \\
\hline & \multirow{2}{*}{\multicolumn{2}{|c|}{$\begin{array}{l}\text { Total } \\
\text { renewable } \\
\text { energy }\end{array}$}} & \multicolumn{2}{|c|}{ Solid biofuels } & \multirow{3}{*}{\begin{tabular}{|l|} 
Hydro \\
2014 \\
\end{tabular}} & \multirow{3}{*}{\begin{tabular}{|l|}
$\begin{array}{l}\text { Liquid } \\
\text { biofuels }\end{array}$ \\
2014 \\
\end{tabular}} & \multirow{3}{*}{\begin{tabular}{|l|} 
Wind \\
2014 \\
\end{tabular}} & \multirow{3}{*}{$\begin{array}{l}\text { Solar } \\
2014 \\
\end{array}$} & \multirow{3}{*}{\begin{tabular}{|l|} 
Geothermal \\
2014 \\
\end{tabular}} & \multirow{3}{*}{\begin{tabular}{|l}
$\begin{array}{l}\text { Other (biogas, } \\
\text { renewable waste, } \\
\text { marine) }\end{array}$ \\
2014
\end{tabular}} & \\
\hline & & & $\begin{array}{l}\text { Traditional } \\
\text { use }\end{array}$ & $\begin{array}{l}\text { Modern } \\
\text { use }\end{array}$ & & & & & & & \\
\hline & 1990 & 2014 & 2014 & 2014 & & & & & & & \\
\hline Afghanistan & 15.9 & 16.8 & 8.82 & 0 & 7.93 & 0 & 0 & 0 & 0 & 0 & 146 \\
\hline Bangladesh & 71.7 & 37.5 & 37.26 & 0 & 0.18 & 0 & 0 & 0.04 & 0 & 0 & 1018 \\
\hline Bhutan & 95.9 & 86.7 & 74.81 & 0.15 & 11.7 & 0 & 0 & 0 & 0 & 0 & 61 \\
\hline China & 34.1 & 17.1 & 10.21 & 0.19 & 4.12 & 0.09 & 0.61 & 1.2 & 0.26 & 0.42 & 76,546 \\
\hline India & 58.7 & 36.5 & 26.6 & 7.6 & 1.62 & 0.07 & 0.46 & 0.17 & 0 & 0.02 & 21,550 \\
\hline Myanmar & 90.9 & 68.5 & 63.21 & 2.09 & 3.22 & 0 & 0 & 0 & 0 & 0 & 700 \\
\hline Nepal & 95.1 & 84.4 & 78.19 & 0.87 & 2.9 & 0 & 0 & 0 & 0 & 2.41 & 483 \\
\hline Pakistan & 57.5 & 47.2 & 39.17 & 4.89 & 3.1 & 0 & 0.04 & 0 & 0 & 0 & 2991 \\
\hline \multicolumn{2}{|c|}{ All HKH countries } & 28 & 20.12 & 2.97 & 3.15 & 0.07 & 0.49 & 0.72 & 0.14 & 0.28 & 105,509 \\
\hline
\end{tabular}

Source IEA and World Bank (2017)

Table 6.10 Electricity generation from various sources in HKH countries (2015)

\begin{tabular}{|c|c|c|c|c|c|}
\hline \multirow[t]{2}{*}{ Country } & \multirow{2}{*}{$\begin{array}{l}\text { Total electricity production } \\
\text { (Gigawatt-hours) }\end{array}$} & \multicolumn{4}{|c|}{ Sources of electricity production (as \% of total) } \\
\hline & & Hydropower & Other renewable sources ${ }^{\mathrm{a}}$ & Fossil fuels $^{\mathrm{b}}$ & Nuclear power \\
\hline Afghanistan & 1034 & 86.1 & 0.0 & 13.9 & 0.00 \\
\hline Bhutan & 7748 & 100.0 & 0.0 & 0.0 & 0.00 \\
\hline Bangladesh & 59,011 & 1.0 & 0.3 & 98.8 & 0.00 \\
\hline China & $5,814,573$ & 19.4 & 3.9 & 73.7 & 2.94 \\
\hline India & $1,354,382$ & 9.0 & 2.7 & 85.5 & 2.76 \\
\hline Myanmar & 15,970 & 59.5 & 0.0 & 40.5 & 0.00 \\
\hline Nepal & 3503 & 99.8 & 0.2 & 0.0 & 0.00 \\
\hline Pakistan & 115,073 & 29.5 & 1.3 & 65.2 & 4.00 \\
\hline
\end{tabular}

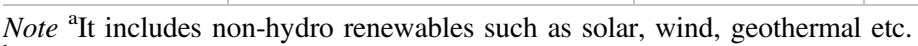

${ }^{\mathrm{b}}$ It includes coal, natural gas, oil etc.

Source Based on data from United Nations Statistics Division for 2015, available online at https://unstats.un.org/unsd/energy/yearbook/2015/t32. pdf

use in all HKH countries, with the share of modern renewable use in the TFEC being marginal (Table 6.9).

In addition to hydropower, there is a large potential for electricity generation from other renewable sources in the HKH. As shown in Table 6.10, large amounts of electricity are being produced from hydro, but renewable sourcessuch as wind or decentralized PV-and small-scale hydropower projects have been increasing in the region in recent years.

Extending national grid electricity to sparsely populated, remote, and low-density settlements in the HKH is difficult and might not contribute much in improving access to electricity in these areas. Small-scale hydropower projects may be more suitable for the HKH. These systems could help in ensuring sustainable energy and improve rural economies and, in the process, check or reduce outmigration to urban centres (KC et al. 2011). For instance, in Afghanistan, nearly $50 \%$ of the beneficiaries of small-scale community-based renewable energy projects in selected areas reported that the projects helped them to improve their living conditions (Shoaib and Ariaratnam 2016).

Loka et al. (2014) found that decentralized micro-grid PV systems could benefit remote villages because they are both viable and cost effective. Proietti et al. (2015) successfully tested the possibility of electricity generation from wind in high-altitude remote regions of Nepal. Chauhan and Saini (2015) found a potential for integrating various sourcessuch as hydropower, biogas, solar, and wind - into off-grid energy systems in the mountainous regions of India. In addition to electricity generation, solar energy can potentially be used for cooking and heating (Badran et al. 2010). Thus, off-grid energy solutions (such as PVor mini-hydro) 
often offer better options for providing electricity in remote areas. Small-scale hydro (micro, mini) can be cost effective in some situations but in others it can be quite costly. PV are now often cheaper, although significant untapped economic potential for mini- and micro-hydro does appear to exist in the HKH. The use of solar power for cooking can reduce the dependency on other fuels (Yettou et al. 2014), such as firewood and fossil fuels.

To summarize: universal electricity access (through a rational combination of grid-connected and off-grid power) and elimination of inefficient use of traditional sources for cooking and heating (through a sustainable supply of clean, affordable, and demand-responsive energy and technology options) should be highlighted as a priority in national energy agenda. This would also entail recognizing that in the short-to-medium term, displacing traditional fuels completely is unlikely owing to economic and cost imperatives; but economic potential exists for greater use of small-scale renewable energy options. Some strategic options for sustainable energy development in the $\mathrm{HKH}$ may include:

- establishing an HKH-specific energy database for evidence-based policy making;

- optimizing effective use of biomass through advanced cookstoves, upgrading the quality of biomass fuels, and increasing access to cleaner fuels such as liquefied petroleum gas (LPG) and electricity to meet cooking and heating needs while addressing indoor air pollution;

- maximizing use of new and renewable decentralized resources and technologies, not only to sustain and increase economic activities, but also to reduce human drudgery, particularly that of women and children;

- initiating large-scale development of hydropower to generate revenue for alleviating the poverty of mountain communities while ensuring overall development of mountain areas within environmental and social limits; and

- developing an integrated approach for bridging demand-and-supply gaps. This could support the principles of energy self-sufficiency, energy efficiency improvements, diversification of revenue sources for mountain communities, pricing, market and regulatory frameworks, and opportunities for mountains to become quality exporters of clean energy.

\subsection{National Energy Policies, Programmes, Institutions, and Markets}

Energy policies and programmes follow many diverse models and exhibit differences in terms of institutions and markets within the HKH. This assessment highlights that:
- several examples of success and policy experiences with regard to electricity access, decentralized energy, and energy efficiency could be scaled up. In particular, micro-hydro, biogas, improved cook stove (ICS) implementation, and solar programmes have made the $\mathrm{HKH}$ a leader in renewable energy and energy efficiency;

- existing national policy frameworks primarily focus on electrification (power sector) with limited attention paid to clean energy for cooking;

- in most HKH countries there is no separate energy policy framework for off-grid-based rural electrification, although some countries do have renewable energy development agencies, off-grid schemes, and programmes;

- generally, the HKH lacks supportive policy, legal, and institutional frameworks and innovations in mountain-specific technology and financing, or enhanced multi-stakeholder capacity building at all levels, for scaling-up successful energy programmes in off-grid mountain areas; and

- there is no one-size-fits-all solution for ensuring universal access to modern forms of energy given the diverse sources of energy supply, a wide portfolio of technologies, and a variety of institutional and local circumstances. Therefore, policies and programmes must be tailored according to local needs, resources, and existing institutional arrangements and capabilities to deliver co-benefits.

\subsubsection{Energy in Relation to National Development Strategies}

A review of national policy papers ${ }^{1}$ indicates that access to energy, energy security, and regional cooperation are the key stated energy objectives for every $\mathrm{HKH}$ country. The countries also share a commitment to electrifying all communities and increasing their use of renewable energy. The target year for complete electrification differs from country to country and has often been pushed back. For example,

\footnotetext{
${ }^{1}$ National policy papers reviewed include, among others, Energy Sector Strategy (2007/08-2012/13), Rural Renewable Energy Policy (2013) and National Development Strategy (2008-2013) from Afghanistan; Power Sector Master Plan (2016), Renewable Energy Policy (2008), Perspective Plan 2021 and National Energy Policy (2004) from Bangladesh; Integrated Energy Policy (2006), Electricity Act 2003, and National Electricity Policy (2011) from India; Intended Nationally Determined Contributions and Sustainable Development Goals (2016) -National Report (2016-2030) from Nepal; Pakistan Energy Vision 2035; Pakistan National Power Policy 2013; Myanmar National Energy Policy 2013 (draft) and National Sustainable Development Strategy of Myanmar 2009.
} 
India's target is to achieve power for all by 2019, whereas it is 2030 for Myanmar (World Bank 2015). Similarly, Bangladesh envisions achieving universal access to electricity by 2021 (Government of the People's Republic of Bangladesh 2012) and $100 \%$ clean cooking solutions by 2030 (Government of the People's Republic of Bangladesh 2013). The Nepalese government's SDG report states that $99 \%$ of households will have access to electricity by 2030 and only $10 \%$ will be using solid fuels for cooking (Government of Nepal 2016). Afghanistan's target is to achieve near $100 \%$ access in the urban areas and $65 \%$ in rural areas by 2032 (ADB 2013).

The region has several examples of on-grid and off-grid electrification that have achieved varying degrees of success. Some HKH countries have demonstrated scaling-up off-grid initiatives that are globally recognized as successful. China has been a leader in parallel development of off-grid and on-grid electrification to achieve $100 \%$ electrification, as well as having one of the largest cookstove and biogas programmes in the world. Unlike many other countries following the top-down approach to rural electrification, China's success is rooted in a bottom-up approach with strong government commitment, active local participation, technological flexibility and diversity, strong emphasis on rural development, and capacity building and training, all of which provide lessons for other countries in the HKH region (Bhattacharyya and Ohiare 2012). Likewise, Bangladesh's IDCOL is recognized as the world's fastest growing off-grid electrification programme and has already deployed 4 million solar home systems using innovative financial and technology packages. This has demonstrated that electrification programmes targeted at poor communities can be scalable and sustainable (Vinci et al. 2015). India has a number of programmes including the Jawaharlal Nehru National Solar Mission (JNNSM) for mini-grids and off-grid applications. Unlike Bangladesh, India adopts a slightly different approach to promotion and channels finance to banks; however, not as many people are taking loans as had been hoped primarily due to perceived difficulty in rectifying non-functional devices. In Nepal more than $10 \%$ of the population has access to off-grid energy through micro-hydro, solar home systems, and domestic biogas. Afghanistan and Pakistan have included off-grid mini-grid programmes under rural infrastructure programmes such as the National Solidarity Programme and Pakistan Poverty Alleviation programme. There is still room for improvement, but there is now sufficient experience from other $\mathrm{HKH}$ countries to evaluate these initiatives and to provide policy recommendations about which programmes work best, and under which conditions. Most countries in the HKH now have a policy framework for rural electrification. Experience shows that while a market-driven approach to off-grid renewable energy deployment is key to bringing technology, financing, and product innovation, the governments have an important role in ensuring that the appropriate environment is established for private sector investment. This will accelerate the expansion of modern energy services in a financially sustainable manner (Vinci et al. 2015).

Despite the progress and efforts made so far, existing governance arrangements and policy frameworks for the energy sector are insufficient to address the broad range of technical, capacity, and policy and regulatory barriers which have hindered promotion of decentralized sustainable energy solutions in the HKH. Rahman et al. (2012) observe that many feasible hydropower projects are located in remote and mountainous areas (where other infrastructure, such as accessible roads and high-voltage transmission lines, does not exist), highlighting the gaps in policy coherence. Further, there are no specific initiatives to improve the overall household connection level (Palit and Chaurey 2011). The sectoral division of responsibilities without full coordination for integrated planning has generally been the rule rather than the exception in most energy policy planning processes. This has limited the scope for treating energy, water, and food in a combined way to maximize synergy and manage trade-offs (Sharma and Banskota 2005). In some cases, ignorance of mountain specificities is reported to have led to improper choice of energy technologies and institutions (Rijal 1999; Sharma 2007). Social inclusion and gender sensitivity in energy policy analyses and design is still not fully integrated into mainstream energy development activities in the region (Box 6.1). Finally, existing national development policy strategies pursued by all HKH countries see energy more as an advancement of electrification, and place limited emphasis on energy for clean cooking, heating, and mechanical power solutions in rural areas.

\section{Box 6.1 Engendering energy and empowering women}

Throughout the Himalayan region, women face the burden of fetching heavy loads of fuelwood and spend hours in drudgery to meet their daily energy and water needs. However, the importance of bringing a gender perspective to energy policy analyses and design is still not fully appreciated in the region. A recent analysis of selected countries revealed that electricity policies rarely address gender issues explicitly and that policies are mostly gender-blind. For energy to become an instrument for poverty alleviation and sustainable development, a fundamental readjustment of public policies is needed. This should recognize the differentiated needs of women and men and, at the same time, also focus on integrating women's roles and needs in decision making for supply chains and using energy. Gender mainstreaming alone may 
encounter challenges because women may not be in a position to participate on an equal basis because of their heavy workloads at home, poor access to finance, low literacy, and entrenched gender norms (EFEWEE 2016; Sharma and Banskota 2005).

\subsubsection{National Energy Policy Framework, Programmes, and Markets}

\section{Energy for lighting and enterprises}

A review of the electrification programmes in the $\mathrm{HKH}$ indicates that most countries in the region have established organizations dedicated to rural electrification or formulated schemes with supportive legislation to extend electrification primarily through central grid extension, either using a government-owned utility model or rural electricity cooperatives. In most cases, electrification plans for mountain communities are included within the national energy plans of the respective countries, although in many cases their special requirements have not been taken into account when formulating the plans.

All HKH countries are targeting universal access to electricity through a two-pronged approach: (1) rapid extension of the national grid; and (2) off-grid electricity for areas the grid may not reach. Off-grid technologies have been used either through the creation of local mini-grids based on solar and/or micro-hydro, or by disseminating household-level technology such as solar home systems for lighting and powering other low-load devices. For example, Afghanistan has acknowledged its national grid will not reach $20-25 \%$ of the population within the next 20 years. These underserved populations will be supplied through decentralized renewable energy sources. In India, the national rural electrification programme also includes a decentralized distributed generation component for 3500 villages, mostly in the eastern Himalayan mountain provinces. However, most countries focus on physical infrastructure rather than on the quality, availability, and affordability of supply: the latter are equally important but vary from place to place.

The electricity grid has been extended mainly by the utility-based delivery model (e.g., India, Bhutan), by rural electricity cooperatives (e.g., Bangladesh), or by community rural electrification (e.g., Nepal). China and India have national programmes that subsidize the extension of grid electricity to rural areas. For areas where grid extension was found to be economically daunting, households are covered by off-grid solutions, implemented primarily by state agencies. Bangladesh and Nepal have been following both community-led and private sector models (with partial subsidy) for expanding their rural electrification programme through grid extension and off-grid interventions. In Nepal, the state-owned Nepal Electricity Authority has achieved considerable success in promoting electrification in close cooperation with community-run local cooperatives (Box 6.2). Nepal used an 80/20 (government/local) financing model for grid-extended rural electrification for many years. According to Nepal's 2016 renewable energy subsidy policy, the subsidy amount differs by technology and region, but generally covers $40 \%$ of the total costs, with approximately $30 \%$ coming from credit and $30 \%$ from private sector investment, communities, households, in-kind, and/or cash (MoPE 2016).

\section{Box 6.2 Community Rural Electrification Pro-} gramme (CREP) in Nepal

CREP is a grid-based rural electrification programme, was launched in 2003 to expand grid-based rural electrification, primarily using hydro resources and involving the community. Community involvement was sought to achieve operational efficiency in the distribution sector, which had seen high system losses and poor revenue collection for some years. Consumer associations, typically in the form of village cooperatives, take responsibility for managing, maintaining, and expanding the rural distribution of electricity. In addition to local management, communities also provide a portion of the required funding (around 20\%) in cash and kind, and the remainder comes from government sources. More than 230 cooperatives in various parts of the country have reportedly entered into agreement for electricity distribution with Nepal Electricity Authority (NEA) (Palit and Chaurey 2011).

Progress in the use of off-grid solutions for rural electricity supply in the HKH has been mixed. The most common technologies are solar PV and micro-hydro systems. While micro-hydro has been used to supply local mini-grids, solar PV technology applications cover solar lanterns, solar home systems, and solar PV-based mini-grids.

In terms of country coverage, Nepal and China have used micro hydropower-based mini-grids extensively. Nepal's Rural Energy Development Programme (REDP) is widely cited as one of the best examples of off-grid electrification programmes, and is centred around the decentralized and participatory decision making and a holistic development approach. India has implemented almost all off-grid electrification technologies, but solar PV has been the preferred modality in the mountains. Small hydro projects in the Indian mountains, on the other hand, feed into the national grid. 
Most off-grid electrification programmes in the HKH have been grant-based and donor-driven, and continue to be so in Myanmar, Nepal, and Pakistan. Markets have emerged, however, for stand-alone solar systems in Bangladesh and India (Palit and Bhattacharyya 2014). Palit and Chaurey (2011) indicate that while community-based models are often adopted for mini-grid-based electrification, fee-for-service, leasing, and consumer financing were used to promote individual solar home systems. Bangladesh has covered approximately 4 million off-grid households with solar home systems using an innovative consumer financing model; this consists of a combination of soft financing, institutional development, and product buy-down grants. Local grassroots organizations with experience in micro-financing were engaged to assist this approach. Other countries - such as Afghanistan, Bhutan, Myanmar, and Pakistan-have developed off-grid systems relatively slowly, although they have made progress in recent years. The role of the private sector is paramount in providing cost-effective solutions that do not depend on public subsidies alone; these are often run by local entrepreneur-driven supply chains (for example, the Lighting India programme).

\section{Energy for cooking and heating}

While electricity access programmes in HKH countries have received the necessary attention from policy planners and governments, energy access for cooking continues to be an overlooked but critical issue in all countries of the region. Policy makers have also failed to influence a shift from biomass-based cooking in rural areas. From India, Srivastava and Rehman (2006) observe that subsidies on LPG and kerosene have mostly benefited middle- and high-income rural households and the urban poor. Palit et al. (2014) find that India's 2010 National Biomass Cookstove Initiative (NBCI) is neither well-organized, nor has received the resources necessary for it to be successful in comparison to the national rural electrification programme.

Today, most cash-poor rural households, especially the mountain community, continue to use biomass (available at zero cash outlay) instead of commercial cooking fuels, even when those commercial fuels are subsidized. Part of the reason is that the time saved by using commercial cookstoves does not necessarily result in increased income-generating time for rural populations. Also, a lack of awareness about the health benefits of cleaner cooking fuels is not yet appreciated locally because of ingrained gender biases. Electricity, on the other hand, is regarded as an aspiration which can also provide people the opportunity to earn more. Cleaner cooking devices, however, are considered expensive and thus usually avoided (Palit et al. 2014), again as a result of clear gender biases where women's health and safety receive lower attention. A study by Kishore and Spears (2014), using national survey data from India, shows that having a son increases the use of clean cooking fuel in Indian households.

Although there has been limited success in shifting from solid biomass fuels to other cleaner sources, some HKH countries have promoted biogas as an alternative cooking energy, and China and Nepal have successful biogas programmes. However, in Bhutan, the shift from biomass is towards electric devices for cooking (Palit and Garud 2010). Induction cookstoves were introduced into one of the Indian mountain states some years ago, but Banerjee et al. (2016) observe that the intervention has largely replaced LPG and not necessarily firewood from the fuel mix (Box 6.3). While evidence from the $\mathrm{HKH}$ does not yet appear in the published literature, there is anecdotal evidence about the increase in use of rice cookers in rural areas of HKH. In Vietnam, 55\% of households in rural areas started using rice cookers after they were connected to the grid (World Bank 2011). In the Khumbu Bijuli Company supplied area in Nepal, 54\% of the customers of micro-hydro have sufficient power subscription $(1.25 \mathrm{~kW})$ to meet the amount of the electricity used for cooking during off-peak hours. In 2016 the Government of India launched a large-scale clean cooking programme, Pradhan Mantri Ujjwala Yojana (PMUY), targeted to provide 80 million LPG connections to underprivileged households. The connection is provided in the name of a woman member of the household, and half of the up-front total capital cost (equivalent to total $\sim$ USD50) required for a new connection is waived, while the balance can be an interest-free loan. While PMUY has enabled 32 million poor women to access subsidized LPG within 20 months since its launch in September 2016, initial reports on programme performance indicate on average only four refills per household. Kar et al. (2018) observe that primary LPG users (i.e., 4-5 cylinders per year) account for only $38 \%$ of UJJWALA beneficiaries, and the majority $(42 \%)$ are more occasional users using 2-3 cylinders annually, or rare users (20\%) who have not come back for refills.

\section{Box 6.3 Induction stoves as an option for clean cooking}

Clean cooking initiatives generally consider improved biomass stoves, biogas, or LPG as potential carriers. Electricity is rarely considered a fuel option as there is a shortage of infrastructure. In induction cooking, a cooking pot is heated by magnetic induction instead of thermal conduction. A survey of 1000 households in Himachal Pradesh, India, indicates that $84 \%$ of the beneficiary households using LPG as a secondary cooking fuel shifted to the induction stoves and that only $5 \%$ of the beneficiary households displayed a shift in their primary cooking from firewood to 
induction stoves. The study concludes that underprivileged households are less likely to use commercial fuels for cooking, either because the expenditure on electricity is likely to increase, or because they can only afford the minimal cash outlay required for biomass. However, there may be ideal areas in mountain regions to introduce electricity as a cooking fuel option, particularly where cheap and reliable electricity from hydropower is available (Banerjee et al. 2016). Of households surveyed in this study, $42 \%$ used a $1300 \mathrm{~W}$ device for an average of $2 \mathrm{~h}$ a day (78 KWh per month), a cost of USD4.10 per month.

Despite these advances, solid fuels will remain an important cooking fuel in the near future, especially in the mountains. For this reason, creating more energy-efficient cookstoves will be an important project, particularly as this technology faces several barriers to more widespread adoption (Khandelwal et al. 2016; Palit and Bhattacharyya 2014). National experiences with stove programmes in the $\mathrm{HKH}$ indicate that strong technical and administrative capacity, sound programme design, sustained national-level attention, and high-level government support are imperative for successful cookstove programmes (Kandlikar et al. 2009). The Chinese National Improved Stove Program (NISP) deployed 120 million improved cookstoves from 1983 to 1996, and is widely regarded as one of the world's most successful Chinese projects in energy efficiency and rural development (Smith et al. 2007). Conversely, the Indian National Programme for Improved Chulhas (NPIC) was considered a failure (Hanbar and Karve 2002) despite distributing 90 million improved cookstoves between 1983 and 2002. India's failure is generally attributed to its top-down approach and dissemination of non-user-friendly stoves (though with much higher efficiency level than traditional stoves) and stoves with lower life (e.g., mud stoves). China's success was owing to strong administrative, technical, and outreach competence, and resources situated at the local level (Sinton et al. 2004). China has integrated the Clean Stove Initiative into its action plan for energy conservation and emissions reduction contained in its Twelfth Five-Year Plan (World Bank 2013).

Given the mixed results of many programmes in the past, it is now widely accepted that developing sustainable biomass-based cookstoves requires consideration of not just the thermal performance of the stove. The behaviour of users and their participation in the design, marketing, and maintenance of cookstoves; commercial scalability; and monitoring of effectiveness through education and outreach efforts to promote use also need to be taken into account (World Bank 2013). Limited affordability also hinders the promotion of cookstoves, and so suitable financing mechanisms to support adoption need to be explored (Palit and Bhattacharyya 2014). In terms of a policy framework, governments could support the development of performance and quality standards of advanced biomass stoves and remove import duties or value-added tax (VAT) so that attractive technologies can be imported from other countries in the region. A mountain-specific requirement is that international standards such as the ongoing International Organization for Standardization (ISO) process for improved cookstoves (ICS) includes performance of space heating stoves within the multi-tier framework, along with cookstoves benchmarking efficiency, indoor and outdoor emissions, and safety.

Fuel stacking, when households simultaneously use multiple fuels for the same purpose, is common in the region and also needs to be considered. Cheng and Urpelainen (2014) observe that, owing to constraints on the availability of LPG, stacking of LPG and traditional biomass has grown rapidly in India over the past two decades. The same phenomenon has also been observed in a national-level study by Jain et al. (2015) in India and by Palit and Garud (2010) in Bhutan, as well as in a local level study by Banerjee et al. (2016) in Himachal Pradesh.

\section{Institutional arrangements and governance mechanisms}

In all HKH countries, the commercial energy sector is regulated by the government and, in some cases, the government is directly responsible for supply, albeit through multiple agencies. For instance, the Ministry of Energy and Water (MEW) in Afghanistan manages and operates the power sector through nine departments and four public sector organizations. ${ }^{2}$ In China, the National Development and Reform Commission (NDRC), its main development planning body, manages the energy sector through the National Energy Bureau. In addition, the National Energy Administration of China is responsible for the development of policy instruments, standards, laws, and regulations. In India, both federal and provincial governments have jurisdiction over electricity. While the jurisdiction of provincial governments includes generation, intrastate transmission, and distribution, the federal government's purview includes policy formulation, generation, and interstate transmission. In the rural electrification sector, principal actors have traditionally been state electricity utilities, because they were responsible for distribution in the states. However, the Indian federal government is now directly implementing a rural

\footnotetext{
${ }^{2}$ Da Afghanistan Breshna Sharkat, or DABS, is the largest of these Afghan organizations and is responsible for the generation, transmission, and distribution of electricity; operation and maintenance of
} assets; and sales of electricity and revenue collection. 
electricity infrastructure development programme to provide access to universal electricity in a time-bound manner.

Government institutions have also played a key role in promoting off-grid electrification. Almost all countries have dedicated agencies for promoting the renewable energy sector. Nepal started to develop the off-grid market after establishing the Alternate Energy Promotion Centre (AEPC) in 1999. Under the AEPC, donor-supported programmesthe Energy Sector Assistance Programme (ESAP) and REDP - substantially helped to promote the supply of off-grid energy. In India, the Ministry of New and Renewable Energy is the nodal ministry for promotion of renewable energy-based off-grid interventions. Bangladesh, China, and Pakistan also have agencies dedicated to the development of the sector. Although Afghanistan does have a specialized agency, its Ministry of Power has implemented several off-grid networks based on micro-hydro, small diesel units, or renewable energy sources. ${ }^{3}$ Most of the micro-hydro and solar home systems in Afghanistan have been installed under the National Solidarity Programme, which was a programme under the Ministry of Reconstruction and Rural Development (MRRD). In Myanmar, off-grid electricity is handled by the Department of Rural Development (DRD) under the Ministry of Agriculture.

\subsubsection{Cross-Regional Experiences and Recommendations}

Challenges to national energy policy can be categorized in four ways: technical, financial, regulatory, and institutional. According to those categories, we make the following recommendations:

The energy sector in each country is governed individually by legal, regulatory, and policy frameworks with little or no coordination between the energy sector institutions and regulators. While institutional structures exist in all the countries in the form of relevant energy ministries and energy subsector institutions, the ability of the institutions to deliver the desired impacts varies from country to country. Regional coordination between countries is also lacking, and this can multiply regulatory risks for future cross-border energy transactions. This lack of coordination also hinders the exchange of ideas and experience from which $\mathrm{HKH}$ countries could mutually benefit.

The rate of success for promoting rural electrification depends on the government's commitment to creating and supporting an enabling environment. Bhutan, Pakistan,

\footnotetext{
${ }^{3}$ Khan Muhammad Alamyar, Renewable Energy for Sustainable Development, Economic Policy Directorate, Ministry of Economy, pers. comm., April 2014.
}

China, and India provide examples where we can see that an enabling policy development and targeted approach have helped to increase the electrification rate substantially. All rural electrification projects examined have involved a significant subsidy (especially capital) component. However, different approaches have been adopted for grid-based and off-grid electrification.

Off-grid electrification, through mini-grids or otherwise, has been developed mainly through community-centred projects. The top-down approach has been adopted primarily by extending the grid to rural areas, with planning and implementation undertaken by federal- or provinciallevel agencies. The approach to off-grid electricity development thus lacks an organized delivery model, which has hindered its scaling-up despite the huge potential in the region. Based on rural electrification experience in India, Palit et al. (2014) observe that an appropriate institutional structure should be a mixture of both participatory and multi-level approaches, while local issues could be better addressed through a participatory mode of governance, policy, regulatory, and financing at appropriate intermediary and/or higher levels.

Merely fixing targets for village electrification is not sufficient unless effective implementation and monitoring are in place to connect rural households and also to ensure sustained electricity supply. While the level of village electrification in Bangladesh and India is high, the actual number of connected households is relatively low as not all households in the villages are electrified. The key issue is thus to improve household-level connection and to provide a sustained electricity supply to rural areas in line with demand, and not just a satisfactory overall rate of extending the electricity infrastructure to the villages.

Sharing information on energy sector policies and plans, and the respective legal, institutional, and regulatory frameworks and lessons are expected to result in strong confidence building among HKH countries. Such sharing platforms are currently limited and are needed. Enhancing institutional capacity for improved coordination and implementation of the joint activities to promote regional energy cooperation will also be important.

\subsection{Challenges and Opportunities for Sustainable Energy}

\subsubsection{Key Sustainable Energy Concerns in the HKH}

As a cornerstone of growth and human development, SDG 7 aims to provide access to modern energy to all people by 2030 in an efficient manner, using modern forms of energy. However, despite all the efforts made thus far, providing 
Table 6.11 Indicators for evaluating energy sustainability in $\mathrm{HKH}$

\begin{tabular}{|c|c|c|c|}
\hline Dimension & Indicators & Theme & Measurement description (Units) \\
\hline \multirow[t]{6}{*}{ Economic } & Per capita electricity consumption & Per capita use & $\begin{array}{l}\text { Ratio of total final electricity } \\
\text { consumption to total population }(\mathrm{kWh} \\
\text { per capita) }\end{array}$ \\
\hline & $\begin{array}{l}\text { Household income share spent on } \\
\text { fuel and electricity }\end{array}$ & Affordability & $\begin{array}{l}\text { Share of household expenditure on fuels } \\
\text { and electricity to the total household } \\
\text { income }(\%)\end{array}$ \\
\hline & $\begin{array}{l}\text { Cooking/heating energy conversion } \\
\text { efficiency }\end{array}$ & End-use efficiency & $\begin{array}{l}\text { Share of useful energy to the } \\
\text { consumption of final energy }(\%)\end{array}$ \\
\hline & T\&D losses & Delivery efficiency & $\begin{array}{l}\text { Transmission and distribution line losses } \\
(\%)\end{array}$ \\
\hline & $\begin{array}{l}\text { Share of renewable energy in } \\
\text { electricity generation }\end{array}$ & Renewability & $\begin{array}{l}\text { Contribution of renewable energy } \\
\text { generation in the total HKH electricity } \\
\text { supply }(\%)\end{array}$ \\
\hline & $\begin{array}{l}\text { Diversification of energy in HKH } \\
\text { (by fuel types/sources) }\end{array}$ & Diversification & $\begin{array}{l}\text { Diversified energy mix and share of } \\
\text { import energy in the total primary } \\
\text { energy }(\%)\end{array}$ \\
\hline \multirow[t]{5}{*}{ Social } & HKH population without electricity & \multirow[t]{2}{*}{ Accessibility } & $\begin{array}{l}\text { Percentage of population without } \\
\text { electricity }(\%)\end{array}$ \\
\hline & $\begin{array}{l}\text { Share of HKH population still using } \\
\text { traditional solid fuels }\end{array}$ & & $\begin{array}{l}\text { Percentage of HKH } \\
\text { population/households using traditional } \\
\text { solid fuels for cooking/heating and other } \\
\text { household energy uses }\end{array}$ \\
\hline & Disparity in electricity distribution & \multirow[t]{2}{*}{ Disparity } & $\begin{array}{l}\text { Ratio of electricity use of lower quintile } \\
\text { to electricity use of upper quintile }\end{array}$ \\
\hline & Disparity in clean energy distribution & & $\begin{array}{l}\text { Ratio of clean fuel use of lower quintile } \\
\text { to clean fuel use of upper quintile }\end{array}$ \\
\hline & Unplanned interruptions/year & Reliability & $\begin{array}{l}\text { Number of days of power supply } \\
\text { interruption (unplanned) each year }\end{array}$ \\
\hline \multirow[t]{3}{*}{ Environmental } & $\begin{array}{l}\text { GHG emissions from energy } \\
\text { production and use per capita }\end{array}$ & Global impact & $\begin{array}{l}\text { Annual GHG emissions from energy } \\
\text { production and use per capita (kg/capita) }\end{array}$ \\
\hline & Impact of HAP from energy systems & \multirow[t]{2}{*}{ Local impact } & DALYS per 1000 people \\
\hline & Annual rate of change in forest area & & Extent of forest land (\%) \\
\hline
\end{tabular}

Source Geng and Ji (2014), Gupta (2008), Mainali et al. (2014), Sovacool (2013), Vivoda (2010)

DALYS, disabled adjusted life years; GHG, greenhouse gas; HAP, household air pollution; T\&D, transmission and distribution

sustainable energy access in hilly and mountain regions remains a challenge (Mainali and Silveira 2013). Lack of access to technology, infrastructure, finance, and subsidies, and the high up-front costs of new technologies, pose additional major challenges. Limited investment in the renewable sector in most HKH countries has impeded harnessing of the full potential capacity of renewable energy sources (Pode et al. 2016).

The framework we employ to define and measure sustainable energy determines the way we design and implement any strategies for sustainable energy solutions. Adopting a systematic framework to assess and monitor energy systems has received as much attention in energy policy strategies, especially for achieving SDG 7, to ensure that they are equally robust enough to adapt to anticipated climate-related impacts. Such a framework must be holistic and rooted in the three dimensions of sustainability (social, economic, and environmental) while aligning with the three pillars of sustainable energy (i.e., the targets of SDG 7 and sustainable energy for all (SE4ALL) - access to modern energy, energy efficiency, and renewable energy. Table 6.11 outlines such a framework, using a set of underlying indicators to capture accessibility, affordability, disparity, security, renewability, and environmental concerns (Geng and Ji 2014; Gupta 2008; Mainali et al. 2014; Sovacool 2013; Vivoda 2010).

In the social dimension, two key indicators that describe accessibility are populations with access to electricity and using non-solid fuels. A distinct positive correlation exists between the use of electricity and the human development index (HDI), especially for low- and medium-income countries (Gómez and Silveira 2010). The correlations are even stronger in low-income HKH countries (Table 6.12).

In terms of economics, affordability and secure energy supply are key concerns. Without affordability, people in 
Table 6.12 Electricity per capita and HDI of HKH countries (1990-2012)

\begin{tabular}{|c|c|c|c|c|c|c|c|c|}
\hline \multirow[t]{2}{*}{ HKH countries } & \multicolumn{2}{|l|}{1990} & \multicolumn{2}{|l|}{2000} & \multicolumn{2}{|l|}{2010} & \multicolumn{2}{|l|}{2012} \\
\hline & KWh/Cap & HDI & KWh/Cap & HDI & KWh/Cap & HDI & KWh/Cap & HDI \\
\hline Bangladesh & 48 & 0.386 & 102 & 0.468 & 241 & 0.546 & 276 & 0.563 \\
\hline China & 511 & 0.501 & 993 & 0.588 & 2944 & 0.699 & 3475 & 0.718 \\
\hline India & 273 & 0.428 & 395 & 0.496 & 644 & 0.586 & 724 & 0.600 \\
\hline Myanmar & 43 & 0.352 & 74 & 0.425 & 122 & 0.520 & 153 & 0.528 \\
\hline Nepal & 35 & 0.384 & 59 & 0.451 & 103 & 0.531 & 119 & 0.540 \\
\hline Pakistan & 278 & 0.399 & 373 & 0.444 & 467 & 0.522 & 452 & 0.532 \\
\hline Correlation coefficient & \multicolumn{2}{|l|}{0.927} & \multicolumn{2}{|l|}{0.915} & \multicolumn{2}{|l|}{0.966} & \multicolumn{2}{|l|}{0.965} \\
\hline
\end{tabular}

Source UNDP (2015), World Bank (2016a, b)

HDI, human development index

Table 6.13 $\mathrm{CO}_{2}$ emissions from fossil energy in 2016

\begin{tabular}{l|l|l|l|l|l|l|l|l|l}
\hline & Afghanistan & Bangladesh & Bhutan & China & India & Myanmar & Nepal & Pakistan & Total \\
\hline $\mathrm{MtCO}_{2}$ & 12 & 82 & 1.1 & 10,151 & 2431 & 24 & 9.1 & 189 \\
\hline$\%$ & 0.1 & 0.6 & 0 & 78.7 & 18.8 & 0.2 & 0.1 & 1.5 & 12,899 \\
\hline
\end{tabular}

Source Global Carbon Atlas (2017). http://www.globalcarbonatlas.org/en/CO2-emissions

$\mathrm{MtCO}_{2}$, million ton of carbon dioxide

Table 6.14 Renewable share in total electricity generation in $\mathrm{HKH}$ countries

\begin{tabular}{l|l|l|l|l|l|l|l|l}
\hline & Afghanistan & Bangladesh & Bhutan & China & India & Myanmar & Nepal & Pakistan \\
\hline $\begin{array}{l}\text { Share of renewable energy in total } \\
\text { electricity generation (\%) }\end{array}$ & 85.3 & 1.3 & 100.0 & 22.6 & 15.4 & 62.4 & 100.0 & 30.2 \\
\hline
\end{tabular}

Source Based on World Bank database for the year 2014, available online at https://data.worldbank.org/indicator/EG.ELC.RNEW.ZS?locations= $\mathrm{AF} \&$ view $=$ chart

these regions cannot benefit from available energy. The poor normally spend a significant share of their income on electricity and cooking fuels (Mainali et al. 2012, 2014; Pachauri and Jiang 2008). Diversifying energy mixes and supply sources, and increasing the share of renewable energy in electricity generation, can be important energy supply solutions.

Environmentally, reducing carbon intensity and air pollution-related health hazards remain central concerns throughout the HKH (see Chap. 10). Currently, about $80 \%$ of GHG emissions from the energy sector in HKH countries come from China, followed by India (19\%) (Table 6.13).

A study from Nepal also points out contradictory policies (e.g., subsidies for both renewable energy and fossil fuels) that may, in fact, impede the transition towards sustainable energy (KC et al. 2011). Sheikh (2010), in a study in Pakistan, identifies a lack of policies to encourage private companies in the renewable energy sector as one of the impediments for the transition. Despite all the efforts made, providing access to sustainable energy in the hilly and mountain regions still remains a challenge (Mainali and Silveira 2013). Among HKH countries, the share of renewable energy in total electricity generation is high in Bhutan $(100 \%)$ and Nepal $(100 \%)$ but lower in other countries such as Bangladesh (1.3\%) and India (15.4\%) (Table 6.14).

Figure 6.6 shows the performance of HKH countries in terms of regulatory indicators for sustainable energy (RISE) score. This is grounded in 27 indicators to capture the quality of policies and regulations for the three pillars of SDG 7 and SE4ALL - energy access, renewable energy, and energy efficiency (Banerjee et al. 2017). Of the possible maximum of 100, scores range from 81 in China to less than 25 in Afghanistan, where the energy efficiency performance scoring is the lowest in all HKH countries.

\subsubsection{Links Between Energy and the SDGs: Synergies and Trade-offs}

Energy is crucial for achieving almost all SDGs. The synergies and trade-offs between energy and other SDG goals happen at multiple levels. McCollum et al. (2017) and Nilsson et al. (2016) define the nature and extent of such 
Fig. 6.6 Performance of HKH countries in regulatory indicators of sustainable energy (RISE) (score value in 2016). (Source IEA and World Bank 2017)

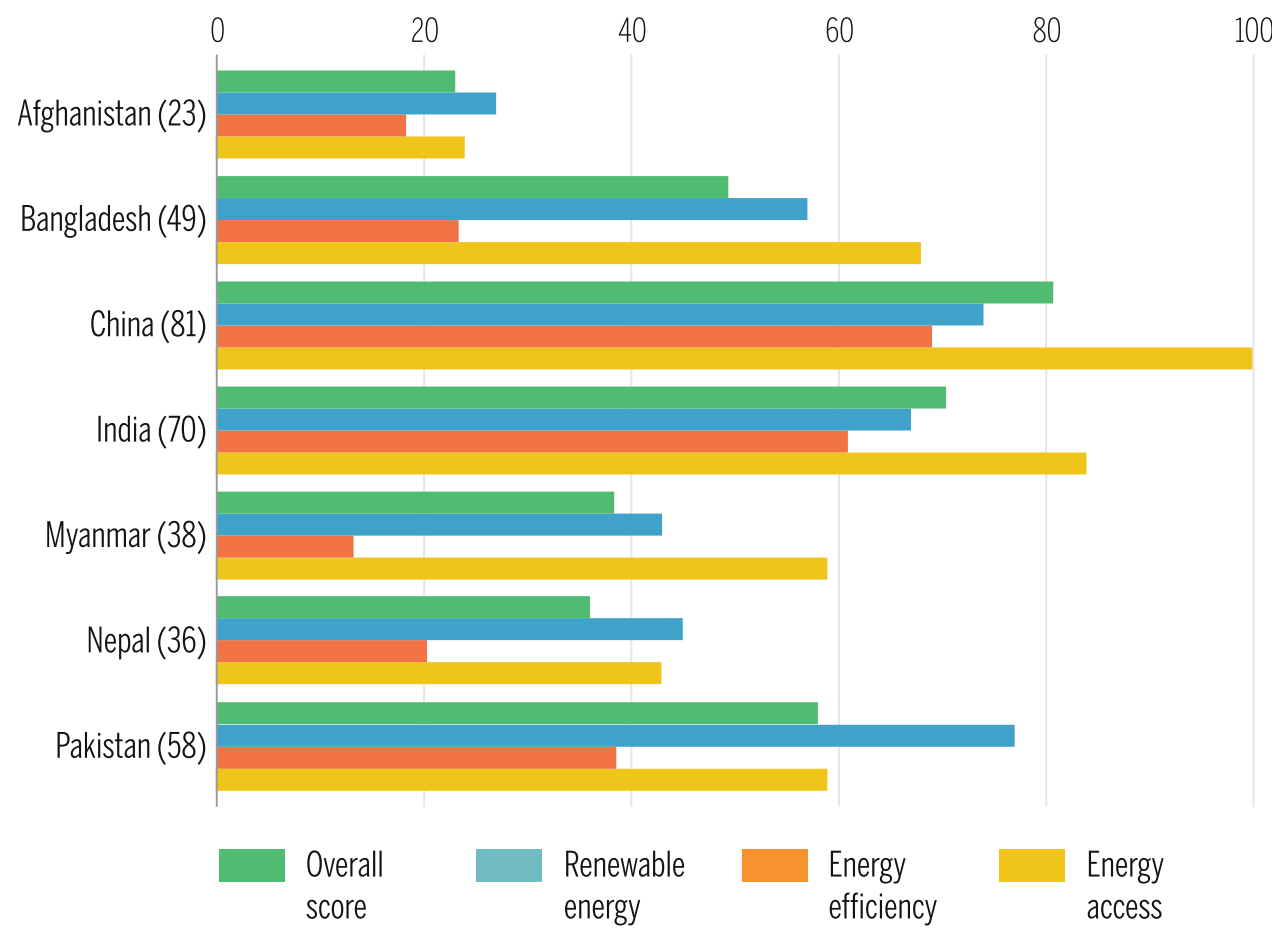

100 linkages from synergies (indivisible, reinforcing, and enabling), to no interactions, to trade-offs (constraining, counteracting, and cancelling). Globally, McCollum et al. (2017) show that access to clean energy enables countries to meet all other SDGs. Goal 7 (energy) reinforces all SDGs except Goals 4 (education), 5 (gender), 8 (work and economy), and 10 (inequality). Goal 11 (cities) is inseparable from Goal 7 (energy). Globally, Goal 7 (energy) also presents some level of trade-off with Goals 2 (hunger) and Goal 15 (land) in particular, and constrains the seven other goals. It is important to understand the interlinkages among various SDGs to create synergies, and also to understand that the hierarchy of needs among these goals is important (Mainali et al. 2018). Electrification may not be the first priority if people are facing hunger and need clean water. Failures have been seen in Nepal and Peru where energy programmes wrongly targeted poor villages where hunger needed to be addressed before energy.

In the $\mathrm{HKH}$ region, access to clean energy and energy efficiency reduces indoor air pollution (Goal 3), which affects women (Goal 5) and children disproportionately. Women in the $\mathrm{HKH}$ are more vulnerable to energy poverty than men. The gender inequality index (GII) published by UNDP in 2012 shows huge gender inequality in $\mathrm{HKH}$ countries (ranging from 0.464 in Bhutan to 0.617 in India) (ENERGIA 2015). Access to improved or modern energy sources can reduce the physical burden associated with carrying wood, and frees up valuable time which could be used for other productive purposes, while reducing health risks posed by indoor pollution. However, this link is very poorly addressed in energy policies as well as in the gender policies of the region. Harnessing abundant renewable energy resources reduces fossil fuel use within and outside the region and thus supports climate change mitigation (Goal 13). The HKH has hydroelectricity potential of over $500 \mathrm{GW}$ (Vaidya 2013) of which a large part could be exported with a suitable benefit-sharing mechanism to promote local livelihoods and infrastructure for economic development (Goal 8). Use of biomass as an energy resource, however, must be complemented with relevant technologies, or might lead to the production of black carbon (Goal 13) and unsustainable land use changes (Goal 15). Greater access to energy could provide opportunities for entrepreneurship and stimulate economic development. Access to electricity and clean energy improves livelihoods and the economy, which could help in improving adaptive capacity (Perera et al. 2015).

SDGs can affect the energy SDG Goal. Climate change (Chap. 3) could have several impacts on the HKH region's water availability for hydropower and energy infrastructure, and thus for energy security. Energy intensity could increase owing to the need to pump water (as a result of water table drawdown). Land degradation and potential consequences for agricultural productivity could affect the supply of biomass (ICIMOD 2011).

Understanding how these multiple targets and SDGs cut across different sectors, and are linked, may help in the 
design and appraisal of common strategies and cross-sectoral policies for integrated development programmes in the region (Mainali et al. 2018).

\subsubsection{Assessing the Vulnerability of Vital Energy Services and Systems}

Supply-side vulnerability: security of primary energy supply sources: Vulnerabilities in sustainable energy systems in the HKH are often interlinked with hydropower development and losses in agricultural productivity linked to the primary supply of biomass sources. The great dependency of primary energy supplies on biomass indicates a high risk for fuel security in extreme climatic events. Another important mechanism that may discourage the use of clean and modern energy sources is the pricing of energy (IEA 2015). Subsidizing energy is an important instrument for addressing price-induced vulnerabilities in the supply of energy sources to end-users in this region. In spite of this, there are claims that subsidies on energy were generally disproportionately beneficial to richer households and were drawn from other development-related expenditures (Parajuli et al. 2014; TERI and IISD 2012). Globally, studies have shown that energy subsidies generally benefit the rich more than the poor, because of how subsidies are designed and implemented. Capped lifeline tariff subsidies up to a maximum consumption level can be effective in dealing with energy poverty, although the rich also get this subsidy. Overall tariff price subsidies are inefficient policy instruments. Subsidized loans for the poor to access modern energy services (e.g., PV/biogas technologies) or preferential taxation treatment for specific technologies (reduced import taxes and duties), and programmes and policies to support private sector service providers (for example, Lighting Asia) can often be more efficient instruments if designed and applied correctly.

The degree of energy self-sufficiency (indicated in terms of the ratio of alternative energy technologies to the TPES) indicates the capacity of a country to withstand shocks that result from vulnerabilities in the energy supply. Even large countries like India and China are considered poor and vulnerable when it comes to this measure of energy self-sufficiency (Sovacool et al. 2011). Furthermore, the energy import dependence of a country also helps us understand its vulnerability to potential energy shocks. From 1996-2009 in Nepal, the annual growth in commercial energy imports (covering all forms of fossil fuels and excluding electricity) was $2.5 \%$. This is often related to the amount of export earnings spent on imports. For example, in Nepal in the fiscal year 2015-16, the import of petroleum products was equivalent to $97 \%$ of the total value of exports (TEPC 2017). However, energy self-sufficiency and reliability or vulnerability are not always positively correlated. For example, a country could be fully self-sufficient through hydropower generation, but be highly vulnerable to prolonged droughts. Energy supply diversity is essential for reducing vulnerability, but so is increased integration and connectivity with wider energy systems.

Demand-side vulnerability: security of energy services in end-use sectors: While supply of energy in HKH countries remains a challenge, demand in these countries has continued to grow. The scale of electricity shortages (gaps between supply and peak demand) in most HKH countries is enormous. For example: 1990 MW for Bangladesh, 10,296 MW for India, $336 \mathrm{MW}$ for Nepal, and $5230 \mathrm{MW}$ for Pakistan; these figures represented $32,12,44$, and $45 \%$ of the total installed capacity of the respective countries, respectively, and shortages are increasing over time (Rahman et al. 2011). Such shortages affect various sectors of the economy. In $\mathrm{HKH}$ countries, the contribution of groundwater to irrigation is three-fifths of the region's irrigation water (Shah 2010) and this could increase energy demand as the population grows and the water table falls. Parajuli et al. (2014) stress that the growth in the agricultural sector's contribution to Nepal's GDP was largely influenced by access to energy and the status of energy consumption in that sector. Demand-side vulnerability could be much more complex, emanating from regulatory, perverse incentives from subsidies and very poor energy efficiency (a neglected area in HKH countries and policy settings).

\subsubsection{Overcoming Barriers and Seizing Potential Opportunities}

Despite all the concerns and vulnerabilities identified above, the $\mathrm{HKH}$ region has several opportunities to enhance its energy security in a sustainable manner.

Studies have shown that quicker transition from traditional to modern fuels in cooking can be achieved by coupling a well-targeted subsidy policy along with availability of easy credit (Ekholm et al. 2010; Mainali et al. 2012). The financial burden of such a policy needs to be evaluated alongside the benefits it can bring-namely, reductions in adverse impacts on health and GHG emissions, and general improvements in people's socioeconomic situations. The opportunity that arises here should not be missed.

For energy importing countries, diversification of sources of imported energy can reduce risks (Geng and Ji 2014). Energy resilience is possible through different measures, such as trade and product diversification with respect to petroleum products, increasing storage capacity to meet the regular energy/fuel demand, increasing the stake in decentralized energy, establishing better energy and power 
connections across borders, and improving energy conservation initiatives. These require structural changes in both demand-and-supply management.

It is critically important to develop strategic plans and policies for meeting the demand for sustainable energy with the aim to address the challenge of increasing electricity deficits, avoiding the dominance of a single fuel type in electricity generation, and decreasing the dependency on imports (ADB 2012). The region has abundant renewable energy resources but these are unevenly distributed geographically (Saroha and Verma 2013), increasing the threat of inter-country conflict (ESCAP 2013). Harnessing available energy resources through mutual cooperation (e.g., technology development, investments, and trade) can strengthen the energy security of the region (ESCAP 2013; Taliotis et al. 2016).

Although biomass is technically renewable, heavy reliance on its traditional use is responsible for serious health effects and environmental problems. Reduced dependency on traditional biomass through more efficient renewable energy technologies is desirable, even though it reduces the share of renewable energy overall. However, improved energy efficiency measures through deployment of efficient cooking and heating technologies, and renovation of buildings, can also increase the renewable energy share by reducing overall final energy consumption (denominator of energy intensity) through avoided energy consumption.

Clearly, integrated thinking around renewable energy and energy efficiency is essential for a transition to a more sustainable energy future in the $\mathrm{HKH}$ region. Increasing the share of renewable energy requires not only rapid energy efficiency improvement measures, but also the adoption of major transformative policies. More specifically, a successful energy efficiency strategy requires a number of supply-side and demand-side measures, including:

- careful energy planning through establishing solid data on energy end uses for proper estimation of energy efficiency potential, and setting proper priority energy efficiency objectives and targets;

- development of energy conservation policies such as standards and appliance labelling, as well as mandatory energy audits, while also strengthening the compliance and enforcement mechanism with sufficient dedicated resources and strong institutional capacity to meet these standards;

- a combination of information, awareness, and incentives to encourage consumers to adopt energy-efficient technologies, and producers to invest in technology innovation and meet energy performance standards;

- introducing cost-reflective electricity tariffs through phasing out subsidies on energy prices for all consuming sectors to unlock the potential of energy efficiency; and
- leveraging private investment in energy efficiency by establishing funding mechanisms to jump-start energy efficiency financing to help an energy service company (ESCO) overcome the initial high set-up costs.

There are major challenges in meeting the SDGs (Weitz et al. 2014) and there is a lack of coordination among various line agencies within the energy sector and across the other sectors (water, sanitation, agriculture etc.). However, the opportunities for the $\mathrm{HKH}$ region are immense as international technology and financial mechanisms for operationalizing the Paris Agreement on Climate Change are being devised. To benefit from these developments, proper institutional structures and mechanisms must be established for creating a bridge that links multiple global initiatives and targets.

\subsection{Future Energy Scenarios and Pathways}

Given the current energy scenario, and the identified barriers and vulnerabilities, HKH countries must have a future plan for the region that empowers them in meeting their sustainable energy goal as well as all related SDGs, and to contribute to the climate goals. Future scenarios and transitions must drive sustainable development and emerging concerns such as low-carbon development, which requires a better understanding of possible pathways.

As energy transitions are often slow and lack a one-size-fits-all-solution, reaching such a sustainable future could entail multiple pathways depending on the local context, policy ambitiousness, and political commitment. The lack of data and knowledge gaps on resource availability, economic feasibility studies of sustainable energy technologies, and demand profile could be key limitations in the HKH.

The HKH's future long-term scenario could aim to fully harness hydro and other renewable energies with efficient and clean technologies to allow a sustainable energy transition. For clean cooking energy transition (and especially for transition to $100 \%$ electric cooking) the region must aspire to ensure complete replacement of traditional, inefficient sources of energy with clean, sustainable energy options that are efficient, reliable, affordable, and demand-responsive. For electricity access, decentralized (off-grid) electrification is the cornerstone of sustainable solutions in the HKH because of the remoteness of settlements where grid extension is not always feasible.

A broad range of barriers (policies, technical, economic, institutional, regulatory, sociocultural, and environmental) continue to hinder transition to sustainable energy in the $\mathrm{HKH}$ in the absence of mountain-specific national energy 
development strategies. The region must seize the emerging opportunities to confront these barriers in the context of the implementation of SE4ALL, SDGs, and the Paris Climate Agreement.

\subsubsection{Future Energy Scenarios of HKH Countries}

Of the eight member countries of the HKH, China and India are shifting the centre of gravity of the global energy system towards Asia. However, the situation in the HKH-which accounts for $9 \%$ of the population of these countries and less than $7 \%$ of GDP - may continue to remain precarious. Using country-level data from China and India to derive sensible directions for individual HKH countries may result in distortions, but nevertheless represents a worthwhile start in beginning the process and identifying knowledge gaps. Five HKH countries have more than $50 \%$ of their population residing in mountainous regions. Nepal and Bhutan are fully contained within the HKH and 83\% of Afghanistan's population is situated in the Himalaya.

When exploring future energy scenarios of the $\mathrm{HKH}$ it is also important to bear in mind the implications of climate pledges on energy choices made by these countries. Bhutan intends to remain carbon neutral with emissions of GHGs

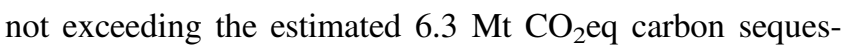
tration by forests. Nepal has committed to achieve $80 \%$ electrification through renewable energy sources by 2050 , while reducing dependency on fossil fuels by $50 \%$ and maintaining $40 \%$ of the total area of the country under forest cover. Afghanistan outlined its intended contribution of reducing its GHG emissions by $13.6 \%$ below the 2030 business as usual (BAU) scenario (UNFCCC 2015). Myanmar has provided a list of policy actions in the energy and forestry sectors. Pakistan showed commitment to reduce up to $20 \%$ of its 2030 projected GHG emissions. China and India committed to 30-45\% (from 2007) and 33-35\% (from 2005) reductions in GHG emissions per unit GDP by 2030. Many of these targets are conditional: subject to affordability, provision of international climate finance, transfer of technology, and capacity building.

Table 6.15 summarizes the growth projections of the Asian Development Bank (ADB) for the countries of the HKH up to 2035. Unfortunately, no projections exist for the delimited HKH region per se, and these are for the $\mathrm{HKH}$ countries as a whole. Total primary energy demand under the BAU case is projected to grow by 2035 in all $\mathrm{HKH}$ countries, with the highest annual average rate being recorded in Afghanistan (6.5\%), followed by Bangladesh $(3.7 \%)$.

Not only will the total primary energy demand be greater in the BAU scenario, but the share of fossil fuels in the primary energy mix is also likely to increase in all countries by 2035 . Table 6.16 presents the future carbon and energy intensity outlook to 2035. While the energy and emissions intensity decreases in BAU and alternative scenarios, Afghanistan's emission intensity increases in the outlook period 2010-35 (ADB 2015). Increasing the share of renewable energy sources and introducing efficient technologies under the alternative scenario will reduce the overall energy demand, improve energy security, and diminish GHG emissions.

Figure 6.7 presents primary energy consumption from 2015 to 2040 under current policies (CP), new policies (NP), and SDG scenarios ${ }^{4}$ for the countries of the HKH region; estimates are based on the IEA (2017) and GAINS model.

Total primary energy consumption (TPES) in $\mathrm{HKH}$ countries will increase by a factor of 1.7 in the CP scenario from 2015 to 2040. TPES will increase by a factor of 1.5 in the NP scenario, and 1.2 in the SDG scenario from 2015 to 2040, primarily because of energy efficiency measures and large-scale renewable energy penetration in China and India. At the national level, TPES will be reduced by $33 \%$ in China and $30 \%$ in India because of sustainable energy strategies.

Many studies have projected future energy use, GHG emissions, and air pollutants for individual HKH countries (Amann et al. 2008; Klimont et al. 2009; IEA 2015; Mir et al. 2016; Purohit et al. 2010, 2013). However, none assess future energy use and GHG emissions in the HKH mountain region alone. The global and national scenario of GHG mitigation relies heavily on initiatives such as rapid deployment of renewable energy, greater use of biomass, deployment of best-practice technologies to boost energy efficiency, and employing emerging technologies such as carbon capture and storage. All these have direct relevance for the $\mathrm{HKH}$, which already needs to modernize the biomass sector and harness clean, decentralized energy sources.

\subsubsection{Pathways Towards Rural Electrification}

Energy consumption is also expected to grow significantly as industrialization, urbanization, and economic growth increase. HKH countries must meet their growing energy demand in an environmentally benign and sustainable

\footnotetext{
${ }^{4}$ The NP scenario is designed to show where existing policies (as well as announced policy intentions) might lead the energy sector. The CP scenario provides a point of comparison by considering only those policies and measures enacted into legislation by mid-2017. The SDG scenario examines what it would take to achieve the three main energy-related components of the "2030 Agenda for Sustainable Development" adopted in 2015 by Member States of the United Nations. The three energy-related goals are: (1) to achieve universal energy access to modern energy by 2030 ; (2) to take urgent action to combat climate change; and (3) to dramatically reduce the pollutant emissions that cause poor air quality (IEA 2017).
} 
Table 6.15 HKH country energy outlook through 2035 under BAU and alternative scenarios

\begin{tabular}{|c|c|c|c|c|c|c|c|c|}
\hline & Afghanistan & Bangladesh & Bhutan $^{\text {a }}$ & China & India & Myanmar & $\mathrm{Nepal}^{\mathrm{a}}$ & Pakistan \\
\hline GDP (constant 2000 USD billion) 2035 & 47.7 & 243.0 & 3.8 & $15,871.9$ & 3877.0 & 135.9 & 20.0 & 269.6 \\
\hline GDP growth rate \% (2010-35) & 6.8 & 4.4 & 5.6 & 6.6 & 5.7 & 7.6 & 3.7 & 3.4 \\
\hline Population 2035 & 59.0 & 187.1 & 0.9 & 1381.6 & 1579.8 & 55.0 & 42.0 & 245.9 \\
\hline \multicolumn{9}{|l|}{ BAU case } \\
\hline Primary energy demand (Mtoe) 2035 & \begin{tabular}{|l}
4.3 \\
$(0.07)$
\end{tabular} & $\begin{array}{l}77.6 \\
(0.41)\end{array}$ & $\begin{array}{l}1.7 \\
(1.84)\end{array}$ & $\begin{array}{l}4218.1 \\
(3.05)\end{array}$ & $\begin{array}{l}1441.6 \\
(0.91)\end{array}$ & $\begin{array}{l}30.3 \\
(0.55)\end{array}$ & $\begin{array}{l}16.6 \\
(0.4)\end{array}$ & $145.8(0.59)$ \\
\hline Primary energy demand growth $\%$ 2010-35 & 6.5 & 3.7 & 0.8 & 2.3 & 3.0 & 3.1 & 2.0 & 2.2 \\
\hline \multicolumn{9}{|l|}{ Sectoral energy demand share (\%) } \\
\hline Industry & 6 & 29.1 & 15.1 & 33.6 & 31 & 11.5 & 6 & 33 \\
\hline Transport & 30.1 & 19.3 & 5.8 & 16.3 & 19.7 & 23.4 & 9.1 & 22.6 \\
\hline Other sectors & 63.9 & 45.6 & 79.1 & 43.8 & 41.1 & 64.6 & 84.9 & 40.5 \\
\hline \multicolumn{9}{|l|}{ Alternative case } \\
\hline Primary energy demand (Mtoe) 2035 & \begin{tabular}{|l}
3.8 \\
$(0.06)$
\end{tabular} & $\begin{array}{l}68.8 \\
(0.37)\end{array}$ & $\begin{array}{l}1.5 \\
(1.58)\end{array}$ & $\begin{array}{l}3418.7 \\
(2.47)\end{array}$ & $\begin{array}{l}1239.2 \\
(0.78)\end{array}$ & $\begin{array}{l}29.2 \\
(0.53)\end{array}$ & $\begin{array}{l}16.3 \\
(0.39)\end{array}$ & $\begin{array}{l}130.9 \\
(0.53)\end{array}$ \\
\hline Primary energy demand growth $\%$ 2010-35 & 6.0 & 3.2 & 0.2 & 1.4 & 2.4 & 3.0 & 1.9 & 1.8 \\
\hline \multicolumn{9}{|l|}{ Sectoral energy demand share (\%) } \\
\hline Industry & 6.2 & 29.3 & 22.2 & 31.6 & 30.5 & 11.4 & 5.8 & 33.5 \\
\hline Transport & 30.9 & 19.1 & 9.5 & 16.3 & 19.9 & 21.1 & 8.6 & 23 \\
\hline Other sectors & 62.9 & 45 & 68.4 & 45 & 40.7 & 66.9 & 85.6 & 39.2 \\
\hline
\end{tabular}

Figures in parenthesis indicate primary energy demand per capita (toe/person)

Figures may not add up to total because of rounding and other sector

BAU, business as usual; GDP, gross domestic product; Mtoe, million tonnes of oil equivalent

${ }^{a}$ Bhutan and Nepal are fully in the HKH while the rest are partially covered. Source ADB (2015)

Table 6.16 Future carbon intensity and energy intensity outlook in HKH countries to 2035

\begin{tabular}{|c|c|c|c|c|}
\hline & \multicolumn{2}{|l|}{ BAU } & \multicolumn{2}{|c|}{ Alternative case } \\
\hline & 2035 & AAGR (\%) 2010-35 & 2035 & AAGR (\%) 2010-35 \\
\hline \multicolumn{5}{|c|}{$\mathrm{CO}_{2}$ intensity ( $t \mathrm{CO}_{2} /$ constant 2000 USD million) } \\
\hline Afghanistan & 224 & 3.1 & 194 & 2.5 \\
\hline Bangladesh & 793 & 0.9 & 547 & -0.6 \\
\hline Bhutan & 333 & -3.4 & 294 & -3.9 \\
\hline China & 759 & -4.3 & 526 & -5.7 \\
\hline India & 957 & -2.3 & 687 & -3.6 \\
\hline Myanmar & 414 & 0.2 & 368 & -0.2 \\
\hline Nepal & 411 & -0.6 & 385 & -0.9 \\
\hline Pakistan & 1,081 & -0.3 & 788 & -1.6 \\
\hline \multicolumn{5}{|c|}{ Primary energy intensity (toe/constant 2000 USD million) } \\
\hline Afghanistan & 89 & -0.3 & 80 & -0.8 \\
\hline Bangladesh & 319 & -0.6 & 283 & -1.1 \\
\hline Bhutan & 445 & -4.6 & 383 & -5.2 \\
\hline China & 266 & -4 & 215 & -4.8 \\
\hline India & 372 & -2.6 & 320 & -3.2 \\
\hline Myanmar & 223 & -4.2 & 215 & -4.3 \\
\hline Nepal & 833 & -1.7 & 815 & -1.8 \\
\hline Pakistan & 541 & -1.2 & 485 & -1.6 \\
\hline
\end{tabular}

AAGR, average annual growth rate; BAU, business as usual; toe, tonne of oil equivalent Source ADB (2015) 
Fig. 6.7 Total primary energy consumption in current and alternative policy scenarios in HKH countries. (Source Author estimation based on IEA (2017) and the GAINS model (http:// gains.iiasa.ac.at/models/index. html))
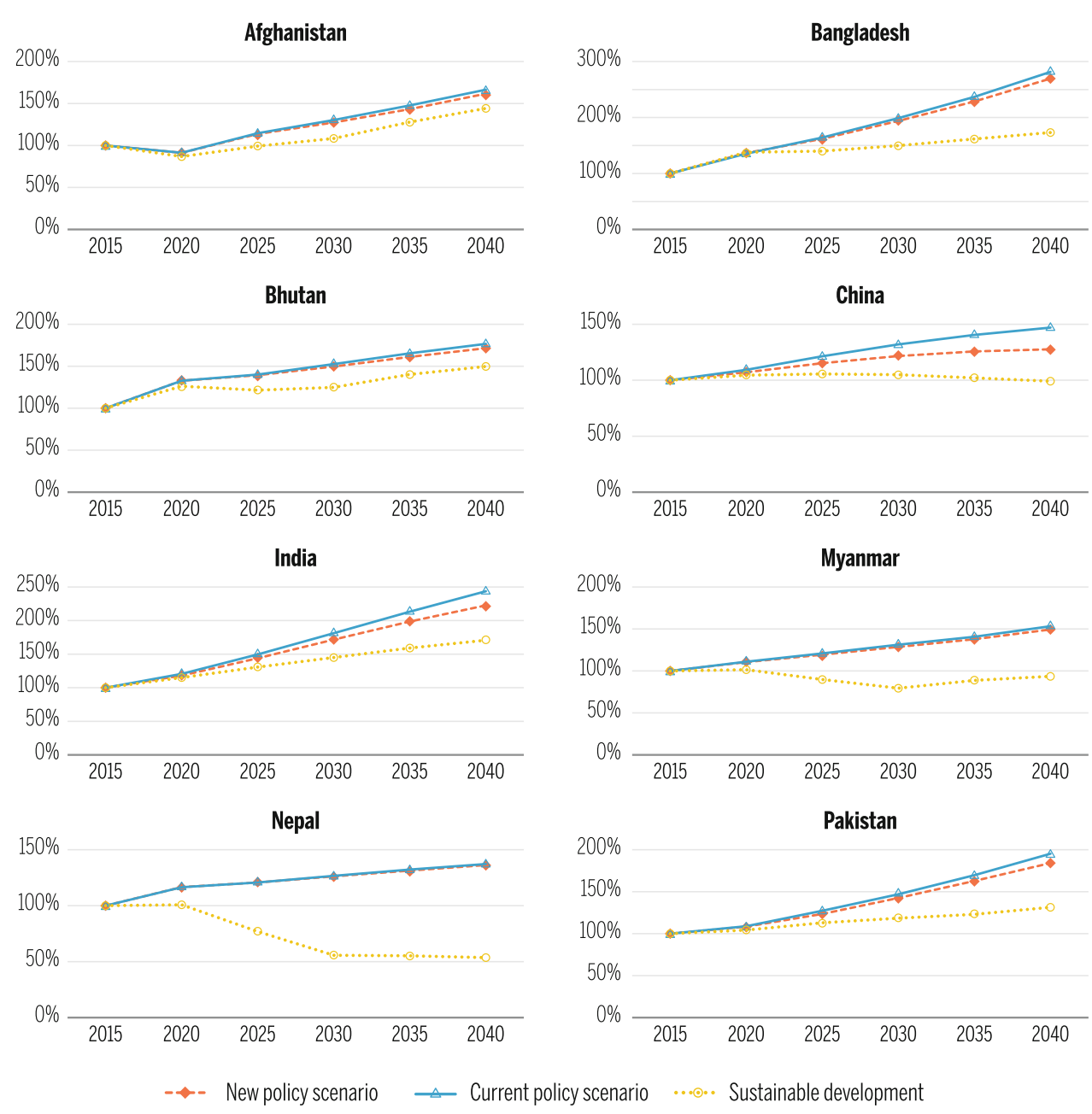

$50 \%$
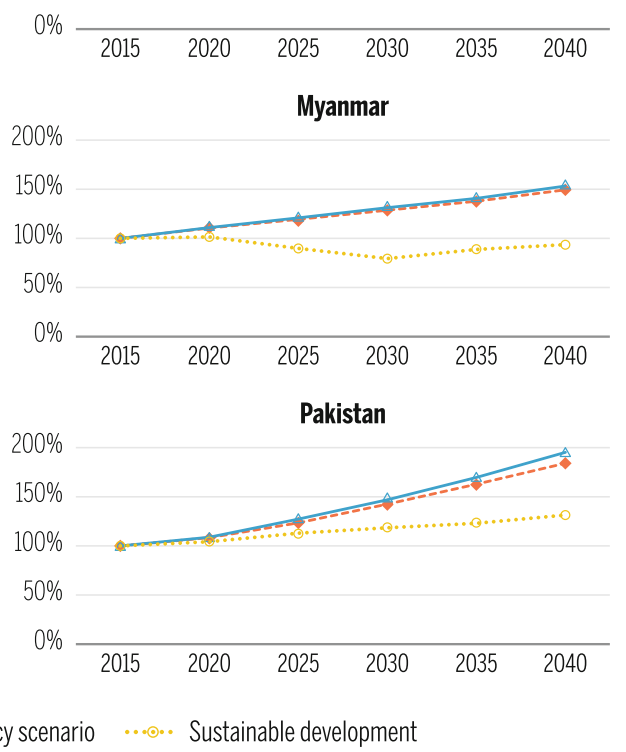

manner. To be truly sustainable, an energy system must (Dincer and Acar 2015):

- have minimal or no negative environmental or social impact;

- cause no natural resource depletion;

- be able to supply current and future population energy demand;

- be equitable and efficient;

- protect air, land, and water;

- have little or no net carbon or other GHG emissions; and

- result in safety today without burdening future generations.

In the HKH, discussions on electrification pathways tend to be between the merits of centralized on-grid versus decentralized off-grid electrification, with both routes being promoted in parallel. There has been no comprehensive and systematic analysis to find a balance between the two. Mainali and Silveira (2013) compare three pathways for rural electrification: (1) off-grid renewable energy technologies for individual households, mainly solar; (2) mini-grids (with micro-hydro, diesel generators, and solar, in some cases); and (3) grid extension. Their analysis shows that micro-hydro-based mini-grid technology is the most competitive alternative to electrify isolated and remote rural areas of the HKH. The choice of technology and the centralized on-grid and decentralized off-grid electrification pathway adopted in Nepal seems to be functional. In Afghanistan, the technological pathways for rural electrification are not well defined. A micro-hydro-based mini-grid has been suggested as a more sustainable option in Afghanistan than diesel generators, which were promoted in the transitional phase (Mainali and Silveira 2013).

Because of the challenges of grid extension in mountain areas due to sparse settlement and smaller load demand, the literature favours decentralized renewable electricity in the majority of cases. However, in some scenarios, it is also possible that off-grid solutions are just an intermediate pathway towards grid electricity. Energy conservation and efficiency can also make an important contribution since they reduce supply burdens and help to provide enhanced 
energy access. For example, Pode et al. (2016) describe a successful rice husk biomass project for sustainable fuel to power rural electrification in Myanmar. Other options such as wind and gasifiers are also discussed as potential options in mountain areas but their applications are not significant. Large hydropower projects are well suited for urban centres of the HKH and provide opportunities for electricity trade with neighbouring regions. Access to renewable energy accelerates growth in the tourism industry, herbal/medicinal products market, cash crops, and other mountain small and medium-sized enterprises (SMEs).

\subsubsection{Pathways Towards Sustainable Clean Cooking Energy}

The HKH needs to chart its own energy transition pathway for cooking in the future. A meaningful cooking energy transition addressing multiple economic, social, and environmental needs (through a sustainable supply of demand-responsive clean, efficient, reliable, affordable energy options) needs to be started and made operational. The challenge is especially daunting for rural areas, given the isolated nature of rural settlements that require innovative technology interventions for efficiency, fuel shifts, innovations in finance, institutional development, and the design of appropriate policy instruments. To achieve a sustainable cooking and heating energy transition, the $\mathrm{HKH}$ must aspire to a $100 \%$ renewable future with multiple pathways as a long-term goal. A more detailed quantitative analysis is necessary but, based on the available limited information, we surmise that the HKH could achieve a $100 \%$ renewable future through two key pathways. These only differ on whether cooking services are to be fully provided by electricity or also by improved biomass and other sources as well as by technologies.

Pathway 1. Electric future: access to renewable electricity and electric cooking: As discussed above, the $\mathrm{HKH}$ has significant renewable energy potential to achieve $100 \%$ electrification in the near future. ${ }^{5}$ Cross-border hydropower

\footnotetext{
${ }^{5}$ For example, Nepal has enormous hydropower potential (43 GW) of which 2\% is tapped (Dhakal and Raut 2010; KC et al. 2011), while Bhutan's vision of $100 \%$ renewable energy supply is based on its existing untapped hydropower $(30 \mathrm{GW})$. The HKH of India has huge hydropower potential $(114,398 \mathrm{MW})$, wind power $(6883 \mathrm{MW})$, and solar power $\left(5-7 \mathrm{kWh} / \mathrm{m}^{2} /\right.$ day) (CEA 2016; NIWE 2016). There is an estimated hydropower potential of 41,722 MW in Pakistan (Mirza et al. 2008), the technical potential of grid-connected solar (PV of 50,174 MW) in Bangladesh (Mondal and Islam 2011), and electricity generation potential of $314,500 \mathrm{MW}$ from solar, wind, and hydro in Afghanistan (Sahel 2014), sufficient for a pathway towards a $100 \%$ renewable electricity system.
}

imports from Bhutan, Myanmar, and Nepal to Bangladesh would also be vital to maintain the country's long-term energy security. There is enormous diversity in the types and amounts of fuels used for cooking in households in $\mathrm{HKH}$ countries and regions. Leapfrogging from solid fuels (fuelwood, agricultural residues, dung cakes, coal, etc.) to electric or induction stoves ${ }^{6}$ using renewable electricity for cooking will skip steps in the energy ladders. Unelectrified households in rural areas are well suited to off-grid renewable electricity (such as solar PV, hydro, and biomass gasifiers), based on resource availability. Switching to electric stoves will have a significant impact on health (particularly of women and young children) through reduced household air pollution. ${ }^{7}$ Yangka and Diesendorf (2016) observe that the electric cooking scenario also complements the vision of $\mathrm{HKH}$ countries for reducing deforestation and carbon emissions. This also helps to eliminate indoor air pollution, and to mitigate climate change by controlling SLCPs from biomass use. Additionally, switching to energy-efficient light-emitting diode (LED) bulbs and appliances in households using grid electricity will provide significant opportunities for climate change mitigation. The case of Bhutan is interesting here, as it has surpassed even China in providing access to clean cooking (IEA and World Bank 2017).

\section{Pathway 2. Access to renewable electricity and transition to} clean fuels/technology for cooking: This pathway differs from the first only in its assumption that full electric cooking could be unrealistic due to high electricity costs, small-scale and limited electricity supply from decentralized sources, expensive grid extension, abundant availability of alternative biomass-based cooking fuels, and other socioeconomic factors. Even in urban areas, electric cooking is not popular, and biogas and improved cookstoves are preferred.

Providing cooking and heating services simultaneously by biomass in rural mountain areas, and the implications for efficiency loss and associated indoor air pollution, needs careful planning. Sharma (2009) observes the trade-off between cooking and space heating efficiency from a single stove in the high mountains, and highlights the need for a housing energy efficiency retrofit policy to overcome this. Solar, micro- and mini-hydro, and biomass gasifiers are promising rural electricity technologies in the HKH. Transition from traditional to advanced biomass cookstoves could yield enormous gains for the health and welfare of the

${ }^{6}$ For example, as part of a programme on "access to clean cooking alternatives in rural India", induction stoves were introduced in nearly 4000 rural households in Himachal Pradesh, one of the few highly electrified states in India (Banerjee et al. 2016).

${ }^{7}$ In 2015, 1.2 million premature deaths in China and 1 million premature deaths in India were attributed to household air pollution (OECD/IEA 2016). 
weakest and most vulnerable sections of society. The HKH has a large potential of biogas ${ }^{8}$ for cooking. Transition to biogas provides clean fuel for cooking and lighting, and organic manure to rural and semi-urban households.

\subsubsection{A Sustainable Energy Future: Barriers and Opportunities}

Sustainable energy transition needs to be accelerated in the $\mathrm{HKH}$, and transformative change is required. While there has been progress in certain areas-particularly at national and regional levels - the HKH faces many policy, regulatory, and technical hurdles in adopting sustainable energy technologies because energy pathways for the region are nascent and immature. Increased financial assistance, technological knowledge, and capacity building are critically important to support clean energy infrastructure. Fortunately, energy transition needs and available options are in line with individual countries' national targets for the SDGs (universal access), Energy for All (clean energy access), and the Paris Agreement (climate change and complete decarbonization of energy systems). The HKH has, therefore, a great opportunity to benefit from support measures formulated globally for meeting these goals globally: these include technology transfer, financing, and capacity building.

Furthermore, financial innovation and private sector involvement are two main factors with the potential to increase the penetration of off-grid renewable energy technologies to enhance access (Palit and Chaurey 2011). Benecke (2008) observes that contextual factors specifically related to political stability, good governance in terms of human rights, participatory and regulatory frameworks, and sociohistorical conditions matter in the successful implementation of new renewable energy options.

Confronting barriers: The barriers to developing a sound and sustainable energy future can be categorized in the following ways (Balachandra 2011; Burns 2011; Ershad et al. 2016; Mondal et al. 2010; Yaqoot et al. 2016):

Capital related:

(1) The availability of capital investment, supported by a viable policy framework, to construct the infrastructure needed to exploit the energy source and transmission potential and/or implement decentralized technological solutions.

\footnotetext{
${ }^{8}$ The HKH area of India has a potential of 759,500 family-size biogas plants, of which 223,857 had been installed by March 2015 (MNRE 2016).
}

(2) Allocation of adequate budgets when programmes are supported nationally, and ensuring timely financial flows.

Governance related:

(1) Restructuring ministries involved in the sector, and policy and institutional coherence, especially of regulatory reform and development of viable regulatory bodies.

(2) Designing taxation regimes and other financial incentives to encourage energy investment and renewable energy; withdrawal of subsidies currently being given to fossil fuels.

(3) Extensive training and capacity building at managerial and technical levels throughout the sector; cooperation with international agencies.

(4) Local community and awareness generation for sustainable management of renewable resources.

Market related:

(1) Developing market-oriented policy implementation and technology promotion.

(2) Lack of standardized power purchase agreements (PPAs) for power generation.

(3) Encouraging private sector participation in an environment of public sector dominance.

(4) Unavailability of skilled manpower for maintenance, unavailability of spare parts, high cost, and lack of access to credit.

(5) Unfair energy pricing (involved accounting of full cost recovery); and ensuring energy utilities operate as financially viable entities, and that the rich are not subsidized.

(6) Lack of adequate training on operation and maintenance of decentralized RE systems.

Available evidence and data:

(1) The lack of an integrated energy strategy, including for RE projects.

(2) Lack of data (comprehensive resource assessments and feasibility studies on potential).

(3) Suitable, replicable business models for the range of contexts and applications in the region.

(4) Lack of information or awareness.

Seizing opportunities: Approximately USD35 billion of climate finance flows through official international public financing outlets, of which a large portion is allocated to the sustainable energy sector. The newly created Green Climate Fund has over USD10 billion in pledges. The demand for 
climate financing has, so far, lagged behind supply, and donors are looking for bankable projects to fund. Considering the large potential for sustainable energy in the $\mathrm{HKH}$, there is a need to help countries understand and navigate this new international carbon financing opportunity. Some HKH countries can continue to use the Clean Development Mechanism (CDM) of the Kyoto Protocol, despite the lower price of current carbon offset projects. HKH countries must be aware of emerging market mechanisms under the Paris Agreement, as well as opportunities in bilateral and internal markets.

Recent studies on energy requirements in HKH countries reveal that China, India, Pakistan, Bangladesh, and Afghanistan have energy demands surpassing their domestic supply. Bhutan, Myanmar, and Nepal have energy resourceshydropower in particular, far in excess of their domestic needs - that can be traded within the region. Bangladesh, India, and Pakistan have potential for significant electricity and gas trade within South Asia. Enabling energy trade between HKH countries is a great opportunity for the region to increase its energy access and security. Regional energy trade and cooperation may be advanced by individual national governments, but first it is necessary to engage in meaningful multilateral energy trade as a cornerstone of regional integration and connectivity in $\mathrm{HKH}$ countries.

\subsection{Energy Cooperation in HKH: National, Regional, and Global Linkages}

Faced with an energy deficit and rising demand, $\mathrm{HKH}$ countries need to seek external cooperation to enhance their energy security and related environmental performance. Key gaps in gaining greater energy independence, identified in earlier sections, relate to: access to modern energy forms (Sect. 6.2); viability of conventional solutions (Sect. 6.5); proven, replicable business models (Sect. 6.4); capacities and capabilities; and poorly designed policies and delivery mechanisms (Sect. 6.3). Energy cooperation for addressing these gaps can take various forms, depending on the problems and possible solutions, and can be undertaken at various scales.

At the same time, the impacts of climate change in the region can negatively affect the flows of energy and related services bi-directionally, making all regions and countries of the HKH into stakeholders for climate action. Therefore, large-scale adoption and deployment of clean and renewable energy through harmonized regional policies and programmes will need to play a central role as they act as both mitigating and adaptive responses to climate change-induced security threats.

In the long term, regional energy security depends heavily on how an innovative multi-governance approach for regional cooperation can be fostered and sustained. Mechanisms are needed to encourage economic cooperation despite continuing political differences. The success of the electricity trade between Bhutan and India demonstrates that, when there is enlightened political leadership and mutual benefit, even very large hydroelectric projects in remote regions can be developed quickly, to the advantage of both parties (Biswas 2011; Ebinger 2011). An overnight shift in the dynamics of regional relationships that have been shaped for decades is not possible. However, by engaging in regional energy trade and cooperation through a mutual understanding of interests, long-term benefits can be ensured by means of dialogue at all levels of governance.

\subsubsection{Energy Challenges and Regional Cooperation}

The rich energy resources of the region are unevenly distributed and largely untapped. None of the HKH countries will be able to meet their energy needs entirely from their own domestic resources; they face a stark choice between rapid development and energy self-sufficiency as they cannot achieve both without energy interdependence and a collaborative approach (McMillan 2008; Mahmud 2012). For example, Nepal and Bhutan have great untapped hydropower potential while India, Pakistan, and Bangladesh have large reserves of gas and coal. Energy resource-surplus countries such as Nepal and Bhutan could benefit from export-led growth by fully exploiting their hydropower potential while simultaneously meeting demands in energy-deficient countries such as India, Afghanistan, Pakistan, and Bangladesh where energy requirements exceed their economically viable hydropower potential (Iftikhar et al. 2015; World Bank 2008). Differences in daily load patterns and seasonal variation in electricity demand, as well as generation, provide ample opportunities for $\mathrm{HKH}$ countries to optimize the use of regional resources and system operation by exploiting cross-border opportunities - even in the current circumstances (Box 6.4).

Box 6.4 Seasonal mismatch between electricity demand and supply

Variability in energy supply and demand during peak and off-peak periods across days and seasons provides a real opportunity to engage in electricity trading even in situations where, at an aggregate level, shortages might exist. For example, within Bangladesh, average sizeable generation capacities of $1200 \mathrm{MW}$ remain unused during off-peak hours even though it faces shortages of power during peak hours. The available capacity of off-peak hours can be a ready source for 
regional cooperation for import-export of electricity within neighbouring countries (Lama 2004). Peak months for hydropower generation are AugustSeptember while the lean season is January-June. In Nepal and Bhutan, generation from hydropower plants is low during peak demand time (December-January) and its supply capacity reaches its peak during the lean demand season (August-September). This mismatch in the seasonality of energy supply and demand leads to a need for complementary cross-border power trade (Nanda and Goswami 2008).

The Indian system faces a deficit of energy and capacity during the hot summer months. The peak season begins in May and runs until August and September, with an overlapping lean demand season in Nepal and Bhutan. Indian thermal power plants complement and balance the lean dry months of the hydro plants in winter and the pre-monsoon season. The same Indian thermal power plants can be redesigned and restructured to address fluctuations in Nepal and Bhutan (Nanda and Goswami 2008), and it has been found viable to import electricity and other products from India for countries such as Nepal, Bhutan, and Bangladesh (World Bank 2007). This can be successful if cross-border transmission infrastructure projects are initiated through a memorandum of understanding (MOU). One such MOU was recently signed for transmission lines between India and Nepal.

An analysis by ADB (2015) of partially or fully integrated SAARC power systems indicates that cross-border power trading is both technically feasible and economically attractive, with the estimated economic benefits of six cross-border transmission interconnections ${ }^{9}$ ranging from USD105 million to USD1,840 million (Wijayatunga et al. 2015). A study by USAID has clearly demonstrated how a regionally interconnected power system can bring a number of technical, operational, economic, and environmental benefits to a country, as well as to the region (USAID 2013). Cooperation can also facilitate integrated planning for sustainable transboundary water resource management to bring additional benefits such as flood control, irrigation, and navigation through multipurpose river projects (Price and Mittra 2016; Rasul 2014b).

Despite the tremendous benefits to be derived from regional cooperation, examples of cross-border hydropower cooperation are limited except between India and Bhutan

\footnotetext{
${ }^{9}$ This refers to the Bhutan-India additional grid reinforcement; the India-Nepal $400 \mathrm{kV}$ transmission link; and the Bangladesh-India high voltage direct current transmission link.
}

(Rahman et al. 2011). India has assisted Bhutan in building almost $96 \%$ of the country's current hydropower capacity, and electricity production now accounts for around one-fifth of Bhutan's GDP while its per capita GDP has increased fivefold from 1992 to 2013 (World Bank 2014). Although the specific political relationship between the two countries cannot be replicated elsewhere in the region, the processes and outcome of cooperation are pertinent to other countries, such as Nepal (Price and Mittra 2016).

\subsubsection{Models for Energy Cooperation}

Electricity: The power sector offers the most obvious and promising area for regional energy cooperation, given the enormous potential for hydropower. While SAARC member states have agreed on the basic idea of sharing electricity through a common regional energy grid to promote regional energy sustainability, the technicalities of realizing this objective still need to be resolved (Dawn 2014). The Bangladesh, Bhutan, India, and Nepal (BBIN) initiative for creating an energy cooperation model has resulted in the emergence of five models of power exchange in the BBIN sub-region (Lama 2016), providing scope for generation and transmission system expansion on a regional basis (Nexant 2001). India also needs to quickly develop policies and implement them so it can act as a transiting country for power transmission in the HKH between Nepal, Bangladesh, Bhutan, and Myanmar.

Currently, there is a constraint in the chicken-neck area (Siliguri corridor that connects West Bengal to Northeast) of India for constructing power transmission lines. To overcome this, India and Bangladesh are discussing the construction of transmission lines through Bangladesh, and a certain percentage of the power will be transferred through Bangladesh. Singh et al. (2015) establish that Bhutan and Nepal have the potential to cost-effectively supply electricity from hydroelectric resources in excess of their own demand, while Bangladesh and India are likely to become more dependent on higher-cost coal and natural gas to generate electricity.

The World Bank (2015) study quantifies the potential economic benefits that the HKH could reap if the countries engage in regional electricity trade and cooperation. According to this study, unrestricted electricity trade provision through optimal expansion of electricity generation capacities and transmission interconnections in the region would save USD226 billion in electricity supply costs over the period 2015-40. To achieve these benefits, the region has to add an estimated 95,000 MW of new cross-border transmission interconnection capacity (Timilsina et al. 2015). The cooperation benefits pertain to direct sector-level gains from generation and transmission assets at the regional level, rather than country by country. 
Fuels and technologies: Existing bilateral energy cooperation has been limited to some hydropower, and there is scope for possible regional collaboration in other energy resources like natural gas. The HKH, except for Bangladesh, is poorly endowed with reserves of natural gas. However, the real benefit in this sector will accrue from a region-wide integrated gas pipeline network to import gas from outside the region, jointly developed and owned by the participating nations (USAID 2006). India's difficulties and apprehensions for establishing gas pipelines through Bangladesh could be mitigated to some extent if India considers creating a regional network -including Nepal and Bhutan - rather than bilateral arrangements (Nanda and Goswami 2008). This energy trading will help countries diversify their energy usage and enable them to reduce their dependence on traditional biomass. A number of proposed gas pipeline projects under discussion could lay the foundation for a regional gas grid, but investment requirements and security concerns must first be addressed before this concept can be fully explored and implemented (USAID 2006).

Biomass: Given a variety of bioenergy technologies emerging as equally competitive with conventional power generation options, there is scope for regional collaboration in further market development and demonstration to stimulate new and larger investments, while taking advantage of economies of scale. This calls for joint R\&D efforts to develop commercially viable and efficient renewable energy technologies such as waste-to-energy, biogasification, and biofuel, which India and China have been actively pursuing (Srivastava and Misra 2007; Srivastava et al. 2013). Biomass-based energy through efficient gasification technology can help deliver energy to rural households in the region, and that energy can be traded through integrated grid networks. However, the technology needs first to be developed, and countries such as India and China need to share their technology in biogas, gasifiers, and cookstoves with other countries of the region. An efficient technology to use the biomass for energy generation can reduce the stress on forest resources and improve ecosystem services, and lead to reductions in GHG emissions, with efficient utilization of biomass resources.

\subsubsection{Role of Multi-level Governance in Securing Sustainable Energy in HKH}

Several studies offer valuable empirical and theoretical insights into the huge potential benefits of regional energy cooperation, especially in hydropower (ESCAP 2013; Iftikhar et al. 2015; Lama 2016; Price and Mittra 2016; Rahman et al. 2011; Timilsina et al. 2015; USAID 2013; Wijayatunga et al. 2015; World Bank 2008). However, these lack a holistic approach and solution-oriented, multi-pronged strategic options for improved regional energy security cooperation (Mahmud 2012; Srivastava and Misra 2007; Srivastava et al. 2013). As a result, far too little has been done to bring about the much-needed change for sustainable energy security cooperation in the region.

Existing energy policies in the region lack integrated energy planning, trade, and institutional mechanisms to leverage complementary regional energy resources. Even modest efforts to encourage regional energy trade are historically blocked by longstanding disputes, political exigencies, and mistrust between the countries of the region (Ebinger 2011; USAID 2006). However, it is rightly stressed that delays in decision making to ensure stronger and mutually beneficial cooperation efforts are associated with high costs, not only for the energy sector, but also for the development agenda of the region (Srivastava and Misra 2007; Srivastava et al. 2013). It is, therefore, critical for all stakeholders in $\mathrm{HKH}$ countries to graduate from the bilateral approach to a multilateral approach to develop a regional energy market.

International experience from a number of regional power sector cooperation initiatives demonstrates that nations with political differences have also come together for regional power sector cooperation and, in the process, realized various technical, economic, and environmental benefits of regional cooperation (USAID 2013). Experience, particularly from the South African Power Poll (SAPP) and the Greater Mekong Sub-Region (GMS), (which have a long history of bilateral arrangements leading to the development of regional power sector cooperation) has special relevance for the HKH (See Box 6.5).

Box 6.5 Regional power sector cooperation: International experience

A number of initiatives have led to regional power sector cooperation, including GMS, SAPP, the South East Asia, Europe, Gulf Coast Countries (GCC), and the Nile Basin Initiative (NBI). Their experiences show that key drivers and motivation for such regional cooperation include reliable system operation, regionally coordinated investment in generation, enhanced regional energy security, lower reserve requirements, and optimized system operations that take into account daily and seasonal variations in demand and generation. The SAPP experience demonstrates the feasibility of trade in power, and reliable and economical operation of the integrated system, even in the presence of 
historically rooted political differences, provided that complementary power sources, an active regional organization for economic cooperation, and political will to support increased regional energy trade is present (USAID 2013).

New ways and mechanisms need to be explored to create innovative multi-governance institutional models for energy cooperation. This calls for a multi-pronged strategy for regional energy cooperation, ranging from several softer options aimed at confidence building, to larger-scale cooperation on information collection and sharing, knowledge networking, and technology cooperation for rural energization, building greater energy efficiency, and enlisting private sector participation (Srivastava and Misra 2007; Srivastava et al 2013). Any successful regional cooperation effort will also depend on a smart policy for tariff setting, given the central role tariffs will play in determining the comparative advantages in regional trade negotiations (Srivastava and Misra 2007). Critically, several barriers related to both domestic policy reforms and regional political climate will need to be addressed in the pursuit of regional energy cooperation in the HKH. At the domestic level, some policy-related barriers include insufficient installation of generation capacity to match growing demand, weak financial performance of utilities due to technical and non-technical losses, poor operational efficiency of installed capacity, politically distorted tariffs, limited private sector participation owing to low financial incentives and political uncertainties, and partial domestic power sector reforms to harmonize policy and regulatory framework (CUTS International 2016).

As regional cooperation entails transboundary activities and shared control over resources, addressing existing trust gaps among governments and other key players (private sector, development partners, civil society) is a critically important first step (CUTS International 2016). Frequent meetings and discussions at appropriate levels and with relevant agencies need to take place at multilateral, bilateral, and regional levels for trust and confidence building. An integrated regional energy master plan must be developed, focusing on joint development mechanisms for maximizing investments in shared energy infrastructure (USAID 2006), and sharing with neighbouring countries through modes of bilateral/trilateral/multilateral cooperation.

Development partners can play an effective role in providing technical assistance to pursue regional and international energy trade, mobilizing international private investments, and developing the capacity of energy sector organizations. Bangladesh is currently taking a pioneering role in trying to push forward a trilateral MOU with India and Bhutan. The governments of Bangladesh, India and Bhutan have signed a MoU to jointly participate in the construction of hydropower project in Bhutan's Lhuentse district $^{10}$ The Bangladeshi government recently approved an equity investment of USD1 billion, for the Dorjilung 1125 MW hydropower project in Lhuentse district in eastern Bhutan, for power that will be exported to Bangladesh.

Relevant institutions with a dedicated regional agency comprising representatives from government, private, and non-governmental sectors with expertize in energy must be initiated to steer inclusive and sustained dialogues at multiple levels for regional cooperation and development. India and Bangladesh have created a Joint Expert Technical Committee (JETC) to study cross-border power transfer by constructing a $700 \mathrm{kV}$ HVDC line through Bangladesh from the eastern part of India (Arunachal Pradesh) with a 10\% power sharing arrangement for Bangladesh. Setting up appropriate back-to-back arrangements by engaging commercial entities (public or private) in the business of electricity trading and lagged energy exchange arrangements ${ }^{11}$ could be other possible options for cooperation (Srivastava and Misra 2007).

Within the structure of bilateral and multilateral energy cooperation, a regional cooperation model structure can be considered. The structure will need to ensure that various institutions and rules can be designed and implemented to address the social, economic, and environmental domains of sustainability in the region. These institutions can also feed into larger regional and global debates on sustainability. Hence, the institutional model of the HKH for energy cooperation has to constantly evolve by being a contributor/receptor of national, regional, and global sustainability issues. This body would need to grow and change over time to remain in tune with regional and worldwide needs.

\subsubsection{Climate Change, Energy Resilience, and Regional Energy Cooperation}

Climate change-induced security threats, particularly those emanating from water stress and natural calamities, are becoming major problems for regional security dynamics in the HKH. They will intensify the loss of livelihood due to food, water, and energy scarcity in the HKH and

\footnotetext{
${ }^{10}$ Asianpower, 12 July 2017, available online at https://asian-power. com/project/news/bhutan-bangladesh-and-india-jointly-develophydropower-project.

${ }^{11}$ Under such arrangements Bangladesh, for example, could begin to provide gas to India for a stipulated period, in exchange for which India would be obligated to provide Bangladesh the contracted amount of energy in future.
} 
downstream river basins, and this loss will exacerbate displacement, migration, and loss of biodiversity (Muniruzzaman 2012). The enormous national, regional, and global linkages of HKH energy resource bases - together with the complex interdependencies in water, food, and energy security-highlight the urgent need for intersectorally integrated and holistic solutions from an ecosystem perspective (Dharmadhikary 2008; Rasul and Sharma 2016).

It is important to assess and quantify various externalities associated with regional energy cooperation, given its implications for large-scale environmental degradation, the costs of climate change, and indoor pollution problems (Srivastava and Misra 2007). As a vital component of sustainable hydropower development, appropriate benefit-sharing mechanisms need to be explored to reach a win-win solution where the benefits derived from hydropower projects are shared with mountain communities in a fair and equitable manner, beyond the compensation and mitigation of project impacts (Shrestha et al. 2016). Benefit sharing from hydropower projects is becoming increasingly important for sustainable hydropower development to ensure that the rights and interests of the affected populations are recognized. Unlike compensation, which is usually covered under the project costs, benefit sharing typically takes a small percentage from the revenues generated by the project. Mekong countries have experience with one or more forms of benefit sharing in the hydropower sector. Nepal and China have laws that allocate a portion $(1-3 \%)$ of gross revenue from hydropower projects to permanent local development and reconstruction funds in reservoir areas; in India, allocation ranges from 10 to $14 \%$. A more recent study has identified a variety of benefit-sharing models and practices evolving in Nepal (Shrestha et al. 2016). Among them, equity share in hydropower projects for local citizens is an innovative market-based strategy of benefit sharing. This mechanism was designed in response to the pronounced demand from local citizens for ownership of shares in hydropower projects, as incentives among stakeholders, to avoid costly conflicts and contestations. Payment for environmental services (PES) schemes ${ }^{12}$ is one way to reward mountain communities for the vital services they provide, and should therefore be promoted at a global scale to make mountain social-ecological systems more resilient in the face of climate change. Capacity-building programmes, sustained financial support, and knowledge exchange are needed for technology development, leading to a reduction in dependence on fossil fuels and lowered GHG emissions. This is important in the HKH, as impacts of climate change there will impact the agriculture and livelihoods of the

\footnotetext{
${ }^{12}$ They consist of payment for the maintenance or provision of an environmental service by the users to the providers of the service.
}

region, affecting the economic, environmental, and social domains of sustainability.

Although the impending crisis is recognized, there is a general lack of policy direction and political will in tackling these multifaceted issues. Mutual distrust hinders effective action, and sovereignty concerns overrule regional interests. Environmental cooperation generally lags far behind economic cooperation in the HKH (Morton 2008). Domestic reforms are under way, but alone are inadequate. Disputes and rivalries must be put aside to achieve regional energy cooperation, as entrenched mistrust has perpetuated parochialism for decades (Ebinger 2011). However, there are good reasons to believe that climate change-induced human security threats have the potential to drive energy cooperation and facilitate multilateral agreements on the basis of a common framework.

\subsection{Way Forward}

The HKH has a huge diversity of contexts and, despite being rich in energy resources, remains energy poor and vulnerable. The urgent challenge for meeting the energy need of the $\mathrm{HKH}$ region is to build on past successes to seize the huge untapped renewable resource opportunities on the one hand. On the other hand, the need is to accelerate the rapid diffusion and scale-up of appropriate, customized business models for off-grid renewable energy solutions by creating an enabling policy environment for clean energy investment in a sustainable manner.

As there is no one-size-fits-all solution for ensuring universal access to modern energy in mountain areas, the $\mathrm{HKH}$ region must pursue multi-goal energy perspectives to chart its own energy transition pathway, drawing lessons from demonstrated examples of success across the region on how to jump-start and leapfrog to reach a meaningful energy transition. This section sets out four priority areas for immediate action to make sustainable energy transition a reality.

- Make mountain-specific energy policies and programmes an integral part of national energy development strategy. Policies based on anecdotal information or that merely mimic national energy strategies for the local $\mathrm{HKH}$ region are unlikely to address mountain-specific energy challenges. Establishing a comprehensive energy database (on supply and demand, resources, technologies in use, and good practices from the region) is a necessary first step towards devising evidence-based strategies for sustainable energy provisioning. To achieve this, a regional mountain-specific data management system supporting national institutions in periodic energy data gathering 
with innovative survey methodologies (using information technology based surveys, remote sensing, etc.) and analysis to assess various aspects of energy access is of utmost importance.

- Establish monitorable quantitative and qualitative targets for each energy end use. A mountain-specific multi-tier assessment framework with appropriate energy access indicators must be established. This must allow proper measurement and tracking of progress of different attributes of access to clean energy (e.g., availability, quality, affordability, health, convenience, safety, and efficiency) for each end use while at the same time promoting integrated and holistic approaches to other related SDGs. The diversity of contexts in this region may also require nuanced signalling and incentivizing of appropriate technology choices. Such targets must give specific attention to meeting cooking energy targets, given their implications for forest degradation, human health, and the environment. Such an outcome-oriented strategy would facilitate a demand-driven approach to energy service provisioning. It would prioritize interventions with the largest co-benefits on SDGs related to poverty elimination, better health and education, reduced emissions of SLCPs, reduced drudgery for women and children, greater gender equality, decent jobs, etc.

- Scale up current investments and ensure access to finance through capacity building at different levels. Mobilizing innovative and affordable international, regional, national, and local funds is crucial for supporting energy planning, infrastructure investments, and creating incentives for commercial lending, generating soft loans, and providing technical assistance. The engagement of the private sector in this effort is critical, for both large-scale energy generation and infrastructure projects and smaller-scale decentralized energy provisioning. Governments can encourage this through the creation of markets and using public funding and financing for de-risking investments and leveraging private finance. Promoting off-grid renewable energy requires customized business and affordable financing models. While engaging and empowering local communities is critical to the sustainability of the off-grid sector, capacity-building efforts must also specifically address themselves to effective design and management of public-private partnerships as well as to private or community-based entrepreneurship.

- Accelerate the pace of regional trade and cooperation in sustainable energy through a high-level, empowered, regional mechanism. With the exception of a few bilateral hydropower exchanges, the region has little else to show as successful cooperation efforts. However, a great opportunity exists to leverage the complementary energy resources in the region to secure sustainable energy. This can be achieved through integrated regional energy planning, trade, and establishment of institutional mechanisms which would also ensure that environmental externalities are managed and revenue-sharing mechanisms for local areas are in place. Concerted regional approaches also help in reducing costs, generating economies of scale, attracting investment, boosting financial capacity, transferring technology and knowledge, and accelerating the deployment of renewable energy. Climate change-induced human security threats have the potential to drive energy cooperation and facilitate multilateral agreements on the basis of a common framework.

\section{References}

ADB. (2012). Energy trade in South Asia: Challenges and opportunity. Mandaluyong City, Philippines: Asian Development Bank.

ADB. (2013). Islamic Republic of Afghanistan-Power Sector Master Plan; Asian Development Bank, Manila. Retrieved October 12, 2016, from https://www.adb.org/sites/default/files/projectdocument/76570/43497-012-afg-tacr.pdf.

ADB. (2015). Energy outlook for Asia and the Pacific. Manila, Philippines: Asian Development Bank.

Afghanistan National Development Strategy Secretariat. (2008). Energy sector strategy (2007/08-2012/13). Kabul: Islamic Republic of Afghanistan. http://mew.gov.af/Content/files/Energy_Sector_ Strategy-English.pdf.

Ale, B. B., \& Shrestha, S. B. (2008). Hydrogen energy potential of Nepal. International Journal of Hydrogen Energy, 33(15), 40304039.

Amann, M., Kejun, J., Jiming, H., Wang, S., Xing, Z., Xiang, D. Y., et al. (2008). GAINS Asia. Scenarios for cost-effective control of air pollution and greenhouse gases in China. International Institute of Applied Systems Analysis (IIASA), Luxenberg, Austria.

Badran, A. A., Yousef, I. A., Joudeh, N. K., Al Hamad, R., Halawa, H., $\&$ Hassouneh, H. K. (2010). Portable solar cooker and water heater. Energy Conversion and Management, 51(8), 1605-1609.

Balachandra, P. (2011). Dynamics of rural energy access in India: An assessment. Energy, 36(9), 5556-5567.

Banerjee, M., Prasad, R., Rehman, I. H., \& Gill, B. (2016). Induction stoves as an option for clean cooking in rural India. Energy Policy, 88, 159-167.

Banerjee, S. G., Moreno, F. A., Sinton, J. E., Primiani, T., \& Seong, J. (2017). Regulatory indicators for sustainable energy: A global scorecard for policy makers. Washington, DC, World Bank. http:// documents.Worldbank.org/curated/en/538181487106403375/pdf/ 112828-REVISED-PUBLIC-RISE-2016-Report.pdf.

Benecke, G. E. (2008). Success factors for the effective implementation of renewable energy options for rural electrification in IndiaPotentials of the clean development mechanism. International Journal of Energy Research, 32(12), 1066-1079.

Beniston, M. (2013, February 20). Mountain water resources in a changing climate. Presented at Mountains under Watch Conference, Val d'Aosta, Italy. www.muw2013.it/ session-details.

Bhatt, B. P., \& Sachan, M. S. (2004). Firewood consumption pattern of different tribal communities in Northeast India. Energy Policy, 32 (1), 1-6. 
Bhattacharyya, S. C. (2006). Energy access problem of the poor in India: Is rural electrification a remedy? Energy Policy, 34(18), 3387-3397.

Bhattacharyya, S. C., \& Ohiare, S. (2012). The Chinese electricity access model for rural electrification: Approach, experience and lessons for others. Energy Policy, 49, 676-687.

Biswas, A. K. (2011). Cooperation or conflict in transboundary water management: Case study of South Asia. Hydrological Sciences Journal, 56(4), 662-670.

BP Statistical Review of World Energy. (2016). BP Statistical Review of World Energy June 2016. Retrieved from https://www.bp.com/ content/dam/bp/pdf/energy-economics/statistical-review-2016/bpstatistical-review-of-world-energy-2016-full-report.pdf.

Burns, R. K. (2011). Afghanistan: Solar assets, electricity production, and rural energy factors. Renewable and Sustainable Energy Reviews, 15(4), 2144-2148. https://doi.org/10.1016/j.rser.2010.12.002.

Cai, J., \& Jiang, Z. (2008). Changing of energy consumption patterns from rural households to urban households in China: An example from Shaanxi Province, China. Renewable and Sustainable Energy Reviews, 12(6), 1667-1680.

CEA. (2016). Status of Hydro Electric Potential Development, Central Electricity Authority (CEA), Ministry of Power, Govt. of India, New Delhi. Retrieved October 22, 2016, from http://www.cea.nic. in/reports/monthly/hydro/2016/hydro_potential_region-02.pdf.

CIA. The World Factbook. (2016). Retrieved June, 2017, from https:// www.cia.gov/library/publications/the-world-factbook/index.html.

Chauhan, A., \& Saini, R. P. (2015). Renewable energy based off-grid rural electrification in Uttarakhand state of India: Technology options, modelling method, barriers and recommendations. Renewable and Sustainable Energy Reviews, 51, 662-681.

Cheng, C. Y., \& Urpelainen, J. (2014). Fuel stacking in India: Changes in the cooking and lighting mix, 1987-2010. Energy, 76, 306-317.

CUTS International. (2016). Promoting Energy Cooperation among South Asian Countries. SDIP Advocacy Brief NO. 5 Sustainable Development Investment Portfolio (SDIP).

Dawn. (2014, November 27). South Asian Leaders Reach Last-Minute Energy Deal at SAARC summit. The DAWN. http://www.dawn. com/news/1147270.

Dhakal, S., \& Raut, A. K. (2010). Potential and bottlenecks of the carbon market: The case of a developing country, Nepal. Energy Policy, 38(7), 3781-3789.

Dharmadhikary, S. (2008, December). Mountains of Concrete, International Rivers Organisation.

Dincer, I., \& Acar, C. (2015). A review on clean energy solutions for better sustainability. International Journal of Energy Research, 39 (5), 585-606.

Duan, X., Jiang, Y., Wang, B., Zhao, X., Shen, G., Cao, S., et al. (2014). Household fuel use for cooking and heating in China: Results from the first Chinese Environmental Exposure-Related Human Activity Patterns Survey (CEERHAPS). Applied Energy, 136, 692-703.

Ebinger, C. K. (2011). Energy and security in South Asia: Cooperation or conflict? Brookings Institution Press.

EFEWEE. (2016). Exploring Factors that Enhance and restrict Women's Empowerment through Electrification (EFEWEE), Scoping study report. http://www.energia.org/cms/wp-content/uploads/ 2016/07/RA1-Scoping-Report.pdf.

Ekholm, T., Krey, V., Pachauri, S., \& Riahi, K. (2010). Determinants of household energy consumption in India. Energy Policy, 38(10), 5696-5707.

ENERGIA. (2015). Regional Gender Assessment of Energy Policies and Programmes in South Asia. The International Network on Gender and Sustainable Energy (ENERGIA), ETC Foundation in the Netherlands.
Ershad, A. M., Brecha, R. J., \& Hallinan, K. (2016). Analysis of solar photovoltaic and wind power potential in Afghanistan. Renewable Energy, 85, 445-453.

ESCAP. (2013). Regional cooperation for energy access and energy security in South and South-West Asia. Prospects and Challenges. South and South-West Asia Development Papers 1302. Economic and Social Commission for Asia and the Pacific.

Global Carbon Atlas. (2017). http://www.globalcarbonatlas.org/en/ CO2-emissions.

Geng, J. B., \& Ji, Q. (2014). Multi-perspective analysis of China's energy supply security. Energy, 64, 541-550.

Gupta, E. (2008). Oil vulnerability index of oil-importing countries. Energy Policy, 36, 1195-1211.

Gómez, M. F., \& Silveira, S. (2010). Rural electrification of the Brazilian Amazon-Achievements and lessons. Energy Policy, 38 (10), 6251-6260.

Government of Nepal. (2016). Intended Nationally Determined Contributions (INDC); Ministry of Population and Environment; Kathmandu. http://www4.unfecc.int/Submissions/INDC/Published \%20Documents/Nepal/1/Nepal_INDC_08Feb_2016.pdf.

Government of Nepal. (2015). Sustainable Development Goals 20162030; National (Preliminary) Report; National Planning Commission, Kathmandu. http://www.np.undp.org/content/dam/nepal/docs/ reports/SDG\%20final\%20report-nepal.pdf.

Government of the People's Republic of Bangladesh. (2012). Perspective Plan of Bangladesh 2010-2021. General Economics Division, Planning Commission, Government of the People's Republic of Bangladesh, Dhaka. Retrieved October 12, 2016, from, http:// bangladesh.gov.bd/sites/default/files/files/bangladesh.gov.bd/page/ 6dca6a2a_9857_4656_bce6_139584b7f160/Perspective-Plan-ofBangladesh.pdf.

Government of the People's Republic of Bangladesh. (2013). Country Action Plan for Clean Cookstoves; Ministry of Power, Energy and Mineral Resources, Government of the People's Republic of Bangladesh, Dhaka. Retrieved October 12, 2016, from http:// cleancookstoves.org/resources/235.html.

Hanbar, R. D., \& Karve, P. (2002). National Programme on Improved Chulha (NPIC) of the Government of India: An overview. Energy for Sustainable Development, 6(2), 49-55.

Hoff, H. (2011). Understanding the nexus: Background paper for the Bonn 2011 Nexus Conference.

Hosier, R. H., \& Dowd, J. (1987). Household fuel choice in Zimbabwe: An empirical test of the energy ladder hypothesis. Resources and Energy, 9(4), 347-361.

Hussey, K., \& Pittock, J. (2012). The energy-water nexus: Managing the links between energy and water for a sustainable future. Ecology and Society, 17(1).

ICIMOD. (2011). Regional Assessment Report for Rio+20: Hindu Kush Himalaya and SE Asia Pacific Mountains. From Rio 1992 to 2012 and beyond: Sustainable Mountain Development Hindu Kush Himalaya (HKH) Region. ICIMOD, Kathmandu, Nepal (pp. 1-71). Retrieved 15 May, 2016, from http://www.uncsd2012.org/content/ documents/HKH_30_9_2011_0\%5b1\%5d.pdf.

IEA. (2015). World Energy Outlook 2015. International Energy Agency (IEA), Paris.

IEA. (2016). Energy Balances. Retrieved 14 July, 2016, from https:// www.iea.org/statistics/statisticssearch.

IEA. (2017). World Energy Outlook 2017. International Energy Agency (IEA), Paris.

Iftikhar, M., Najeeb, N., Mohazzam, F., \& Khan, A. K. (2015). Sustainable Energy for All in South Asia: Potential, Challenges, and Solutions. Sustainable Development Policy Institute. Working Paper \#151. Sustainable Development Policy Institute (SDPI), Islamabad, Pakistan. 
IEA and World Bank. (2015). Sustainable Energy for All 2015Progress Toward Sustainable Energy. World Bank, Washington, DC. https://doi.org/10.1596/978-1-4648-0690-2.

IEA and World Bank. (2017). Sustainable Energy for All 2017Progress toward Sustainable Energy (Summary). World Bank, Washington, DC.

Jain, A., Ray, S., Ganesan, K., Aklin, M., Cheng, C. Y., \& Urpflainen, J. (2015). Access to clean cooking energy and electricity - Survey of states. Report. New Delhi, India: Council on Energy, Environment and Water (CEEW).

Kaltenborn, B. P., Nellemann, C., \& Vistnes, I. I. (Eds). (2010). High mountain glaciers and climate change-Challenges to human livelihoods and adaptation. United Nations Environment Programme, GRID-Arendal. www.grida.no.

Kandlikar, M., Reynolds, C. C., \& Grieshop, A. P. (2009). A perspective paper on black carbon mitigation as a response to climate change. Copenhagen: Copenhagen Consensus Center.

Kar, A., Singh, D., \& Zerriffi H. (2018). Has India's Ujjwala Program enabled millions to shift to Liquefied Petroleum Gas as a primary cooking fuel? http://erdelab.forestry.ubc.ca/2018/04/.

Kc, S., Khanal, S. K., Shrestha, P., \& Lamsal, B. (2011). Current status of renewable energy in Nepal: Opportunities and challenges. Renewable and Sustainable Energy Reviews, 15(8), 4107-4117.

Khair, M. (2013). The efficacy of groundwater markets on agricultural productivity and resource use sustainability: Evidence from the upland Balochistan region of Pakistan. Unpublished Ph.D. thesis, Charles Sturt University, Wagga Wagga.

Khandelwal, M., Hill, M. E., Greenough, P., Anthony, J., Quill, M., Linderman, M., et al. (2016). Why Have Improved Cook-Stove Initiatives in India Failed? World Development.

Kishore, A., \& Spears, D. (2014). Having a son promotes clean cooking fuel use in urban India: Women's status and son preference. Economic Development and Cultural Change, 62(4), 673-699.

Klimont, Z., Cofala, J., Xing, J., Wei, W., Zhang, C., Wang, S., et al. (2009). Projections of SO2, NOx and carbonaceous aerosols emissions in Asia. Tellus Series B: Chemical and Physical Meteorology, 61 B(4), 602-617.

Lama, M. (2016). BBIN Initiatives: Options for Cross-Border Power Exchange.

Lama, M. P. (2004, August 20-21). Energy Cooperation in South Asia, SAFMA Regional Conference, Dhaka.

Loka, P., Moola, S., Polsani, K., Reddy, S., Fulton, S., \& Skumanich, A. (2014). A case study for micro-grid PV: Lessons learned from a rural electrification project in India. Progress in Photovoltaics: Research and Applications, 22(7), 733-743.

Li, K., \& Lin, B. (2015). Impacts of urbanization and industrialization on energy consumption/ $\mathrm{CO}_{2}$ emissions: Does the level of development matter? Renewable and Sustainable Energy Reviews, 52, $1107-1122$.

Mahmud, K. (2012). Power grid interconnection of south Asian region to retain sustainable energy security and figure out the energy scarcity. Global Journal of Research in Engineering, 12(10-F).

Mainali, B., \& Silveira, S. (2013). Alternative pathways for providing access to electricity in developing countries. Renewable energy, 57, 299-310.

Mainali, B., Pachauri, S., \& Nagai, Y. (2012). Analyzing cooking fuel and stove choices in China till 2030. Journal of Renewable and Sustainable Energy, 4(3), 031805.

Mainali, B., Pachauri, S., Rao, N. D., \& Silveira, S. (2014). Assessing rural energy sustainability in developing countries. Energy for Sustainable Development, 19, 15-28.
Mainali, B., Luukkanen, J., Silveira, S., \& Kaivo-oja, J. (2018). Evaluating synergies and trade-offs among Sustainable Development Goals (SDGs): Explorative analyses of development paths in South Asia and Sub-Saharan Africa. Sustainability, 10, 815.

Marsh, D. M., \& Sharma, D. (2007). Energy-water nexus: An integrated modeling approach. International Energy Journal, 8(4), 235-242.

McCollum, D., Gomez Echeverri, L., Busch, S., Pachauri, S., Parkinson, S., Rogelj, J., et al. (2017). Connecting the Sustainable Development Goals by their energy inter-linkages. IIASA Working Paper. IIASA, Laxenburg, Austria.

McMillan, J. (2008, September). Energy security in South Asia: Can interdependence breed stability? In Strategic forum (Vol. 232). National Defense University. Washington DC: Institute for National Strategic Studies.

Menon, S., Hansen, J., Nazarenko, L., \& Luo, Y. (2002). Climate effects of black carbon aerosols in China and India. Science, 297 (5590), 2250-2253.

Ministry of Energy and Water \& Ministry of Rural Rehabilitation and Development. (2013). Afghanistan Rural Renewable Energy Policy, Kabul: Islamic Republic of Afghanistan. http://www.red-mew.gov. af/wp-content/uploads/2014/11/4.3-Rural-Renewable-EnergyPolicy.pdf.

Ministry of Foreign Affairs. (2008). Afghanistan National Development Strategy, 2008-2013: Strategy for Security, Governance, Economic Growth \& Poverty Reduction; Kabul: Islamic Republic of Afghanistan. Retrieved October 2016, from http://mfa.gov.af/en/ page/6547/afghanistan-national-development-strategy/afghanistannational-development-strategy-ands.

Ministry of Power, Energy and Mineral Resources. (2004). National energy policy. Dhaka: Government of the People's Republic of Bangladesh. http://www.asialeds.org/sites/default/files/resource/file/ NEP_2004_fulldoc.pdf.

Ministry of Power, Energy and Mineral Resources. (2008). Renewable energy policy of Bangladesh. Dhaka: Government of the People's Republic of Bangladesh. https://www.iea.org/media/pams/ bangladesh/Bangladesh_RenewableEnergyPolicy_2008.pdf.

Ministry of Power, Energy and Mineral Resources. (2016). Power system master plan 2016. Dhaka: Government of the People's Republic of Bangladesh. http://powerdivision.portal.gov.bd/sites/ default/files/files/powerdivision.portal.gov.bd/page/4f81bf4d_ 1180_4c53_b27c_8fa0eb11e2c1/(E)_FR_PSMP2016_Summary_ revised.pdf.

Ministry of Power. (2011a). The Electricity Act 2003; Power Compendium-A compilation of Act, Polices, Rules, Guidelines 2011. Government of India, New Delhi. http://www.cea.nic.in/ reports/isacpower/power_compendium.pdf.

Ministry of Power. (2011b). National Electricity Policy, Power Compendium-A compilation of Act, Polices, Rules, Guidelines 2011. Government of India, New Delhi. http://www.cea.nic.in/ reports/isacpower/power_compendium.pdf.

Ministry of Water and Power. (2013). National Power Policy 2013, Government of Pakistan, Islamabad. https://www.scribd.com/ document/187041200/National-Power-Policy-2013-Pakistan.

Mir, K. A., Purohit, P., Goldstein, G. A., \& Balasubramanian, R. (2016). Analysis of baseline and alternative air quality scenarios for Pakistan: An integrated approach. Environmental Science and Pollution Research, 23(21), 21780-21793.

Mirza, U. K., Ahmad, N., Majeed, T., \& Harijan, K. (2008). Hydropower use in Pakistan: Past, present and future. Renewable and Sustainable Energy Reviews, 12(6), 1641-1651. 
Misra, N., Chawla, R., Srivastava, L., \& Pachauri, R. K. (2005). Petroleum pricing in India: Balancing efficiency and equity. Delhi: The Energy and Resources Institute.

MNRE (Ministry of New and Renewable Energy). (2016). Annual Report, 2016-2017. Retrieved from http://mnre.gov.in/filemanager/annual-report/2016-2017/EN/pdf/1.pdf.

Mondal, M. A. H., \& Islam, A. S. (2011). Potential and viability of grid-connected solar PV system in Bangladesh. Renewable energy, 36(6), 1869-1874.

Mondal, M. A. H., Kamp, L. M., \& Pachova, N. I. (2010). Drivers, barriers, and strategies for implementation of renewable energy technologies in rural areas in Bangladesh-An innovation system analysis. Energy Policy, 38(8), 4626-4634.

MoPE. (2016). Renewable Energy Subsidy Policy 2073 BS, Ministry of Population and Environment, Government of Nepal.

Morton, K. (2008). China and environmental security in the age of consequences. Asia-Pacific Review, 15(2), 52-67.

Mukherji, A., Chowdhury, D. R., Fishman, R., Lamichhane, N., Khadgi, V., \& Bajracharya, S. (2017). Sustainable financial solutions for the adoption of solar powered irrigation pumps in Nepal's terai.

Muniruzzaman, A. N. M. (2012). Climate change and regional security. In T. Delinic \& N. Pandey (Eds.), Regional environmental issues: Water and disaster management. Centre for South Asian Studies (CSAS) and Adenauer Stiftung (KAS).

Nanda, N., \& Goswami, A. (2008). Energy cooperation in South Asia. Man and Development, 30(1), 109-120.

National Commission for Environmental Affairs, Ministry of Forestry. (2009). National Sustainable Development Strategy of Myanmar. http://extwprlegs1.fao.org/docs/pdf/mya152933.pdf.

Nexant. (2001). The four borders project: Reliability improvement and power transfer in South Asia, a pre-feasibility study. Prepared for USAID-SARI/ Energy Program.

Nilsson, M., Griggs, D., \& Visbeck, M. (2016). Map the interactions between sustainable development goals. Nature, 534, 320-322.

NIWE. (2016). Estimation of Installable Wind Power Potential at $80 \mathrm{~m}$ level in India. National Institute of Wind Energy (NIWE), Chennai. Retrieved October 22, 2016, from niwe.res.in/department_wra_est. php.

OECD/IEA. (2016). Energy and Air Pollution: World Energy Outlook Special Report. International Energy Agency (IEA), Paris.

Pachauri, S., \& Jiang, L. (2008). The household energy transition in India and China. Energy Policy, 36(11), 4022-4035.

Pakistan Energy Vision 2035. https://www.sdpi.org/publications/files/ Pakistan\%20Energy\%202035-FINAL\%2020th\%20October\% 202014.pdf.

Planning Commission. (2012). Perspective plan of Bangladesh 2021Making vision 2021 a reality. Dhaka: Government of the People's Republic of Bangladesh. http://bangladesh.gov.bd/sites/default/files/ files/bangladesh.gov.bd/page/6dca6a2a_9857_4656_bce6 139584b7f160/Perspective-Plan-of-Bangladesh.pdf.

Planning Commission. (2006). Integrated Energy Policy, Government of India, New Delhi. http://planningcommission.gov.in/reports/ genrep/rep_intengy.pdf.

Palit, D., \& Bhattacharyya, S. (2014). Adoption of cleaner cookstoves: Barriers and way forward.

Palit, D., \& Chaurey, A. (2011). Off-grid rural electrification experiences from South Asia: Status and best practices. Energy for Sustainable Development, 15(3), 266-276.

Palit, D., \& Garud, S. (2010). Energy consumption in the residential sector in the Himalayan kingdom of Bhutan. Boiling Point, 58, 34 36.

Palit, D., Bhattacharyya, S. C., \& Chaurey, A. (2014). Indian approaches to energy access. In Energy poverty: Global challenges and local solutions (pp. 237-256).
Papola, T. S. (2002). Poverty in mountain areas of the Hindu Kush-Himalayas: Some basic issues in measurement, diagnosis and alleviation. International Centre for Integrated Mountain Development. Kathmandu, Nepal.

Parajuli, R., Østergaard, P. A., Dalgaard, T., \& Pokharel, G. R. (2014). Energy consumption projection of Nepal: An econometric approach. Renewable Energy, 63, 432-444.

Perera, N., Boyd, E., Wilkins, G., \& Phillips, R. (2015). Literature Review on Energy Access and Adaptation to Climate Change. Evidence on demand.

Pode, R., Pode, G., \& Diouf, B. (2016). Solution to sustainable rural electrification in Myanmar. Renewable and Sustainable Energy Reviews, 59, 107-118.

Practical Action. (2014). Poor people's energy outlook 2014: Key messages on energy for poverty alleviation. Retrieved from Rugby, UK.

Price, G., \& Mittra, S. (2016). Water, Ecosystems and Energy in South Asia Making Cross-Border Collaboration Work. Asia Programme. Research Paper. The Royal Institute of International Affairs, Chatham House: London.

Proietti, S., Sdringola, P., Castellani, F., Garinei, A., Astolfi, D., Piccioni, E., et al. (2015). On the possible wind energy contribution for feeding a high altitude Smart Mini Grid. Energy Procedia, 75, 1072-1079.

Purohit, P., Amann, M., Mathura, R., Gupta, I., Marwan, S., Varma, V., et al. (2010). Gains Asia: Scenarios for cost-effective control of air pollution and greenhouse gases in India. International Institute for Applied Systems Analysis (IIASA), Ladenburg, Austria.

Purohit, P., Munir, T., \& Rafaj, P. (2013). Scenario analysis of strategies to control air pollution in Pakistan. Journal of Integrative Environmental Sciences, 10(2), 77-91.

Rahman, S. H., Wijayatunga, P. D., Gunatilake, H., \& Fernando, P. (2011). Energy trade in South Asia: Opportunities and challenges. Asian Development Bank, Philippines.

Rahman, S. H., Wijayatunga, P. D., Gunatilake, H., \& Fernando, P. (2012). Energy trade in South Asia: Opportunities and challenges. Asian Development Bank, Manila. http://www.adb.org/sites/default/ files/publication/29703/energy-trade-south-asia.pdf.

Rahut, D. B., Behera, B., \& Ali, A. (2016). Household energy choice and consumption intensity: Empirical evidence from Bhutan. Renewable and Sustainable Energy Reviews, 53(C), 993-1009.

Ramanathan, V., \& Carmichael, G. (2008). Global and regional climate changes due to black carbon. Nature Geoscience, 1(4), 221-227.

Ramanathan, V., Li, F., Ramana, M. V., Praveen, P. S., Kim, D., Corrigan, C. E., et al. (2007). Atmospheric brown clouds: Hemispherical and regional variations in long range transport, absorption, and radiative forcing. Journal of Geophysical Research: Atmospheres, 112(D22).

Ramji, A., Soni, A., Sehjpal, R., Das, S., \& Singh, R. (2012). Rural energy access and inequalities: An analysis of NSS data from 1999-00 to 2009-10.

Rasul, G. (2014a). Food, water, and energy security in South Asia: A nexus perspective from the Hindu Kush Himalayan region. Environmental Science and Policy, 39, 35-48.

Rasul, G. (2014b). Why Eastern Himalayan countries should cooperate in transboundary water resource management. Water Policy, 16(1), $19-38$.

Rasul, G., \& Sharma, B. (2016). The nexus approach to water-energyfood security: An option for adaptation to climate change. Climate Policy, 16(6), 682-702.

Rijal, K. (1999). Energy use in mountain areas: Trends and patterns in China, India, Nepal and Pakistan. ICIMOD, Kathmandu, Nepal.

Rockström, J., Steffen, W., Noone, K., Persson, Å. Chapin III, F. S., Lambin, E., et al. (2009). Planetary boundaries: Exploring the safe operating space for humanity. Ecology and society, 14(2). 
Sahel, B. K. (2014). Afghanistan has potential to generate 314,500 MW electricity-Minister. Afghanistan Times, 14th November 2014.

Santner, M., \& Jussel, R. (2003). Rural Stoves for Bhutan. Interdisciplinary Research Institute for Development Cooperation, Johannes Kepler University, Linz, Austria.

Saroha, S., \& Verma, R. (2013). Cross-border power trading model for South Asian regional power pool. International Journal of Electrical Power and Energy Systems, 44(1), 146-152.

Schild, A. (2008). ICIMOD's position on climate change and mountain systems: The case of the Hindu Kush-Himalayas. Mountain Research and Development, 28(3), 328-331.

Shah, T. (2010). Taming the anarchy: Groundwater governance in South Asia. Routledge.

Sharma, B. (2009). Sustainable Energy for the Himalayan Rangelands. Information sheet \#9/09, ICIMOD.

Sharma, B. (2007, November 21-23). Renewable energy and energy efficiency in the Himalayan Region: Opportunities and challenges. In 7th meeting of the Global Forum for Sustainable Energy (GFSE) energy efficiency for developing countries-Strong policy and new technologies, Vienna, Austria.

Sharma, B., \& Banskota, K. (2005) Women, energy and water in the Himalayas: Project learning. Nairobi: UNEP and Kathmandu: ICIMOD.

Sharma, B., Banskota, K., \& Luitel, S. (2005). Women, energy and water in the Himalayas: Policy guidelines. Nairobi: UNEP and Kathmandu: ICIMOD.

Shoaib, A., \& Ariaratnam, S. (2016). A study of socioeconomic impacts of renewable energy projects in Afghanistan. Procedia Engineering, 145, 995-1003.

Shrestha, P., Lord, A., Mukherji, A., Shrestha, R. K., Yadav, L., Rai, N. (2016). Benefit sharing and sustainable hydropower: Lessons from Nepal. ICIMOD Research Report 2016/2. Kathmandu: Nepal.

Shrestha, R. M. (2013). Energy use and greenhouse gas emissions in selected Hindu Kush-Himalayan countries. Mountain Research and Development, 33(3), 343-354.

Singh, A., Jamasb, T., Nepal, R., \& Toman, M. (2015). Cross-border electricity cooperation in South Asia.

Sinton, J. E., Smith, K. R., Peabody, J. W., Yaping, L., Xiliang, Z., Edwards, R., et al. (2004). An assessment of programs to promote improved household stoves in China. Energy for Sustainable Development, 8(3), 33-52.

Smith, K. R., Dutta, K., Chengappa, C., Gusain, P. P. S., Masera, O., Berrueta, V., et al. (2007). Monitoring and evaluation of improved biomass cookstove programs for indoor air quality and stove performance: Conclusions from the Household Energy and Health Project. Energy for Sustainable Development, 11(2), 5-18.

Sovacool, B. K. (2013). An international assessment of energy security performance. Ecological Economics, 88, 148-158.

Sovacool, B. K., Mukherjee, I., Drupady, I. M., \& D’Agostino, A. L. (2011). Evaluating energy security performance from 1990 to 2010 for eighteen countries. Energy, 36(10), 5846-5853.

Srivastava, L., \& Misra, N. (2007). Promoting regional energy co-operation in South Asia. Energy Policy, 35(6), 3360-3368. https://doi.org/10.1016/j.enpol.2006.11.017.

Srivastava, L., Misra, N., \& Hassan, S. (2013, April). Promoting Regional Energy Cooperation in South Asia (Revised Draft), Commonwealth Secretariat.

Srivastava, L., \& Rehman, I. H. (2006). Energy for sustainable development in India: Linkages and strategic direction. Energy Policy, 34, 643-654.

State of the Planet Declaration. (2012, March 26-29). Planet under pressure: New knowledge towards solutions conference, London. International Council for Science (ICSU), Paris.

Taliotis, C., Shivakumar, A., Ramos, E., Howells, M., Mentis, D., Sridharan, V., et al. (2016). An indicative analysis of investment opportunities in the African electricity supply sector-Using TEMBA (The Electricity Model Base for Africa). Energy for Sustainable Development, 31, 50-66.

TEPC. (2017). Foreign Trade Statistics of Nepal $2016 / 2017$. Kathmandu: Trade and Export Promotion Centre, Government of Nepal, Ministry of Industry, Commerce and Supply.

TERI and IISD. (2012). A citizens' guide to energy subsidies in India (pp. 1-44). The Energy and Resources Institute, and International Institute for Sustainable Development. Retrieved May 20, 2016, from https://www.iisd.org/gsi/sites/default/files/ffs_india_czguide. pdf.

Timilsina, G. R., Toman, M., Karacsonyi, J., \& de Tena Diego, L. (2015). How much could South Asia benefit from regional electricity cooperation and trade? Policy Research Working Paper; No.7341. World Bank, Washington, DC.

UNDP. (2013). 'SE4All, Nepal: Rapid assessment and gap analyses, GoN, UNDP.

UNDP. (2015). Human Development Report 2015: Work for Human Development. United Nations Development Programme, 1 UN Plaza, New York, NY 10017, USA.

UNFCCC. (2015). Intended Nationally Determined Contributions (INDC). United Nations Framework Convention on Climate Change (UNFCCC), Bonn. http://unfccc.int/focus/indc_portal/ items/8766.php.

United Nations Statistics Division. (2015). Energy Statistics Yearbook, New York. https://unstats.un.org/unsd/energy/yearbook/default.htm

USAID. (2013). Prospects for regional cooperation on cross-border electricity trade in south Asia. Integrated Research and Action for Development (Tirade).

USAID. (2006). Regional energy security for south Asia. Regional report. http://pdf.usaid.gov/pdf_docs/Pnads866.pdf.

U Thoung Win. (2013). Myanmar National Energy Policy 2013 (draft). http://www.dmr.go.th/ewt_dl_link.php?nid=79472\&filename=roya.

Vaidya, R. (2013). Water and hydropower in the green economy and sustainable development of the Hindu Kush-Himalayan region. Hydro Nepal: Journal of Water, Energy and Environment, 10, 1119.

Van Vuuren, D. P., Nakicenovic, N., Riahi, K., Brew-Hammond, A., Kammen, D., Modi, V., et al. (2012). An energy vision: The transformation towards sustainability-Interconnected challenges and solutions. Current Opinion in Environmental Sustainability, 4 (1), $18-34$.

Vinci, S., Nagpal, D. N., Hodges, T., \& Ferroukhi, R. (2015). Accelerating off-grid renewable energy IOREC 2014: Key findings and recommendations. In Second international renewable energy conference.

Vivoda, V. (2010).Evaluating energy security in the Asia-Pacific region: A novel methodological approach. Energy Policy 38, 52585263.

WECS. (2014). Energy Data Sheet, Water and Energy Commission Secretariat (WECS), Government of Nepal.

Weitz, N., Nilsson, M., Huber-Lee, A., \& Hoff, H. (2014). Cross-sectoral integration in the sustainable development goals: A nexus approach. In SEI discussion brief. Stockholm: Stockholm Environment Institute.

Wijayatunga, P., Chattopadhyay, D., \& Fernando, P. N. (2015). Cross-Border Power Trading in South Asia: A Techno Economic Rationale. ADB South Asia Working Paper Series No. 38. Manila: Asian Development Bank.

World Bank. (2007). South Asia Energy: Potential and Prospects for Regional Trade. Washington DC: World Bank.

World Bank. (2008). Potential and Prospects for Regional Energy Trade in the South Asia Region. Energy Sector Management Assistance Programme. World Bank. Washington D.C. 
World Bank. (2011). State and people, central and local, working together: The Vietnam rural electrification experience. Washington, DC: World Bank.

World Bank. (2013). China: Accelerating household access to clean cooking and heating. In East Asia and Pacific clean stove initiative series. Washington, DC: World Bank.

World Bank. (2014). Bhutan: Country Snapshot. http://www. worldbank.org/content/dam/Worldbank/document/SAR/bhutancountrysnapshot.

World Bank. (2015). Myanmar: Achieving universal access to electricity by 2030 . Energy Sector Management Assistance Programme /the World Bank, Washington DC. Retrieved October 12, 2016, from http://pubdocs.worldbank.org/en/ 384351442415891708/pdf/Myanmar-Electrification-Plan-Sept2015.pdf.

World Bank. (2016a). Access to Energy. Retrieved June 15, 2016, from http://databank.worldbank.org/data/reports.aspx?source= 2andTopic $=5$.

World Bank. (2016b). World Bank database for Electric power consumption (kWh per capita). http://data.worldbank.org/indicator/ EG.USE.ELEC.KH.PC.

World Bank. (2017). World Bank database for urban population. https://data.worldbank.org/indicator/SP.URB.TOTL.IN.ZS?end= $2015 \&$ start $=1960$.
Wu, N., Ismail, M., Joshi, S., Yi, S. L., Shrestha, R. M., \& Jasra, A. W. (2014). Livelihood diversification as an adaptation approach to change in the pastoral Hindu-Kush Himalayan region. Journal of Mountain Science, 11(5), 1342-1355.

Yadama, G. N., Peipert, J., Sahu, M., Biswas, P., \& Dyda, V. (2012). Social, economic, and resource predictors of variability in household air pollution from cookstove emissions. PloS one, 7(10), e46381.

Yang, B., Li, Y., Wei, H., \& Lu, H. (2016). Is urbanisation rate a feasible supplemental parameter in forecasting electricity consumption in China? Journal of Engineering.

Yangka, D., \& Diesendorf, M. (2016). Modeling the benefits of electric cooking in Bhutan: A long term perspective. Renewable and Sustainable Energy Reviews, 59, 494-503.

Yaqoot, M., Diwan, P., \& Kandpal, T. C. (2016). Review of barriers to the dissemination of decentralized renewable energy systems. Renewable and Sustainable Energy Reviews, 58, 477-490.

Yettou, F., Azoui, B., Malek, A., Gama, A., \& Panwar, N. L. (2014). Solar cooker realizations in actual use: An overview. Renewable and Sustainable Energy Reviews, 37, 288-306.

Yupapin, D. P., Pivsa-Art, D. S., Ohgaki, D. H., Kyaw, W. W., Sukchai, S., Ketjoy, N., et al. (2011). 9th eco-energy and materials science and engineering symposium energy utilization and the status of sustainable energy in union of Myanmar. Energy Procedia, 9, 351-358. https://doi.org/10.1016/j.egypro.2011.09.038.
Open Access This chapter is licensed under the terms of the Creative Commons Attribution 4.0 International License (http:// creativecommons.org/licenses/by/4.0/), which permits use, sharing, adaptation, distribution and reproduction in any medium or format, as long as you give appropriate credit to the original author(s) and the source, provide a link to the Creative Commons license and indicate if changes were made.
The images or other third party material in this chapter are included in the chapter's Creative Commons license, unless indicated otherwise in a credit line to the material. If material is not included in the chapter's Creative Commons license and your intended use is not permitted by statutory regulation or exceeds the permitted use, you will need to obtain permission directly from the copyright holder. 